\title{
Two-dimensional Material-based Biosensors for Virus Detection
}

\author{
Cécilia Ménard-Moyon, ${ }^{1, *}$ Alberto Bianco, ${ }^{1}$ and Kourosh Kalantar-Zadeh ${ }^{2, *}$
}

${ }^{1}$ CNRS, Immunology, Immunopathology and Therapeutic Chemistry, UPR3572, University of Strasbourg, ISIS, 67000 Strasbourg, France

${ }^{2}$ School of Chemical Engineering, University of New South Wales, Kensington, New South Wales 2052, Australia

\begin{abstract}
Viral infections are one of the major causes of mortality and economic losses worldwide. Consequently, efficient virus detection methods are crucial to determine the infection prevalence. However, most detection methods face challenges related to false-negative or falsepositive results, long response times, high costs, and/or the need for specialized equipment and staff. Such issues can be overcome by access to low-cost and fast response point-of-care detection systems, and two-dimensional materials (2DMs) can play a critical role in this regard. Indeed, the unique and tunable physicochemical properties of 2DMs provide many advantages for developing biosensors for viral infections with high sensitivity and selectivity. Fast, accurate, and reliable detection, even at early infection stages by the virus, can be potentially enabled by highly accessible surface interactions between the 2DMs and the analytes. High selectivity can be obtained by functionalization of the 2DMs with antibodies, nucleic acids, proteins, peptides or aptamers, allowing for specific binding to a particular virus, viral fingerprints or proteins released by the host organism. Multiplexed detection and discrimination between different virus strains are also feasible. In this review, we present a comprehensive overview of the major advances of 2DMbased biosensors for the detection of viruses. We describe the main factors governing the efficient interactions between viruses and 2DMs, making them ideal candidates for the detection of viral infections. We also critically detail their advantages and drawbacks, providing insights for the development of future biosensors for virus detection. Lastly, we provide suggestions to stimulate research in the fast expanding field of 2DMs that could help in designing advanced systems for preventing virus-related pandemics.
\end{abstract}

KEYWORDS: antibody, diagnosis, graphene, metal organic frameworks, molybdenum disulfide, nucleic acids, proteins, transducers 
Viruses are ubiquitous in our environment and can cause diseases in all forms of lives, including humans and animals, potentially resulting in high morbidity and fatality. Indeed, viral infections cause around one third of deaths as a result of different types of infectious diseases. The increased number of viral outbreaks in the last decade has raised worrying concerns, in particular the severe acute respiratory syndrome coronavirus 2 (SARS-CoV-2 virus) that appeared in late 2019. This virus spread rapidly and turned into a worldwide pandemic, resulting in unprecedented economic and social burdens in many countries. Since viral diseases are real threats to human life, there is an urgent need for rapid, sensitive, effective, and low-cost detection techniques for the clinical diagnosis of such disorders to bring them under control and achieve disease management in both developed and developing countries. Viruses also infect microorganisms, plants and animals and, as such, their timely and accurate detection is equally essential for environmental monitoring. In this context, nanotechnology plays a key role for the development of biosensors by increasing both sensitivity and specificity.

Owing to their size and physicochemical properties, two-dimensional materials (2DMs) have shown potential for the development of biosensors for virus detection with extremely small dimensions, in one direction, and great performance in terms of selectivity and sensitivity. Furthermore, they could overcome disadvantages of existing methods for virus detection related to high cost and long procedures. Two-dimensional structures can allow enhancing the electrical, optical, and electrochemical properties of biosensors, and they can also favorably adsorb and interact with small entities ranging from single molecule analytes, extracted from viruses, to viruses themselves. The rapid advances of 2DM-based-biosensors have led to new opportunities in the development and commercialization of such devices in the healthcare industry. While a large number of reviews have been dedicated to $2 \mathrm{DMs}$ for biosensing and healthcare, ${ }^{1,2}$ to the best of our knowledge, the implementation of these materials for virus sensing and detection has not been comprehensively reviewed and analyzed yet, and the available literature has so far been mostly focused on graphene. ${ }^{3-5}$

Here, we aim to critically evaluate existing works of multiple groups in the field of 2DM-based biosensors for virus sensing and detection. First, we briefly introduce different classes of viruses. In the following section, we describe the main 2DMs used for biosensing applications. On this basis, we highlight how 2DMs interact with viruses either directly or through functional groups conjugated on their surface. While interactions between microbes and 2DMs (specially graphene- 
family nanomaterials) have been extensively investigated ${ }^{6-8}$ the interactions of 2DMs with viruses have been much less studied. Consequently, we review breakthroughs for the detection of virus and viral infections using $2 \mathrm{DM}$ biosensors. This part is divided into two sub-sections: i) direct detection of intact viruses and viral nucleic acids), ii) detection of proteins, such as antibodies, produced by infected patients, or overexpressed/downregulated enzymes and cytokines. Finally, we provide an outlook on the future of $2 \mathrm{DMs}$ in biosensing for virus detection and their potential for applications in clinical and point-of-care technologies. In particular, we lay out current challenges and make suggestions for research opportunities that could be explored for the realization of next-generation biosensors incorporating 2DMs.

\section{VIRUSES: STRUCTURE AND CLASSIFICATION}

As viruses do not possess the genetic information that is required to produce metabolic energy and synthesize macromolecules, they behave as intracellular parasites that use the genetic material replication system of host cells. Their main function is to deliver their genome into the host cells so that the genome can be expressed by these cells. Because viruses display diversity in structure, shape, genome, and replication strategies, their identification is challenging. To date, more than 1,500 human and animal viruses have been identified.

Viruses consist of a nucleic acid core (single- or double-stranded RNA or DNA) and an outer protein coating (capsid). It is noteworthy to consider that the rates of mutation for RNA viruses are superior in comparison to DNA viruses. The capsid is a single or double protein shell and is constituted by only one or a few types of structural proteins. This shell surrounds the viral genome and protects it from nucleases. The genome together with the nucleic acid-associated proteins forms the nucleocapsid. Some virus families have also an envelope surrounding the nucleocapsid, consisting of a lipid bilayer derived from the modified host cell membrane, which is studded with an outer layer of glycoproteins. The viral envelope incorporates host proteins and also exhibits glycosylated (trans)-membrane proteins as spikes or knobs. Viruses have been categorized into different classes according to their strategies for the storage and replication of their genomes via DNA and/or RNA intermediates (Baltimore classification). ${ }^{9}$

The viral genome is rather small and contains only the genes encoding proteins that the virus cannot obtain from the host cells (from 2 to 900 proteins depending on the virus species). ${ }^{10}$ For 
instance, the genome of coronaviruses codes for structural proteins, such as spike, membrane, envelope, and nucleocapsid proteins, as well as other proteins involved in replication and cellular uptake.

The size of viral particles ranges from 20 to $400 \mathrm{~nm}$. They can be categorized according to their shape as enveloped, filamentous, icosahedral (or isometric), or head-and-tail viruses (Figure 1). Animal viruses and human immunodeficiency virus (HIV) are examples of enveloped viruses with a membrane surrounding the capsid. Many recent outbreaks have been caused by enveloped viruses including avian influenza viruses, SARS-CoV, Ebola virus, Zika virus, Middle East respiratory syndrome-related coronavirus (MERS-CoV), and SARS-CoV-2. Icosahedral viruses have nearly spherical shapes, it is the case of adenoviruses and herpes viruses. Filamentous viruses, like plant viruses, are cylindrical and long. Head-and-tail viruses have a head like icosahedral viruses containing nucleic acids, while the tail shape is similar to filamentous viruses. Such viruses have the capacity to infect bacteria.

The binding to host cells can vary from one virus to another. Enveloped viruses use glycoproteins embedded in the envelope whereas non-enveloped viruses (e.g., adenoviruses) exploit glycoprotein spikes, protruding from the capsid to attach to host cells. In the case of headand-tail viruses, like the T4 bacteriophage, the tail structure allows efficient binding to host cells. 
a)

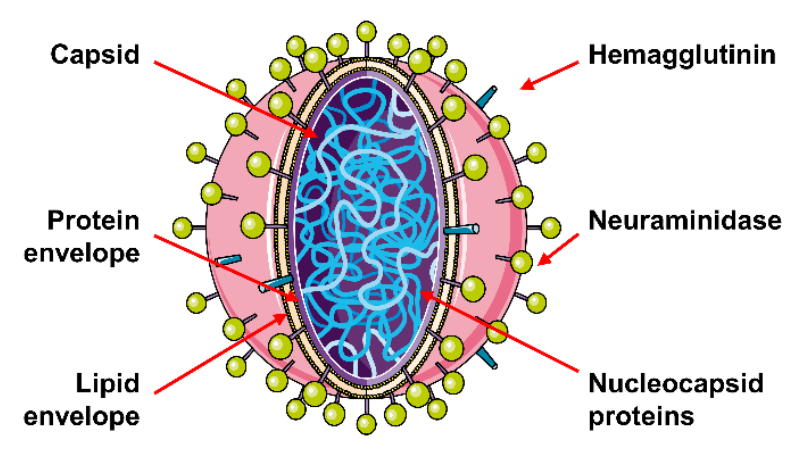

c)

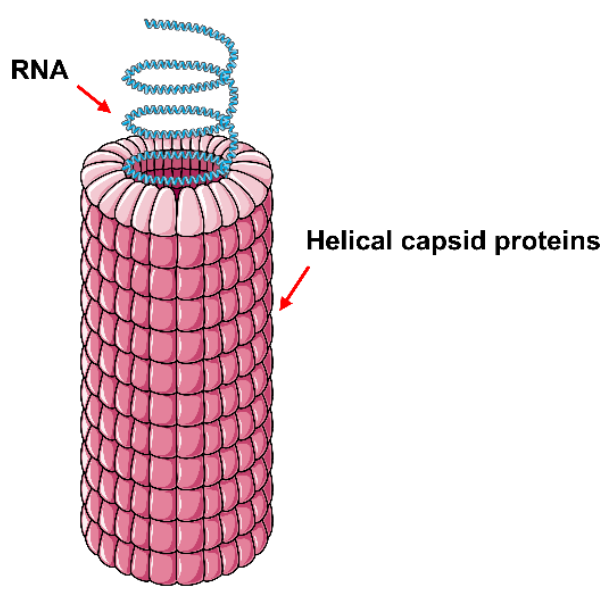

b)

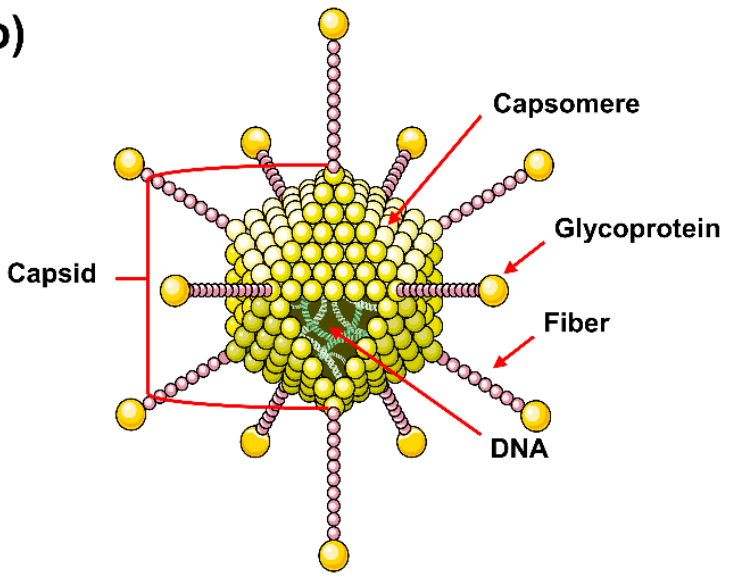

d)

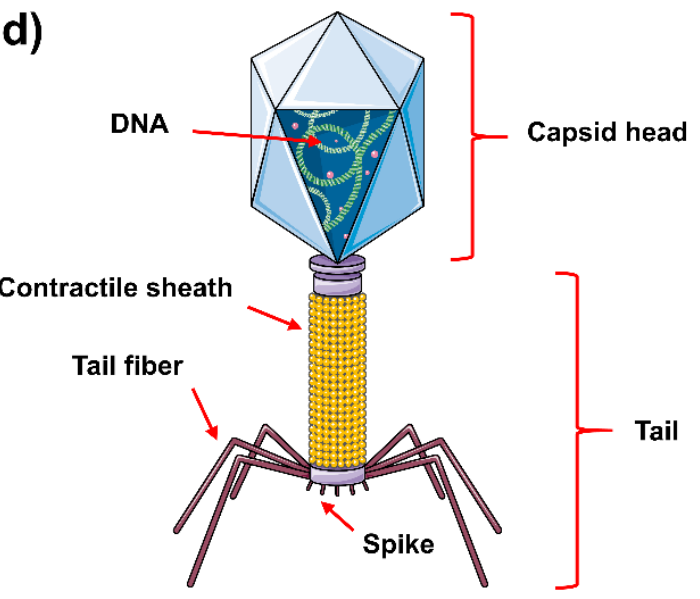

Figure 1. Schematic structures of (a) an enveloped virus (influenza virus), (b) an icosahedral virus (adenovirus), (c) a filamentous virus (tobacco mosaic virus), and (d) a head-and-tail virus (bacteriophage).

\section{DIAGNOSIS OF VIRAL DISEASES: CONVENTIONAL ASSAYS, LIMITATIONS AND EMERGING TECHNIQUES}

The risk of global outbreaks due to virus spread stresses the necessity of developing rapid, precise, and sensitive detection techniques for early diagnosis. In addition, some viruses have a long latent period and are able of mutation from one person to another, which makes diagnosis during the incubation period highly important to increase healing rates and avoid risk of pandemics. 
Virus detection can be classified into i) the direct detection of intact viruses (oldest methods), ii) the detection of virus molecular fingerprints (e.g., viral proteins and nucleic acids), and iii) serology through the detection of antibodies as a response of host organisms to viruses. ${ }^{11,12}$

\section{Conventional virus detection techniques}

In the current biomedical laboratories, a variety of methods are used for the detection of viruses, which are presented below. Other procedures, such as methods relying on electron microscopy or virus-infected cell cultures, are also possible but are not detailed here.

\section{Plaque and hemagglutination assays}

The conventional plaque and hemagglutination assays allow virus quantification. The plaque assay is used for determining the number of plaque-forming units in a viral sample, while the hemagglutination assay titrates an antibody response to a virus. Nevertheless, both techniques are labor-intensive and are limited by calibration issues and applicability to only certain types of viruses.

\section{Detection of antibodies}

The exploitation of virus-specific antibodies, produced by the host immune system in response to viral antigens, leads to detection methods alternative to direct virus sensing. It is indeed possible to distinguish infection relying on immunoglobulin class $\mathrm{G}(\mathrm{IgG})$ subclass of antibodies as they are supposed to persist a long time in the host after the infection, whereas immunoglobulin class $\mathrm{M}$ $(\operatorname{IgM})$ antibodies are generated early after a viral infection and disappear faster over time. The main serological testing techniques include enzyme-linked immunosorbent assays (ELISA), immunofluorescence assays, Western blot, hemagglutination inhibition, particle agglutination, plaque-reduction neutralization, and complement fixation. For example, immunofluorescence assays are based on the formation of a sandwich structure around the antibody, which is bound specifically between a capture antigen immobilized on a surface and a detection molecule such as a secondary antibody labeled with a fluorophore (Figure 2A). Fluorescence emission from the dye accumulated on the surface is indicative of the presence of the target antibody.

Currently, serology is the gold standard for viral disease diagnosis in biomedical laboratories. Nevertheless, during the first few weeks to several months after virus exposure (the so-called 
"window period"), the quantity of antibodies can be too low. As a consequence, serologic tests are inappropriate for early viral infections. Moreover, the generation of antibodies by patients treated by an immunosuppressive therapy may not be efficient. To overcome these limitations, the reliance on nucleic acid-based methods can be a better option, specifically during the "window period".

\section{Detection of antigens}

Viral antigens, specially proteins encoded by a viral genome, appear in blood circulation when viruses are released after cell lysis. They can be detected when viruses are actively replicating. The main approaches for viral antigen detection also rely on serological techniques previously mentioned (ELISA, immunofluorescence assays, Western blot) and also on electrochemiluminescence, radioimmunoassay, and radioimmunobinding assays. If the host organism has developed antibodies against a viral antigen, an additional step may be necessary to disrupt the antibody-antigen complex formed in vivo and thus release the antigen.

In the case of HIV, the patient is highly infectious during the "window period". Because of the explosive replication of the virus after an acute infection, the HIV type 1 (HIV-1) capsid protein (p24 antigen) appears at an earlier stage of HIV infection compared to antibodies. As a result, the p24 antigen is an excellent biomarker for an early diagnosis of HIV-1. The determination of p24 concentration makes diagnosis of HIV-1 highly accurate. With regards to hepatitis B virus, due to long incubation period most patients do not present symptoms during the initial infection. Therefore, early diagnosis through the detection of hepatitis B virus biomarkers is crucial to increase healing rates. The hepatitis B surface antigen is the first virological marker that appears in blood. It is a coat protein secreted by the virus residing in liver cells. It can be detected in blood during the incubation period and it is the most important serum biomarker in the early diagnosis of hepatitis B.

\section{Detection of nucleic acids}

Since the emergence of nuclear-based analytical techniques, such as polymerase chain reaction (PCR), the plaque and hemagglutination assays have been less widely used for virus detection. Nucleic acids of viruses present in host cells can be detected immediately after infection without considering the window period. Differentiation of virus subtypes is possible. Reverse transcriptionPCR (RT-PCR) is a nucleic acid amplification assay in which an enzyme (reverse transcriptase) is 
used for converting RNA to its complementary DNA followed by PCR amplification (Figure 2B). However, while highly sensitive and specific, this technique has some limitations as well. One limiting factor is the need to isolate the viral nucleic acids at a sufficient concentration and purity for subsequent amplification. The viral genome usually represents a very small component of the total amount of nucleic acid material recovered. For example, during the Ebola virus epidemic, diagnosis using RT-PCR produced high false negative results for patients in the first few days of the infection because of very low levels of viral particles present in blood when symptoms appeared. ${ }^{13}$ Waiting for sufficient amount of virus delays diagnosis and the risk of contagion rises accordingly, while the virus can rapidly multiply to fatal level. PCR process is still costly, relatively long (few hours) due to the preparation of viral RNA, and it can be performed only by specialists. Furthermore, low sensitivity, high false negative or false positive rates, and lack of specificity are additional limitations of conventional nucleic acid detection methods resulting in risks of misdiagnosis in patients suffering from other viral infections. ${ }^{14}$ Sequencing is another approach that can provide the full sequence of a virus genome. ${ }^{15,16}$ Next-generation sequencing can allow distinguishing between viruses and mutated strains that give similar results using other tests. 
A)

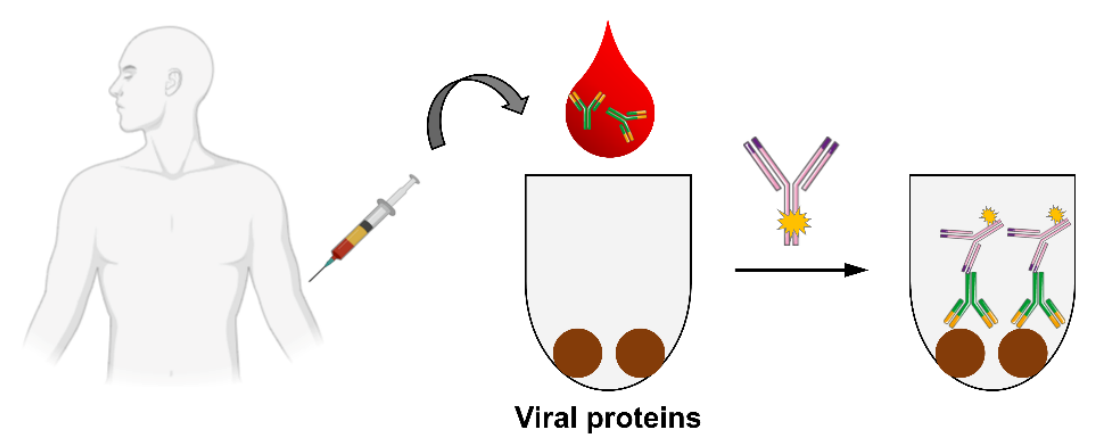

B)
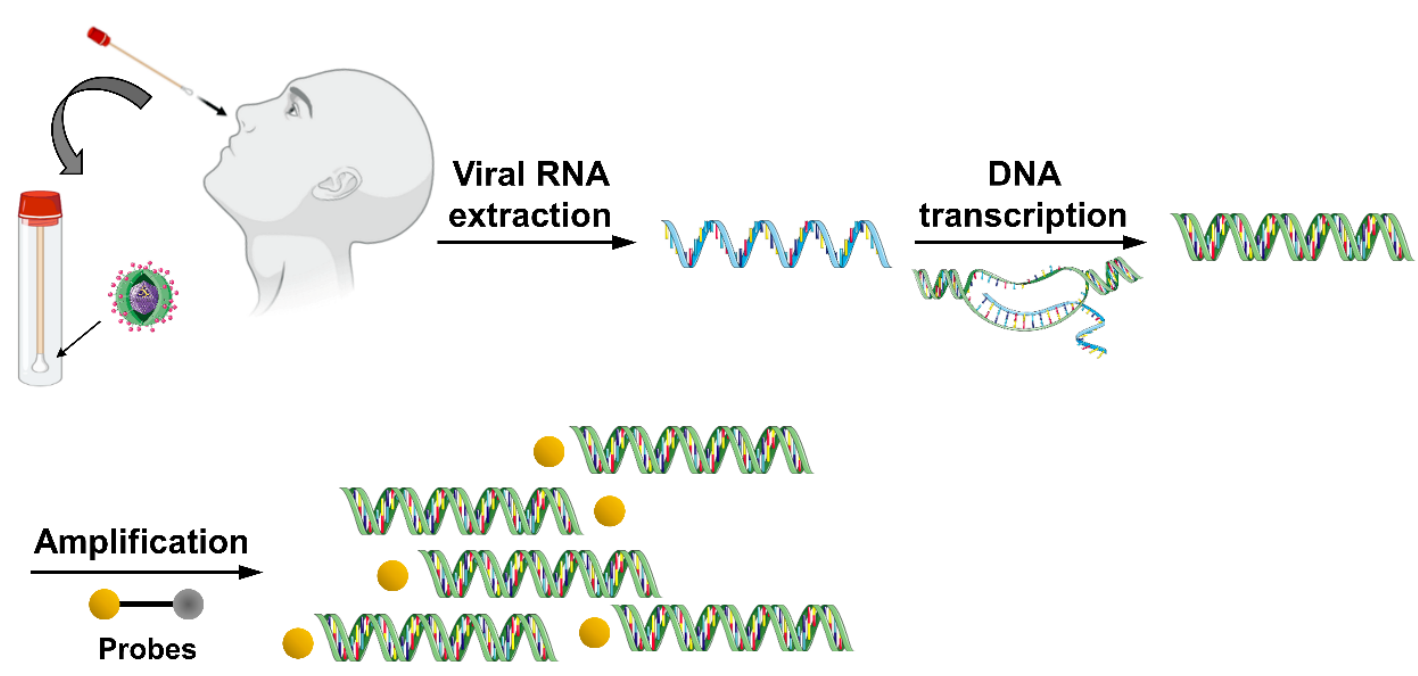

Figure 2. A) Antibody test and B) nucleic acid test. During the process of antibody testing, viral proteins bind to virus-specific antibodies present in blood followed by binding to labeled secondary antibodies (A). In the case of the nucleic acid test: i) viral RNA is extracted from a nose or throat swab; ii) the enzyme reverse transcriptase converts RNA to DNA; iii) polymerase chain reaction makes millions of copies of the transcribed DNA; iv) virus-specific short oligonucleotides labeled with a fluorophore bind to the copies; v) an enzyme cleaves the probe causing fluorescence emission (B).

\section{Emerging virus detection techniques}

Some techniques to address the problems of nucleic acid-based systems have been developed such as loop-mediated isothermal amplification (LAMP) processes and rolling circle amplification. Although these methods are more rapid and do not necessitate sophisticated laboratory facilities, they still require trained staff. ${ }^{17}$ Paper-based lateral flow assays have received increased interest to 
overcome shortcomings of such systems thanks to their low cost, easy production, and possibility of translation into point-of-care devices. Yet, these techniques also still face certain challenges.

\section{Isothermal amplification}

Isothermal nucleic acid amplification methods, such as reverse transcription loop-mediated isothermal amplification, allow simplifying PCR as no thermal cycler is required to perform amplification. As a result, these techniques can be carried out at milder temperatures $\left(40-65^{\circ} \mathrm{C}\right)$. In addition, they generally display higher sensitivity, but the level of false-positive results encountered with this assay is higher compared to conventional PCR. ${ }^{17}$

\section{Rolling circle amplification}

Rolling circle amplification is another isothermal amplification technique for sensitive nucleic acid detection. This process is more simple in comparison with the loop-mediated isothermal amplification method as it involves less steps and is performed at room temperature. The sensitivity is high and comparable to RT-PCR, while the number of false-positive results is reduced. Nonetheless, one issue is the need of a circular template that is difficult to prepare. Hence, there is a risk of amplification failure because of incorrect design of the complementary sequences.

\section{Lateral flow assays}

Lateral flow assays are a combination of nucleic acid detection methods and immunoassays. They are often made of papers containing immobilized capture probes. The binding of nucleic acid targets to probes generates a visible signal. Nevertheless, this technique still requires initial nucleic acid extraction and amplification. Besides, the sensitivity may be low with the immunoassay-based lateral flow assays due to weak signals. As a consequence, signal enhancement strategies are necessary, for instance by using probes conjugated to gold nanoparticles that aggregate and change color upon binding with the nucleic acid targets.

Overall, most of the conventional virus detection techniques are time consuming, often expensive, and some require complex laboratory manipulations. ${ }^{18}$ In addition, the identification of viral genomes by PCR-based assays is generally complicated due to low viral abundance in collected samples and possible contamination by the nucleic acids from the host. To overcome these 
limitations, different types of biosensors have been conceived for accurate, sensitive, and rapid virus detection using nanomaterials that allow signal amplification and/or enhancement of the biological recognition of viruses, antibodies, viral antigens or nucleic acids. ${ }^{19,20}$

\section{BIOSENSING APPLICATIONS OF TWO-DIMENSIONAL MATERIALS}

Two-dimensional materials have attracted extensive interest because of their unique properties. ${ }^{21}$ The most popular 2DMs include graphene, transition metal dichalcogenides (e.g., $\mathrm{MoS}_{2}$ ), nonmetallic nanosheets such as hexagonal boron nitride and graphitic $\mathrm{C}_{3} \mathrm{~N}_{4}\left(\mathrm{gC}_{3} \mathrm{~N}_{4}\right)$, transition metal dioxides (e.g., $\mathrm{MnO}_{2}$ ), transition metal carbides and nitrides known as MXenes (e.g., $\mathrm{Ti}_{3} \mathrm{C}_{2}$ ), and Xenes (e.g., phosphorene commonly named black phosphorous) (Figure 3).

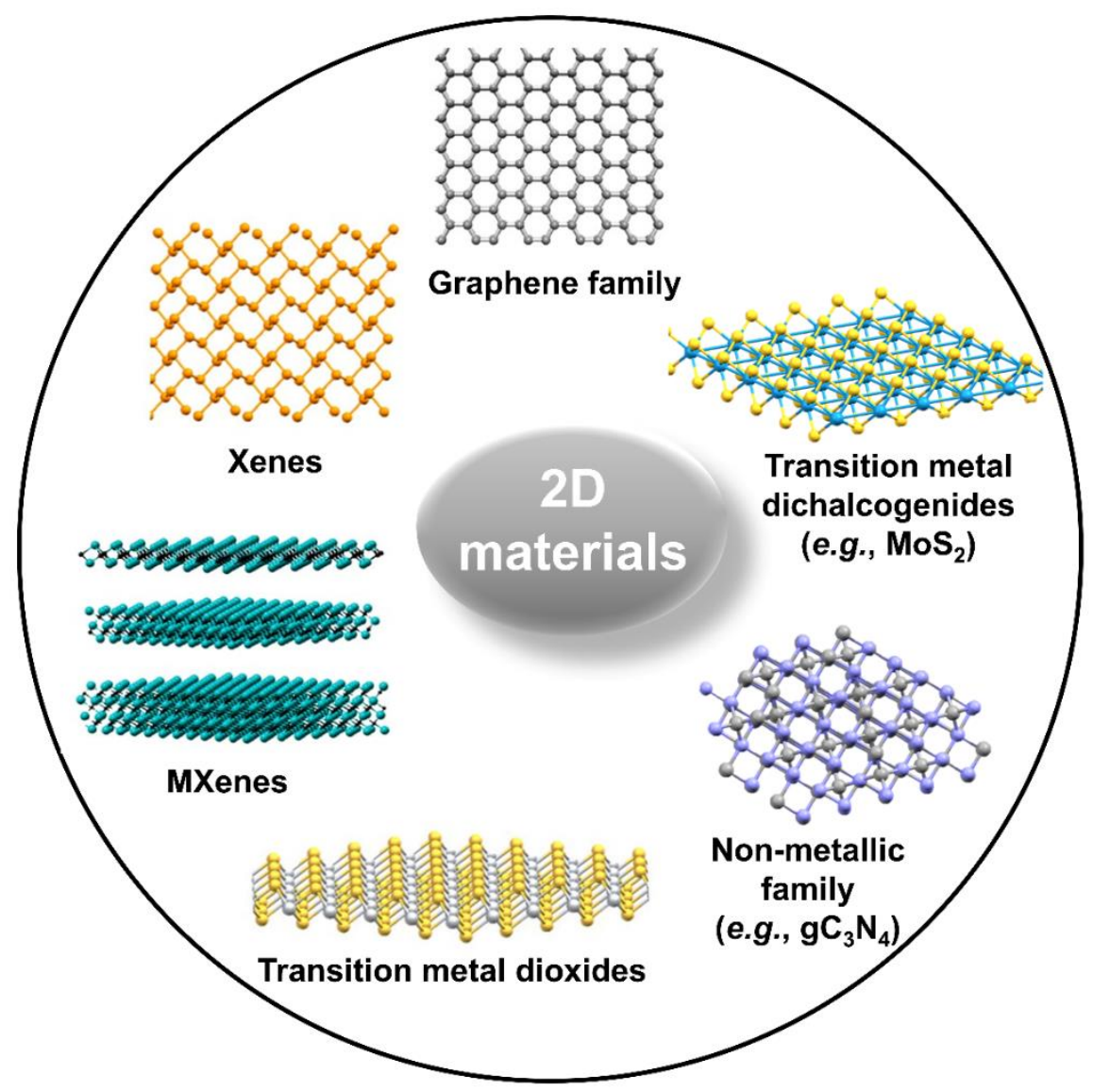

Figure 3. Molecular structure of different families of 2DMs.

Transition metal dichalcogenides $\left(\mathrm{MX}_{2}\right)$ are composed of a transition metal, typically from groups 4-7 ( $\mathrm{M}=\mathrm{Mo}, \mathrm{W}, \mathrm{Ta}, \mathrm{Nb}, \mathrm{Re}, \mathrm{Mn})$, and two chalcogenide atoms $(\mathrm{X}=\mathrm{S}, \mathrm{Se}, \mathrm{Te})$. MXenes have a 
general formula of $\mathrm{M}_{n+1} \mathrm{X}_{n}(n=1-3)$ where $\mathrm{M}$ is an early transition metal (e.g., Cr, Hf, Mo, Nb, Sc, $\mathrm{Ta}, \mathrm{Ti}, \mathrm{V}, \mathrm{Zr}$ ) and $\mathrm{X}$ is a carbon or a nitrogen atom. Xenes are monoelemental 2DMs comprising arsenene, antimonene, bismuthene, borophene, germanene, phosphorene, silicene, stanene, and tellurene.

Since the revolutionary discovery by Novoselov and Geim in 2004 awarded by the Nobel prize in physics in $2010,{ }^{22}$ graphene has been widely studied in various fields such as electronics, ${ }^{23}$ energy, ${ }^{24}$ sensing, ${ }^{25}$ catalysis ${ }^{26}$ membranes, ${ }^{27}$ and nanomedicine. ${ }^{28}$ It is one-atom-thick and contains $\mathrm{sp}^{2}$-hybridized carbon atoms with a honeycomb structure (Figure 3). It displays outstanding structural, electrical, optical, mechanical and thermal properties, in particular a high electrical and thermal conductivity, ${ }^{29,30}$ tunable optical properties and electronic band structure, ${ }^{31-}$ 33 as well as a high elasticity and mechanical strength. ${ }^{34,35}$ Encouraged by the great success of graphene, a plethora of 2DMs have subsequently emerged, creating new fields of research thanks to their unique combination of properties, in particular $\mathrm{MoS}_{2}$, which is composed of a single sandwiched S-Mo-S layer bound by van der Waals interactions in a hexahedral filled structure where each Mo is coordinated to six S atoms (Figure 3). Various 2DMs beyond graphene have been applied for a wide range of applications ${ }^{36,37}$ in electronics, ${ }^{38}$ optoelectronics, ${ }^{39}$ energy storage, ${ }^{40}$ sensors, ${ }^{41}$ catalysis, ${ }^{42}$ and they also hold great potential in the biomedical field. ${ }^{43-46}$ In particular, they have been exploited for drug delivery, bioimaging, tissue engineering, biosensing, as antimicrobial, antibacterial and antifungal agents, ${ }^{47}$ and for photothermal and photodynamic therapy. ${ }^{48}$ They can be used as carriers of drugs for the treatment of different diseases including cancer, ${ }^{49}$ inflammatory diseases ${ }^{50}$ and viral infections. ${ }^{51,52}$ Biomedical devices including blood glucose sensors ${ }^{53}$ and deep brain stimulators ${ }^{54}$ have been developed. The photothermal properties of 2DMs have been exploited for tumor treatment, bacteria killing, and even to design reusable and recyclable graphene-coated surgical masks endowed of superhydrophobicity and sterilization capacity under sunlight. ${ }^{55}$

Owing to their excellent properties including remarkable electrical and mechanical properties, tunable fluorescence, and surface-enhanced Raman scattering (SERS), 2DMs have been widely exploited for the development of biosensors. In addition, the extremely large surface area of 2DMs makes the interactions of the biosensors with analytes, such as viruses, antibodies, and nucleic acids, very efficient as a large amount of these analytes can be captured. Current 2DM-based biosensors for diagnosing infected patients can be classified into two main types: electrode-based 
devices, including electrochemical and field-effect transducers, and optical systems mainly relying on sensing by fluorescence, surface plasmon resonance (SPR), and SERS (Figure 4). These devices integrate bioreceptors including antibodies, nucleic acids, proteins, aptamers or peptides, and these bioreceptors interact with the analytes, producing a physical or chemical change, which is transformed into a quantifiable electrical or optical signal.

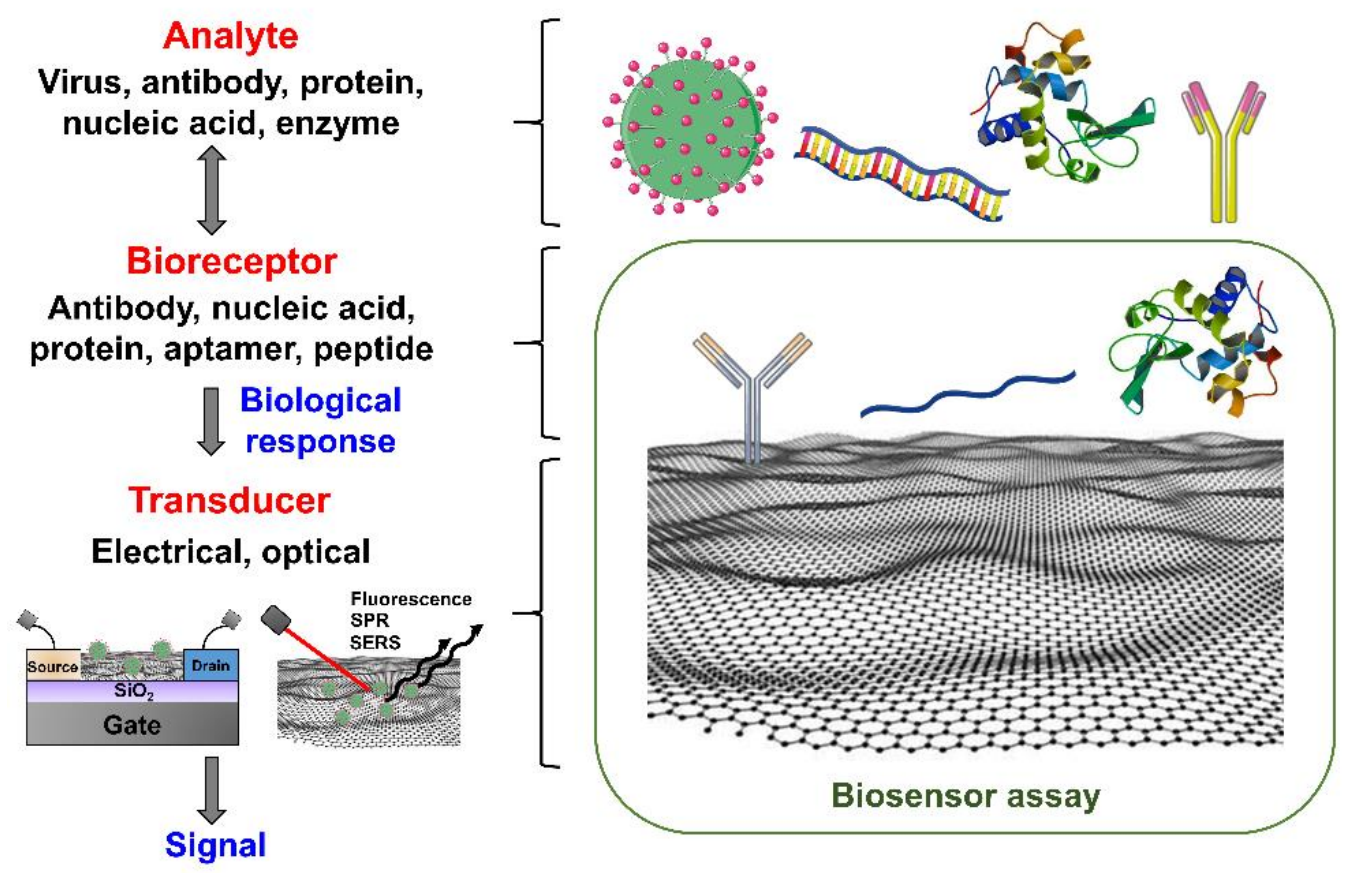

Figure 4. 2DM-based biosensors using electrode-based devices and optical systems.

\section{Electrode-based 2DM biosensors}

The main biosensors comprising electrodes are field-effect transistors (FETs) and electrochemical systems. The electrical measurements (current, resistance, or impedance change) allow for the quantification of biospecific binding. Different from electrical sensing modality, electrochemical sensing requires redox molecules.

\section{Field-effect transistors}

Thanks to their superior electrical properties, 2DMs are better candidates than many other nanostructures for designing FETs. ${ }^{56}$ Moreover, their large surface area makes them particularly sensitive to environmental changes. Upon interactions between probes and analytes at the FET gate, the electric charge distribution affects the charge carrier density. As a result, FET-based biosensors are ideal for the monitoring of charged molecules. Graphene displays high electron 
mobility across sheets, but because of its zero band gap, graphene-based biosensors may suffer from increased current leakage and thus reduced sensitivity. ${ }^{25}$ Contrarily, emerging 2DMs like $\mathrm{MoS}_{2}, \mathrm{MnO}_{2}$, and $\mathrm{g}_{-} \mathrm{C}_{3} \mathrm{~N}_{4}$ exhibit relatively large band gaps, which can be tuned between semiconducting and insulating states. ${ }^{1,57,58}$ Consequently, there is minimal current leakage in this case and high sensitivity can be achieved. The band gap and carrier concentration of 2DMs can be also tailored by surface modification.

\section{Electrochemical biosensors}

2DM-based electrochemical biosensors involve an electron transfer between the 2DMs and the analytes during oxidation or reduction processes. They can be categorized into four main classes: potentiometric, amperometric, impedimetric, and voltammetric transducers. Conducting and semiconducting 2DMs can be effective transducing elements that allow direct electron exchanges between the analytes and the electrodes thanks to their high surface area. ${ }^{59-61}$ They can facilitate this electron transfer in a wide range of oxidizing and reducing voltages.

\section{Optical-based 2DM biosensors}

Optical biosensors measure changes in the optical properties of the transducer upon the interaction between 2DM-based probes and analytes. They can be categorized into three main classes based on sensing by fluorescence, SPR, and SERS.

\section{Fluorescence biosensors}

A popular approach for optical biosensing by 2DMs relies on reversible fluorescence quenching of dyes, quantum dots, or gold nanoclusters. The quenching occurs through fluorescence resonance energy transfer (FRET), which is a non-radiative energy transfer from the fluorophores to the 2DMs separated by a distance of up to $10 \mathrm{~nm}$. In 2009 theoretical calculations showed that graphene could act as an efficient quencher of fluorophores. ${ }^{62}$ Since this prediction, many strategies have been inspired by this property. Transition metal dioxides and transition metal dichalcogenides, such as $\mathrm{MoS}_{2}$ nanosheets, present excellent fluorescence quenching abilities. Conversely, another possibility is to take the advantage of fluorescence that is produced by the 2DMs and rely on their quenching upon their affinity or interaction with target analytes. 2DMs, such as monolayer $\mathrm{MoS}_{2}$, own direct band gaps and hence emit strong fluorescence. For example, the band gap for monolayer 
$\mathrm{MoS}_{2}$ is $1.8 \mathrm{eV}$ and the fluorescence emission is well located within the visible region suitable for the operation of many of the laboratory optical equipment. ${ }^{63}$ Additionally, changing the lateral dimensions of graphene (graphene quantum dots) ${ }^{64}$ and $\mathrm{MoS}_{2}{ }^{65}$ may shift the fluorescence to lower wavelengths and enhance their intensity.

\section{Surface plasmon resonance biosensors}

The principle of SPR biosensors is based on changes in sensor chip thickness upon interactions with biomolecules inducing a modification of the refractive index. As a result, the surface plasmon wave is excited and produces an SPR signal. The changes are directly proportional to the mass change at the surface and therefore, it is possible to determine the total amount of analytes bound in a highly sensitive, specific, and label-free manner. The plasmonic properties of graphene and other 2DMs have been exploited in SPR biosensors. ${ }^{66-71}$ Nevertheless, this method requires some attention to distinguish different binding events for multiplex analysis.

\section{Surface-enhanced Raman scattering biosensors}

The fundamental concept of SERS is the enhancement of the Raman scattering efficiency of molecules adsorbed on rough substrates. This technique provides the potential for single-molecule detection and high specificity due to unique molecular fingerprinting. The SERS enhancement originates from a chemical mechanism, which relies on a charge transfer between the molecules and the substrate, and an electromagnetic mechanism coming from an increase of the local electric field caused by the SPR properties of metal substrates (e.g., gold or silver). 2DMs, in particular graphene, decorated with gold nanoparticles have been exploited to favor the interactions with Raman-active molecules and significantly contribute to the chemical enhancement in the SERS effect. $^{72,73}$

\section{INTERACTIONS BETWEEN VIRUSES AND 2D MATERIALS}

Owing to their unique properties, 2DMs (mainly graphene-family nanomaterials) have been exploited as substrates for visualization of viruses by electron microscopy, for characterization of viral structures, for inhibition and/or destruction of viruses through either direct interactions or functionalization with molecules that are able to bind to viral proteins. 


\section{Visualization and characterization of virus structure}

There is a great interest in direct visualization and characterization of virus structures in nanoscales using techniques such as electron microscopy, atomic force microscopy (AFM), X-ray diffraction, and Fourier transform infrared spectroscopy (FTIR), which can also be potentially used for early detection of viruses.

Thanks to their properties, 2DMs can help in the characterization of individual viral particles by different techniques. As an example, unique vibration peaks of hemagglutinin area (HA1) of swine influenza (H1N1) and the avian influenza (H5N1, which is the most contagious and fatal influenza strain, and it has the capacity of interspecies transmission to humans) viruses bound to a graphene coated-plasmonic metal substrate could be detected. ${ }^{74}$ Hemagglutinin is a glycoprotein found on the surface of influenza viruses. In this work, HA1 was sensed through selective binding to sialylated glycan receptors immobilized on the graphene surface. More precisely, amphiphilic phospholipid molecules with the capacity to self-assemble into sheet-like structures were deposited onto the graphene substrate followed by the incorporation of sialosaccharide ligand receptors in the lipid membranes. HA1 was not able to bind to graphene devoid of sialylated glycans, demonstrating the importance of graphene functionalization. In another study, the high surface area and infrared transparency of graphene were exploited for nanoscale FTIR (also termed as nano-IR or nano-FTIR) investigation in an aqueous environment. ${ }^{75}$ Nano-IR is a combination of FTIR spectroscopy and scattering scanning near-field optical microscopy. Spectroscopic resonances specific to the tobacco mosaic virus in water trapped beneath a graphene sheet were observed. In this case, graphene acted as an impermeable monolayer barrier.

The high electron conductivity and transparency of graphene for electron beams, and the possibility of functionalization to tune its surface from hydrophobic to hydrophilic are required features of transmission electron microscopy (TEM) supports. The properties of graphene make it an ideal support for direct observation of viruses with no staining, high contrast and resolution by minimizing the background signal, leading to high signal-to-noise ratio for sensing. Graphene is a strong material and it can support any submicrometer object. Finally, owing to its high level of crystallinity, graphene has a highly ordered and stable structure, and its interference with the images can be easily filtered out. In this context, H3N2 influenza viruses were imaged by liquid cell TEM,${ }^{76}$ while tobacco mosaic virus was observed by conventional TEM, ${ }^{77}$ cryo-TEM,,${ }^{78,79}$ and 
low-energy electron holography, ${ }^{80}$ resolving the helical arrangement of the outer protein shell of the tobacco mosaic virus.

Graphene was also exploited as support for femtosecond X-ray coherent diffractometry with very low background scattering for characterization of the tobacco mosaic virus. ${ }^{81}$ Serial femtosecond crystallography is a type of $\mathrm{X}$-ray crystallography that uses X-ray free-electron lasers. Owing to the femtosecond pulse duration and high resolution of X-ray free-electron laser beams, this technique allows studying viruses as crystals and single particles.

Other characterization techniques could also be used for studying the interactions between graphene and biomolecules at the molecular levels such as AFM-based single-molecule force spectroscopy. ${ }^{82-84}$ This method can offer indications on the structure, dynamics, surface properties, and thermodynamics of viruses. Instrumentations including electron microscopy, X-ray diffraction spectroscopy, and AFM are relatively expensive, which limits their potential for routine analysis.

\section{Interactions}

Owing to their tunable surface properties, 2DMs can interact directly with viruses via multiple noncovalent interactions. Table 1 summarizes the available reports on the types of interactions between 2DMs and viruses, leading to antiviral effects. 
Table 1. Interactions between 2DMs and viruses leading to antiviral effects.

\begin{tabular}{|c|c|c|c|}
\hline 2DMs & Viruses & Antiviral activity & References \\
\hline GO & Pseudorabies virus and porcine epidemic diarrhea virus & Structural destruction & 85 \\
\hline $\mathrm{GO}, \mathrm{MoS}_{2}$ & Herpes simplex virus type- 1 & Inhibition & 86 \\
\hline GO, few-layer graphene & SARS-CoV-2 & Inhibition & 87 \\
\hline $\mathrm{GO}$ & Feline coronavirus & Inhibition & 89 \\
\hline $\begin{array}{l}\text { rGO decorated with } \mathrm{Ag} \\
\text { nanoparticles }\end{array}$ & Infectious bursal disease virus & Inhibition & 89 \\
\hline $\begin{array}{l}\text { GO decorated with } \mathrm{Ag} \\
\text { nanoparticles }\end{array}$ & $\begin{array}{l}\text { Porcine reproductive and respiratory syndrome virus } \\
\text { and the porcine epidemic diarrhea virus }\end{array}$ & $\begin{array}{l}\text { Inhibition and higher production of interferon- } \alpha \\
\text { and interferon-stimulating genes }\end{array}$ & 91 \\
\hline $\mathrm{GO}$ & $\begin{array}{l}\text { Enterovirus } 71 \text { and endemic gastrointestinal avian } \\
\text { influenza A virus of waterfowl (H9N2) }\end{array}$ & Thermal destruction & 94 \\
\hline $\begin{array}{l}\text { Graphene tungsten } \\
\text { oxide }\end{array}$ & Bacteriophage MS2 virus & Photocatalytic destruction & 95 \\
\hline $\mathrm{g}-\mathrm{C}_{3} \mathrm{~N}_{4}$ & Bacteriophage MS2 virus & Photocatalytic destruction & 96,97 \\
\hline $\begin{array}{l}\text { Sodium nonatitanate } \\
\text { nanosheets }\end{array}$ & Phage $\lambda$ & Photocatalytic destruction & 98 \\
\hline
\end{tabular}


Thanks to its shape and negatively charged surface, GO can exhibit antiviral activity against viruses such as pseudorabies virus (PRV), an alphaherpesvirus, and porcine epidemic diarrhea virus (PEDV), an $\alpha$-coronavirus. ${ }^{85}$ Although vaccines are available for both viruses, the diseases have emerged again because of antigenic variations. The unique effect of GO on PRV and PEDV, due to the intimate interactions between these viruses and GO, was identified through a comparative study using reduced GO (rGO), graphite, and graphite oxide. GO and rGO demonstrated higher antiviral activity than graphite and graphite oxide, also showing that monolayers favored interactions with the viruses. GO coated with cationic polymers, such as polydiallyldimethylammonium chloride (PDDA) and non-ionic polymers, such as polyvinylpyrrolidone (PVP), showed different behaviors. The zeta potential of GO-PDDA was found to be positive, whereas it was negative for GO-PVP. Interestingly, an efficient antiviral activity was observed for GO-PVP but not for GO-PDDA, indicating that electrostatic interactions are essential for virus adsorption. GO sheets could also inactivate viruses prior to its internalization into cells through structural destruction induced by their sharp edges (the so-called nano-knife effect). PRV is a spherical entity and it consists of a nucleocapsid surrounded by an envelope, containing glycoprotein spikes, while PEDV is a round and pleomorphic entity surrounded by a crown-like corona. GO destroyed the envelope and crown of PEDV, while only part of the envelope and glycoprotein spikes of PRV were damaged. Overall, this comparative study demonstrated that the negatively charged and single-layer structure of GO, with sharp edges, allowed direct interactions with both positively charged enveloped viruses.

In another study, GO showed a higher antiviral effect toward an enveloped virus, the herpes simplex virus type-1 (HSV-1), compared to $\mathrm{MoS}_{2} \cdot{ }^{86} \mathrm{GO}$ could efficiently interact with the positively charged glycoproteins on HSV-1. In this case, small size nanosheets were more effective than bigger flakes to disrupt the virus membrane, probably due to the presence of sharper edges, resulting in significant inhibition.

GO can also interact with another type of enveloped virus, the SARS-CoV-2, and it has the capacity to reduce infectivity in vitro. ${ }^{87}$ With perspectives for the design of new face masks, polyurethane or cotton material was loaded with GO or few-layer graphene. When in contact with a culture medium containing SARS-CoV-2 viral particles, the hybrid materials led to an efficient infectivity inhibition. 
The presence of various oxygenated groups on GO, mainly epoxides and hydroxyl groups on the basal plane and carboxylic acids at the edges, are also fundamental as adsorption sites. This rich chemistry of GO was exploited to improve the augmentation of the virus concentration during PCR analysis using GO-coated microbeads. ${ }^{88}$ The coating with GO was much more efficient to gather non-enveloped human adenovirus type 5 particles on the microbeads thanks to electrostatic interactions and van der Waals forces compared to tetraethyl orthosilicate and (3-aminopropyl) triethoxysilane.

The interactions between 2DMs and viruses also depend on the viral structure, in particular whether the viruses are surrounded by a lipid envelope or not. A comparative study was performed using an enveloped virus (feline coronavirus) and a non-enveloped virus (infectious bursal disease virus) ${ }^{89}$ Interestingly, GO inhibited the infection of the enveloped virus only. Nevertheless, the inactivity of GO in response to the non-enveloped virus could be avoided by the reduction of GO and decoration with metallic nanoparticles, leading to antiviral activity through binding of the thiol groups of the viral glycoproteins to metals. In this work, the differences in the behavior of GO on enveloped and non-enveloped viruses highlighted the specific interactions between negatively charged GO and positively charged lipid membranes. ${ }^{90}$ Enhanced antiviral activity was also observed for GO decorated with silver nanoparticles compared to GO and the nanoparticles alone against two types of enveloped viruses, the porcine reproductive and respiratory syndrome virus and the porcine epidemic diarrhea virus. ${ }^{91}$ As the silver nanoparticles were synthesized using citrate, they were negatively charged. GO was coated with positively charged polydiallyldimethylammonium chloride to favor the adsorption of the nanoparticles via electrostatic interactions. The inhibitory effect on the virus infection was not only due to the inhibition of the entry into the host cells, but also to higher production of interferon- $\alpha$ (IFN- $\alpha$ ) and IFN-stimulating genes, which could directly stop the virus proliferation.

The functionality of the protein segments of viruses should be considered. The viral protein $R$ (Vpr) is a small nuclear accessory protein of HIV-1 involved in the regulation of nuclear importing of HIV genes through the formation of ion channels. The fragment of Vpr13-33 was shown to be preferentially adsorbed onto GO. ${ }^{92}$ The adsorption was accompanied by a conformational change, providing opportunities for anti-HIV application as a possible mutation of Vpr13-33 that could reduce the viral replication and delay the progression of the infection. Molecular dynamics 
simulation confirmed the aggregation and conformational change of Vpr on GO through $\pi$-stacking and electrostatic interactions. ${ }^{93}$

GO was also able to induce thermal destruction of Enterovirus 71 (EV71), a non-enveloped virus causing epidemics of hand, foot, and mouth disease in children, and the endemic gastrointestinal avian influenza A virus of waterfowl (H9N2) ${ }^{94}$ Influenza A viruses display a wide phenotypic and genetic diversity in avian and mammalian hosts. The two enteric viruses, EV71 and H9N2, are less sensitive to detergents than other viruses, while the localized oxygenated groups on the surface of GO were found to play a key role in the interactions with the viruses via hydrogen bonding, electrostatic interactions, and redox reaction. After heating at $56^{\circ} \mathrm{C}$ (the most common temperature to induce virus inactivation), the viruses lost their structural integrity. The capsid of EV71 was broken and the morphology of the enveloped H9N2 was also changed with no more protein spikes visible, resulting in leaking of RNA (Figure 5). The efficient capture of viruses by GO and the damage on their integrity was exploited to simplify the viral RNA extraction procedure in the RT-PCR assay, which is usually complicated, for rapid virus detection. In addition to the heat transfer and electron transfer properties of $\mathrm{GO}$, the oxygenated groups are also fundamental for efficient capture and destruction of viruses as rGO offered a lower capacity to induce RNA leaking.
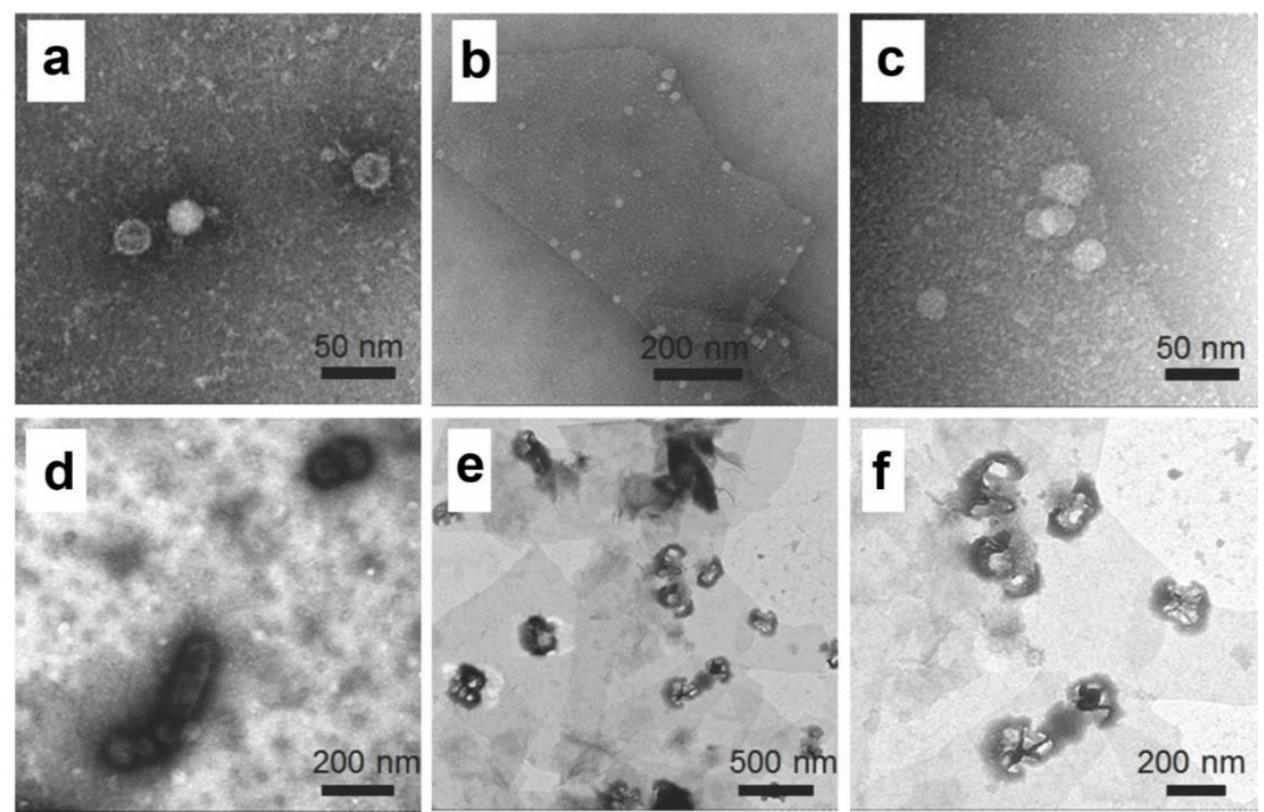

Figure 5. TEM images of negatively stained (a) EV71, (b, c) EV71 captured by GO, negatively stained (d) H9N2, and (e, f) H9N2 captured by GO after thermal heating treatment. Adapted with permission from Ref. 94. Copyright 2015 WILEY-VCH Verlag GmbH \& Co. 
The excellent electron-acceptor properties of graphene, associated to high electron mobility, were exploited for virus photo-inactivation. The photocatalytic destruction of the bacteriophage MS2 virus was induced by a graphene-tungsten oxide composite thin film under visible light irradiation. ${ }^{95}$ Here, tungsten oxide, with a band gap of $\sim 3 \mathrm{eV}$, was an ideal material to receive irradiation energy in the form of produced excitons. The generated photoexcited electrons could trigger the photodegradation of the protein capsid, leading to its breakage and the efflux of the viral RNA. The composite film was stable against photodegradation, showing less than $10 \%$ reduction in the RNA efflux after 20 cycles. The photocatalytic inactivation of the bacteriophage MS2 virus under visible light irradiation was also achieved by $\mathrm{g}-\mathrm{C}_{3} \mathrm{~N}_{4} \cdot{ }^{96,97}$ In this case, reactive oxygen species (ROS), mainly superoxide and hydroxyl radicals, were responsible for the destruction of the virus, resulting from the distortion of the virus shape, damage of surface proteins, and rupture of the capsid shell. Another type of 2DMs, titanate nanosheets, was exploited to photocatalytically degrade bacteriophages by generating free radicals. ${ }^{98}$ When exposed to UV light, delaminated sodium nonatitanate $\left(\mathrm{Na}_{4} \mathrm{Ti}_{9} \mathrm{O}_{20}\right)$ nanosheets produced $\mathrm{HO} \cdot$ and $\mathrm{O}_{2} \cdot{ }^{-}$radicals that degraded phage $\lambda$.

Simulations allow studying interactions between 2DMs and viruses theoretically and make predictions. The interactions between graphene sheets and the C-terminal DNA-binding domain of HIV-1 integrase were investigated by molecular dynamics simulations. ${ }^{99}$ The HIV-1 integrase can form a dimer in a solution with a hydrophobic interface. Thanks to its hydrophobic nature, graphene can insert into the protein-protein interface, leading to the separation of the dimer. Therefore, the capacity of graphene to break hydrophobic protein-protein interactions may significantly contribute to its virucidal performance. Similarly, molecular dynamics simulations demonstrated that graphene could interact strongly with Ebola virus matrix protein VP40 and break hydrophobic protein-protein interactions. ${ }^{100}$ In this case, graphene could insert through the C-terminal domain (CTD-CTD) interface of VP40 hexamers, which is essential for the formation of the Ebola virus matrix. The disruption of the CTD-CTD interface could provide opportunities to reduce the spread of Ebola disease.

In another study, computational molecular approaches were used for investigating the molecular interactions of graphene with three target proteins to fight HIV infection. ${ }^{101}$ The proteins included the HIV-viral protein R (Vpr), involved in cellular entry and virus replication, the negative regulatory factor (Nef) protein, promoting virus replication, and the group-specific antigen (Gag) 
protein that codes for core structural proteins. The docking study showed that graphene could bind strongly to all three proteins. While the number of layers in the graphitic sheets (from 1 to 5) did not impact the binding affinity, a larger size of these sheets increased the affinity because of higher contact area.

To date, studies on the direct interactions between viruses and 2DMs have mainly involved graphene-family nanomaterials. Comparative studies allowed defining key parameters (negative charges and single layer) favoring interactions with viruses and eventually inhibition, demonstrating the superior capacity of GO to immobilize viruses. Indeed, the presence of abundant negatively charged oxygenated groups on the GO surface enables to strongly adsorb non-enveloped and enveloped viruses with positively charged lipid membranes via electrostatic interactions and hydrogen bonding. An antiviral effect can be induced either through physical destructuring of viruses due to their nano-knife effect or by photocatalytic destruction as observed for $\mathrm{rGO}, \mathrm{g}-\mathrm{C}_{3} \mathrm{~N}_{4}$, and titanate nanosheets. Graphene was shown to be an efficient material to break hydrophobic protein-protein interactions, which may contribute to a virucidal activity. Therefore, depending on the type of viruses, in particular their surface charge, different kinds of 2DMs with appropriate or tailored surface properties, especially a well-designed hydrophobic/hydrophilic ratio, can be used to efficiently immobilize viruses and potentially lead to inhibition or destruction activities.

\section{Functionalization of 2DMs with sulfate/sulfonate groups or targeting ligands}

Viral infection is generally initiated by the attachment of viruses to host cells via receptors (typically proteins or glycans) on the virus surface. Imparting affinity of 2DMs for these receptors is a strategy for virus attachment to their surface. To favor interactions with viral particles, the surface of 2DMs can be functionalized with ligands (e.g., aptamers, carbohydrates) that can present strong affinity for viral proteins or with sulfate/sulfonate-containing molecules that can mimic heparan sulfate present on the surface of host cells. Table 2 summarizes the type of molecules conjugated on 2DMs to initiate interactions with viruses. 
Table 2. Molecules allowing 2DMs to efficiently interact with viruses.

\begin{tabular}{|c|c|c|c|c|c|}
\hline Functional groups & 2DMs & Viruses & $\begin{array}{l}\text { Recognition elements on } \\
\text { viruses }\end{array}$ & Antiviral effect & References \\
\hline 1 & $\mathrm{GO}$ & \multirow{2}{*}{$\begin{array}{l}\text { Herpes simplex virus } \\
\text { type- } 1\end{array}$} & \multirow{2}{*}{ / } & \multirow[t]{2}{*}{ Inhibition } & \multirow{2}{*}{104} \\
\hline Benzenesulfonic acid & Partially reduced GO & & & & \\
\hline Benzenesulfonic acid & $\begin{array}{l}\text { rGO coated with iron- } \\
\text { based magnetic } \\
\text { nanoparticles }\end{array}$ & $\begin{array}{l}\text { Herpes simplex virus } \\
\text { type-1 }\end{array}$ & / & Photothermal destruction & 105 \\
\hline $\begin{array}{l}\text { Dendritic polyglycerol } \\
\text { sulfate }\end{array}$ & rGO & Orthopoxviruses & $\begin{array}{l}\text { Heparin-binding surface } \\
\text { protein A27 }\end{array}$ & Inhibition & 107 \\
\hline $\begin{array}{l}\text { Dendritic polyglycerol } \\
\text { sulfate }\end{array}$ & rGO & $\begin{array}{l}\text { Vesicular stomatitis } \\
\text { virus }\end{array}$ & Viral envelope glycoproteins & Inhibition & 108 \\
\hline $\begin{array}{l}\text { Dendritic polyglycerol } \\
\text { sulfate }\end{array}$ & rGO & $\begin{array}{l}\text { Herpes simplex virus } \\
\text { type } 1 \text { and equine } \\
\text { herpesvirus type } 1\end{array}$ & $\begin{array}{l}\text { Viral envelope glycoproteins } \\
\text { (mainly gB and gC) }\end{array}$ & Inhibition & 109 \\
\hline $\begin{array}{l}\text { Dendritic or linear } \\
\text { polyglycerol sulfate }\end{array}$ & rGO & $\begin{array}{l}\text { African swine fever } \\
\text { virus }\end{array}$ & $\begin{array}{l}\text { Viral membrane proteins } \\
\text { p12 and/or p54 }\end{array}$ & Inhibition & \multirow{2}{*}{112} \\
\hline $\begin{array}{l}\text { Linear polyglycerol } \\
\text { sulfate }\end{array}$ & rGO & Pseudorabies virus & $\begin{array}{l}\text { Viral envelope glycoproteins } \\
(\mathrm{gB}, \mathrm{gC})\end{array}$ & Inhibition & \\
\hline $\begin{array}{l}\text { Dendritic polyglycerol } \\
\text { sulfate and alkyl } \\
\text { chains }\end{array}$ & rGO & $\begin{array}{l}\text { Herpes simplex virus } \\
\text { type } 1\end{array}$ & $\begin{array}{l}\text { Viral envelope glycoproteins } \\
(\mathrm{gB}, \mathrm{gC})\end{array}$ & Inhibition & 113 \\
\hline Aptamer & GO & $\begin{array}{l}\text { Bacteriophage } \mathrm{MS} 2 \\
\text { virus }\end{array}$ & Viral surface proteins & Photocatalytic destruction & 114 \\
\hline Sialic acid & $\begin{array}{l}\text { Polyglycine } \\
\text { nanosheets }\end{array}$ & Influenza virus & Sialic receptors & Inhibition & 116 \\
\hline
\end{tabular}




\section{Functionalization with sulfate/sulfonate groups as heparan sulfate mimics}

Almost all mammalian cells express heparan sulfate, a negatively charged polymer sulfated at various positions, on their surface. Viruses bind to heparan sulfate via electrostatic interactions with a rather low affinity. This relatively non-specific process allows increasing the concentration of viruses on the cell surface, thus facilitating subsequent binding to high-affinity receptors. Heparin has been used as a viral entry inhibitor as it can compete with heparan sulfate, which prevents virus adhesion to cell and thus infection. Nevertheless, its anticoagulant effect limits its therapeutic application. On the contrary, polymeric heparin analogs, such as negatively charged dendritic polyglycerol sulfate, show slight or no anticoagulant effect. ${ }^{102}$ Compared to the size of viruses, single polymer molecules are much smaller and their contact areas are thus limited. The conjugation of sulfate-rich polymers onto 2DMs with a large surface area and sufficient flexibility can be used as a strategy to overcome such an issue. In this regard, the presence of multiple copies of the polymer on 2DMs can dramatically enhance the affinity towards viruses due to multivalency. Generally, multivalent interactions between viruses and cell surface lead to stable attachment of viral particles to host cells, resulting in enhanced cellular entry. ${ }^{103}$

Both GO and partially reduced sulfonated GO were efficient in inhibiting HSV-1 infection (Figure 6A-B). ${ }^{104}$ The sulfonate-functionalized partially reduced GO sheets were prepared by arylation of these sheets using sulfanilic acid diazonium salt. The two GO derivatives displayed similar highly negative zeta potentials, indicating that the surface charges were likely the main parameter impacting their inhibition properties. The main inhibition mechanism was attributed to a competitive attachment of the sheets to the virus and not to cell-to-cell spreading inhibition. Indeed, because of their large lateral dimensions, varying from hundreds of nanometers up to a few micrometers, the GO derivatives were not able to enter the intercellular regions between the cells and inhibit the spreading.

In another study, the photothermal capacity of rGO and the conjugation of an antiviral molecule was exploited to destroy viruses. Here, rGO functionalized with sulfanilic acid diazonium after coating the surface with iron-based magnetic nanoparticles was able to bind to HSV-1. ${ }^{105}$ Using an external magnet, the captured virus was aggregated and concentrated at one point, allowing efficient photothermal destruction upon near-infrared (NIR) light irradiation. Additionally, the sulfonated rGO was also exploited for immobilization of $\beta$-cyclodextrin followed by loading of the antiviral compound curcumin in the hydrophobic cavity of cyclodextrin. ${ }^{106}$ 
Curcumin is known to prevent the replication and budding of the respiratory syncytial virus (RSV). The curcumin/sulfonated-rGO revealed efficient antiviral properties by inhibiting RSV infection probably through a combined mechanism of direct virus inactivation, inhibition of the binding of the virus onto the host cells, and interference with virus replication.

A)

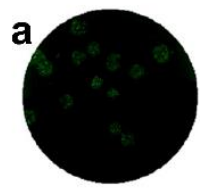

e
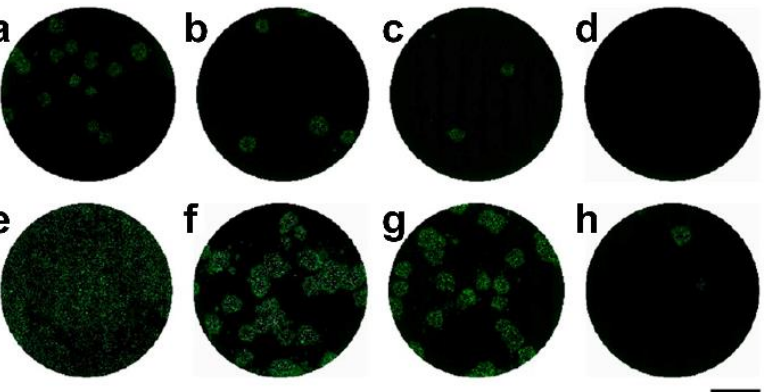

B)

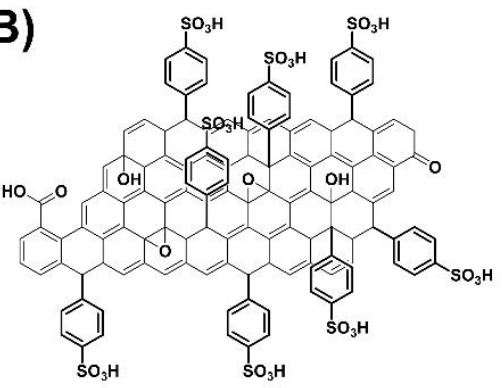

C)
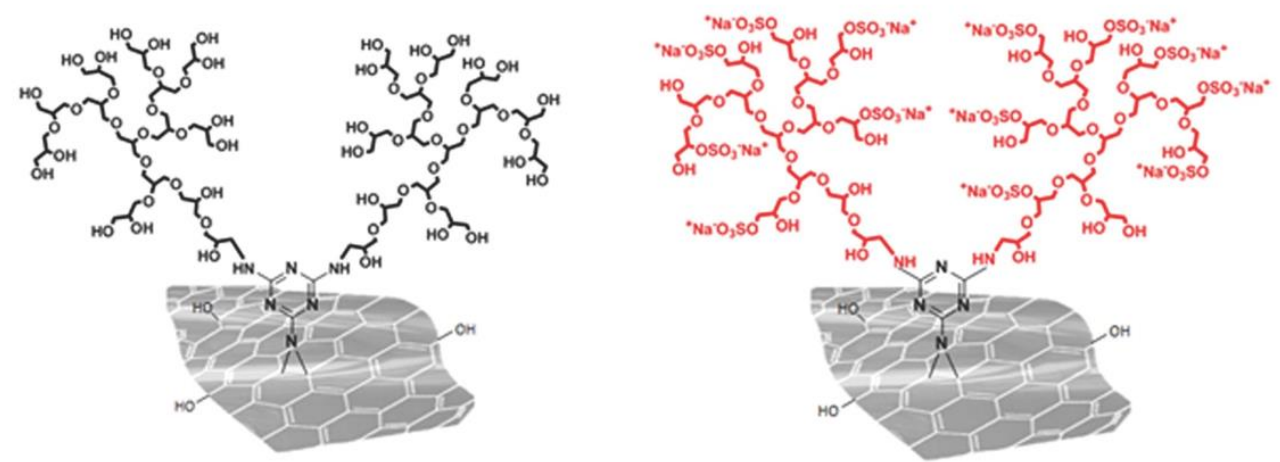

D)
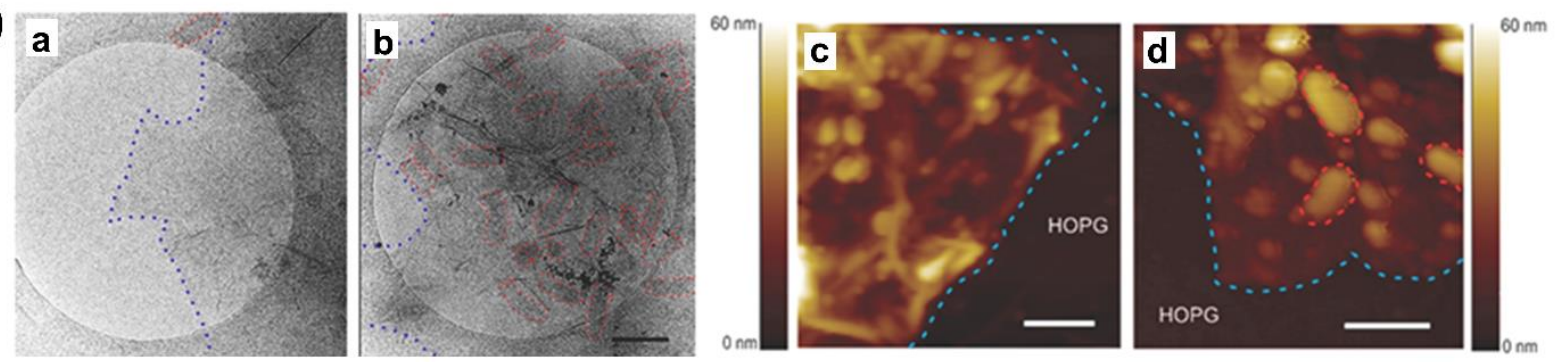

Figure 6. A) Plaque reduction assay observed by fluorescence microscopy of Vero cell cultures infected with a green fluorescent protein-expressing HSV-1 strain with loads of 50 (top) and 500 (bottom) plaque-forming units per well and (a, e) no addition of partially reduced sulfonated GO (control), addition of (b, f) $0.5,(\mathrm{c}, \mathrm{g}) 5$, and $(\mathrm{d}, \mathrm{h}) 15 \mu \mathrm{g} \cdot \mathrm{mL}^{-1}$ of partially reduced sulfonated GO to the virus suspension prior to the addition to the Vero cell cultures (scale bar: $10 \mathrm{~mm}$ ). Figure A reprinted with permission from Ref. 104. Copyright 2014 American Chemical Society. B) 
Chemical structure of the partially reduced sulfonated GO. C) Chemical structures of (left) dendritic polyglycerol-rGO bearing a high density of hydroxyl groups ( $\mathrm{rGO}-\mathrm{PG}_{\text {high }}$ ) and (right) the

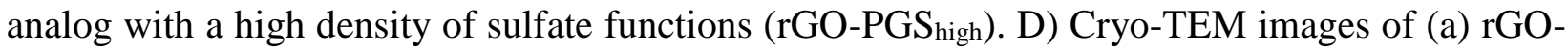

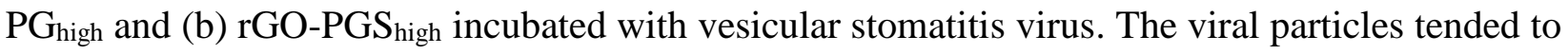
bind to rGO-PGS high $(\mathrm{b})$. In contrast, the $\mathrm{rGO}-\mathrm{PG}_{\text {high }}$ sheets and the viral particles were uniformly and individually distributed in the vitrified sample showing no specific interactions (a). The viral particles are outlined by red dashed lines and the edges of the rGO sheets are delineated by blue dashed lines. Tapping mode AFM height images of (c) rGO-PG $\mathrm{Ph}_{\text {high }}$ and (d) rGO-PGS $\mathrm{Sigh}_{\text {incubated }}$ with vesicular stomatitis virus. The viral particles were adsorbed onto the rGO-PGS $\mathrm{Sigh}_{\text {sheets }}(\mathrm{d})$ to a higher extent in comparison to $\mathrm{rGO}-\mathrm{PG}_{\text {high }}$ (c). The scale bar in images a-d is $200 \mathrm{~nm}$. Figure C-D reprinted with permission from Ref. 108. Copyright 2017 WILEY-VCH Verlag GmbH \& Co.

As alternative to the functionalization of graphene materials by arylation using sulfanilic acid diazonium salt, the decoration with polyglycerol sulfate polymers has been extensively explored. Compared to the size of viral particles $(20-400 \mathrm{~nm})$, dendritic polyglycerol sulfate is a small molecule $(\sim 3 \mathrm{~nm})$ and the contact area with viruses is thus limited. In this context, 2DMs provide a vast functional and flexible surface area for multivalent interactions with viruses, allowing augmented binding. In particular, several graphene-dendritic polyglycerol sulfate hybrid architectures were developed to investigate interactions with various viruses. The influence of the degree of sulfation, polymer grafting density, and size of the graphene sheets allow the design of graphene-based conjugates with strong virus inhibition potentials. In this regard, it was observed that rGO functionalized with dendritic polyglycerol sulfate was able to interact with different orthopoxvirus strains through binding to the heparin-binding surface protein A27, leading to virus inhibition. ${ }^{107}$ SPR and enzyme linked lectin assay-like demonstrated that the protein A27 bound strongly to dendritic polyglycerol sulfate immobilized on $\mathrm{GGO}$, while other orthopoxvirus surface proteins, devoid of a heparin binding sites, showed no interaction. In their work, modulation of the degree of polymer functionalization and sulfation allowed to optimize the binding efficiency. A high level of functionalization with dendritic polyglycerol and a medium sulfation degree were necessary for strong interactions between rGO and orthopoxvirus. While rGO bearing a high density of sulfate groups ( $6 \% \mathrm{rGO}$ and $94 \%$ sulfated polyglycerol) strongly interacted with vesicular stomatitis virus leading to inhibition, the analog with hydroxyl functions (rGO-dendritic 
polyglycerol) did not bind significantly to the virus (Figure 6C-D). ${ }^{108}$ The virus morphology was unchanged after the binding of rGO-dendritic polyglycerol sulfate.

The impact of both the size of rGO and the degree of sulfation on the inhibition of virus entry and replication, were investigated using HSV-1 and equine herpesvirus type 1 (EHV-1), two spherical viruses with diameters of 150 and $250 \mathrm{~nm}$, respectively. ${ }^{109}$ It was found that sheets with the smallest sizes $(\sim 300 \mathrm{~nm})$ and $10 \%$ sulfation were the most efficient for virus inhibition. Interestingly, sulfated rGO inhibited the virus infection at an early stage during cellular entry, but did not affect the cell-to-cell spread. The higher inhibitory effect of the small sulfated rGO sheets was attributed to a combined result of bending and cooperative encapsulation of the virus by rGO. Membrane bending is known to play a key role in the endocytosis process and it is altered by the presence of proteins. ${ }^{110}$ As multiple interactions are necessary for remodeling membranes, ${ }^{111}$ the contact area between the virus and rGO was larger when the energy required for virus membrane bending was overcompensated by the energy gain through the multivalent interactions. In this case, the wrapping of at least one virus by two or more rGO sheets was observed. It is known that the nucleocapsid of HSV-1 is surrounded by a flexible membrane envelope constituted of glycoproteins. From the observations, it was postulated that the sulfated rGO interacted with viral envelope glycoproteins, mainly $\mathrm{gB}$ and $\mathrm{gC}$ in the case of $\mathrm{HSV}-1$ and $\mathrm{EHV}-1$, which are known to bind to cell surface heparan sulfate proteoglycans. In another report, the influence of the polymer conformation on the inhibitory effect of rGO-polyglycerol sulfate was examined on two enveloped viruses, namely pseudorabies virus (PrV, Suid herpesvirus 1) and African swine fever virus (ASFV). ${ }^{112}$ While rGO with either dendritic or linear polyglycerol sulfate (with the same molecular weight and degree of sulfation) exhibited similar inhibitory effect on ASFV, the linear conjugate was more efficient than the dendritic analog on PrV. This result could be explained based on the conformational similarity between the linear polyglycerol sulfate and the linear structure of heparan sulfate. Interestingly, the viral proteins of ASFV did not interact preferentially with the linear or dendritic conjugate.

Besides electrostatic interactions, as the main driving forces for the binding of polyglycerol sulfate-graphene derivatives to viruses, hydrophobic interactions with long alkyl chains can also enhance the inhibitory effect of graphene onto HSV-1 by disrupting the virus membrane. ${ }^{113}$ Among the rGO sheets doubly functionalized with dendritic polyglycerol sulfate and a broad range of alkyl chains ranging from $\mathrm{C} 3$ to $\mathrm{C} 18$, the $\mathrm{C} 12$-derivative exhibited the highest antiviral activity, but it 
was also toxic against the Vero cell line. A good compromise was found with the C6- and C9-alkyl chains displaying a high antiviral potential and low cytotoxicity. In this case, the wrapping of the virus by the graphene sheets was observed. It was shown that the combined effect of electrostatic and hydrophobic interactions with the doubly functionalized graphene led to a higher inhibition compared to only electrostatic interactions for dendritic polyglycerol sulfate-rGO.

Altogether, the large contact area and high degree of flexibility of 2DMs combined with the negative charges of GO or rGO functionalized with either sulfated polymers or sulfonated groups could enable the binding to viruses through multivalent electrostatic interactions with viral recognition proteins.

\section{Functionalization with aptamers or carbohydrate ligands}

The use of specific ligands, such as carbohydrates or aptamers, conjugated on 2DMs has not been exploited much to selectively target viruses. Aptamers are DNA or RNA synthetic molecules capable of binding a wide range of (bio)molecules (proteins, nucleic acids) with high specificity and considerable affinity. Their properties allow detecting viruses and make them competitive to antibodies. As an example, GO was functionalized with an aptamer specifically designed to target the bacteriophage MS2 virus. ${ }^{114}$ The bacterial virus MS2 is composed of a protein capsid and an enveloped RNA genome. As such, the aptamer on GO was able to specifically bind to the coat proteins on the virus surface. In contrast, there was no significant adsorption of the virus on the non-modified GO. The photocatalytic activity ${ }^{115}$ of GO was then exploited to destroy the MS2 virus adsorbed onto its surface. Visible light irradiation triggered the inactivation of the virus via the generation of ROS, causing the disruption of the protein capsid, RNA release, and breaking of RNA strands. The sharp edges of GO might also contribute to the physical damage of the surface proteins.

Beyond graphene, polyglycine II nanosheets also demonstrate antiviral activity through specific binding to receptors on the surface of proteins. This was shown for influenza virus strain A/H3N2/NIB/44/90M with sialic receptors. ${ }^{116}$ Tetraantennary peptides [glycine $\left.{ }_{n}-\mathrm{NHCH}_{2}\right]_{4} \mathrm{C}$ (named tectons) were found to form stable non-covalent structures through highly cooperative intermolecular H bonds (Figure 7A). This self-assembly process, leading to a [2+2] conformation, resulted in the formation of polyglycine II flat and rigid sheets (tectomers) of one-moleculethickness and sub-micron lateral dimensions. The carbohydrate ligand $N$-acetylneuraminic acid 
(also named sialic acid) was attached to the terminal glycine residues. The influenza virus has the capacity to bind to host cells through specific interactions between the spike glycoprotein hemagglutinin, expressed in high amounts on the surface of influenza virus envelope, and sialic acid-glycoside receptors located on the host cell surface resulting in cellular entry via membrane fusion (Figure 1a). The inhibition of the virus adhesion onto cells was much more efficient in the presence of sialic acid-polyglycine II in comparison with a sialic acid-containing oligosaccharide, probably because of multivalent interactions and large surface area of the polyglycine II nanosheets that shielded the virus and prevented the binding to sialic receptors on the host cells (Figure 7B). Interestingly, the assembly of the tectons into tectomers was also observed directly on the virus providing novel opportunities for specific interactions between viruses and 2DMs. 

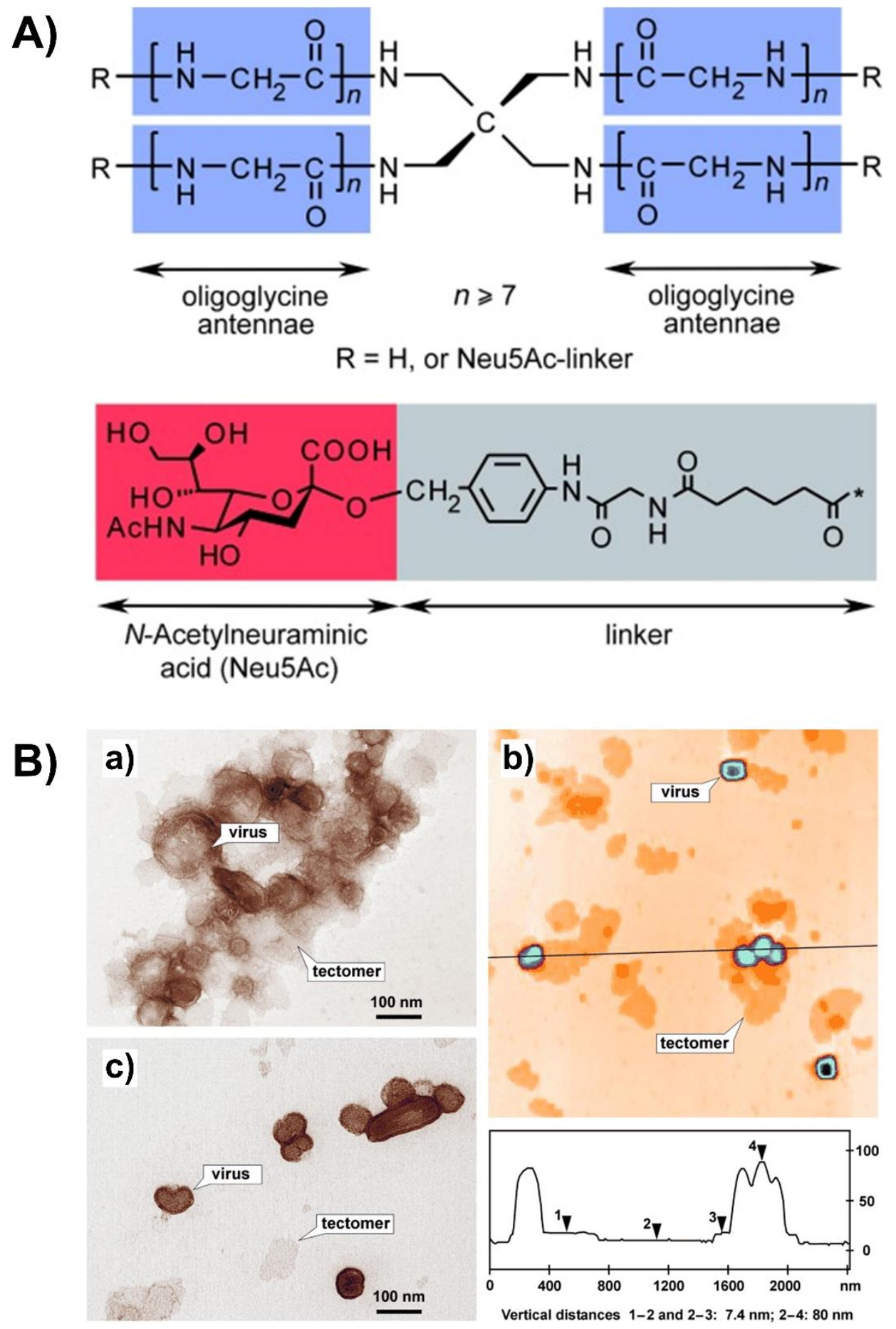

Figure 7. A) Chemical structures of the tetraantennary peptides and targeting glycopeptides. The tetraantennary peptides can self-assemble into polyglycine II nanosheets. B) (a) Electron microscopy and (b) AFM images of the influenza virus with [Neu5Aca-linker-Gly7- $\left.\mathrm{NHCH}_{2}\right]_{4} \mathrm{C}$ tectomer showing that the tectomers are in close proximity to the viral particles. (c) Electron 
microscopy image of the influenza virus and the structural analog [Neu5Ack-linker-Gly7$\left.\mathrm{NHCH}_{2}\right]_{4} \mathrm{C}$ with unnatural Neu5Ac $\beta$ groups. In this case, the tectomers are distanced from the viral particles showing no specific interactions. Reprinted with permission from Ref. 116. Copyright 2003 WILEY-VCH Verlag GmbH \& Co.

The conjugation of aptamers with 2DMs has not been in-depth investigated to explore their specificity with viruses, despite their advantages compared to antibodies that may present limitations related to selection issues, selectivity problems, cross-reactivity, low stability, immunogenicity, and preparation difficulties. ${ }^{117}$ Furthermore, aptamers can be raised against any type of targets with an affinity similar or higher than antibodies. They are relatively small in size and thus 2DM surface can be decorated with many of such molecules in comparison to antibodies.

\section{Future possibilities for functionalization of 2DMs against viruses}

There are many future possibilities that should be investigated regarding functionalization of 2DMs for their interactions with viruses. We presented here that functionalization of graphene derivatives with sulfate/sulfonate groups can offer great potentials to efficiently immobilize viruses. The control on the level of functionalization gives the possibility to finely tune their interactions with viruses and this should be further explored.

After the immobilization of viruses on the surface of 2DMs, the full virus inactivation depends on the type of viruses and 2DMs. Several parameters were so far demonstrated to be crucial to favor the interactions between graphene derivatives and viruses such as surface charge, type of functional groups, number of layers, and folding of the sheets. We also discussed that the sharp edges of graphene-family sheets can induce significant damage to virus membranes, leading to its destruction, an effect similar to the one that was also observed for bacteria. Similarly, the nanoknife effect has been described for other types of 2DMs leading to killing of bacteria. ${ }^{6}$ For example, $\mathrm{Ti}_{3} \mathrm{C}_{2} \mathrm{~T} x$ MXene ( $\mathrm{T}$ stands for surface termination, such as $-\mathrm{O},-\mathrm{F}$, or $-\mathrm{OH}$ ) exhibited superior antibacterial activity compared to GO. ${ }^{118}$ It was also found that cellular membranes of bacteria could be pierced by the extremely sharp edges of graphdyine nanosheets, causing the leakage of intracellular substances. ${ }^{119}$ The antibacterial activity of graphdyine was higher in comparison to graphene and GO. Therefore, potential similar antiviral effects can be expected for graphdiyne and possibly $\mathrm{Ti}_{3} \mathrm{C}_{2} \mathrm{~T} x$ MXene and also for other 2DMs with high flexibility, stiffness, and strains. 
In addition to the mechanical effect, we also recognized that virus destruction could be induced by the photothermal effects of $\mathrm{rGO}$, or the ROS generated by $\mathrm{GO}, \mathrm{g}-\mathrm{C}_{3} \mathrm{~N}_{4}$, or titanate nanosheets upon NIR or UV/visible light irradiation. ${ }^{120}$ Other 2DMs with inherent photothermal capacity could certainly be investigated for the thermal destruction of viruses upon NIR light irradiation. For instance, transition metal dichalcogenides, MXenes, Pd nanosheets, and some emerging Xenes (e.g., phosphorene, borophene, antimonene, tellurene) could be explored. ${ }^{48}$ Similarly, other types of $2 \mathrm{DMs}$ with the ability to produce ROS could be examined, for example transition metal dichalcogenides and hexagonal boron nitride. ${ }^{121,122}$ Moreover, virus photo-inactivation can also be triggered by combining GO with semiconductor photocatalysts. Finally, the combination of graphene derivatives with silver nanoparticles or the functionalization with alkyl chains can enhance antiviral activity. Therefore, the association of 2DMs with antiviral agents (drugs or nanoparticles) or photocatalysts, or suitable functionalization with sulfate/sulfonate groups, targeting ligands or alkyl chains offer wide range of opportunities for 2DMs to interact efficiently with viruses and induce their destruction through a combined or synergistic antiviral effects.

\section{DETECTION OF VIRUSES AND PROTEINS RELEASED BY INFECTED ORGANISMS}

The properties of 2DMs allow the design of different types of biosensors able to detect and sense a variety of analytes. ${ }^{1}$ In the context of viral infections, 2DM-based sensors have been applied for the detection of viruses (whole viral particles or nucleic acids) and proteins released by host organisms.

\section{Detection of viruses and viral nucleic acids}

\section{Detection of viral particles and antigens}

So far, to allow interactions with viruses, 2DMs (primarily graphene and $\mathrm{MoS}_{2}$ to a lower extent) were functionalized mainly with antibodies and also with proteins and aptamers. Most of the currently developed 2DM-based biosensors rely on electrochemical ${ }^{123,124}$ and electrical ${ }^{125}$ detection of the viruses, but a colorimetric immunoassay, ${ }^{126}$ as well as SERS, ${ }^{127,128}$ SPR and fluorescent ${ }^{129}$ optical sensors were also reported. The majority of biosensors are immunosensors taking advantage of the high surface area of the 2DMs, allowing to overcome limitations of other immunosensors related to low control of the surface density of antibodies. Table $\mathbf{3}$ summarizes the type of 
molecules immobilized on 2DM-based detection systems for virus detection according to the selected examples reported thereafter. 
Table 3. Specific molecules conjugated onto 2DM biosensors for virus detection.

\begin{tabular}{|c|c|c|c|c|c|c|c|c|c|}
\hline $\begin{array}{l}\text { Targeting } \\
\text { molecules } \\
\text { on 2DMs }\end{array}$ & 2DMs & Viruses & $\begin{array}{l}\text { Recognition } \\
\text { elements on } \\
\text { viruses }\end{array}$ & $\begin{array}{l}\text { Type of } \\
\text { biosensor } \\
\text { s }\end{array}$ & $\begin{array}{l}\text { Clinical } \\
\text { samples }\end{array}$ & $\begin{array}{l}\text { Limit of } \\
\text { detection }\end{array}$ & Linear range & $\begin{array}{l}\text { Limit of } \\
\text { detection using } \\
\text { other } \\
\text { techniques }^{\mathrm{a}}\end{array}$ & References \\
\hline $\begin{array}{l}\text { Rotavirus- } \\
\text { specific } \\
\text { antibody }\end{array}$ & GO & Rotavirus & n.d. & Fluorescent & I & $10^{5} \mathrm{pfu} \cdot \mathrm{mL}^{-1}$ & n.d. & $\begin{array}{l}10^{4}-10^{5} \mathrm{pfu} \cdot \mathrm{mL}^{-1} \\
(\mathrm{PCR})^{130}\end{array}$ & 138 \\
\hline $\begin{array}{l}\text { EV71- } \\
\text { specific } \\
\text { antibody and } \\
\text { CVB3- } \\
\text { specific } \\
\text { antibody }\end{array}$ & GO & $\begin{array}{l}\text { Human } \\
\text { EV71 } \\
\text { and } \\
\text { CVB3 }\end{array}$ & n.d. & Fluorescent & $\begin{array}{l}\text { Human } \\
\text { throat } \\
\text { swabs from } \\
\text { patients } \\
\text { infected by } \\
\text { EV71 or } \\
\text { CVB3 }\end{array}$ & $\begin{array}{l}0.42 \mathrm{ng} \cdot \mathrm{mL}^{-1} \\
(\mathrm{EV} 71) \text { and } \\
0.39 \mathrm{ng} \cdot \mathrm{mL}^{-1} \\
(\mathrm{CVB} 3)\end{array}$ & $\begin{array}{l}1-14 \mathrm{ng} \cdot \mathrm{mL}^{-1} \\
(\mathrm{EV} 71) \text { and } \\
1-19 \mathrm{ng} \cdot \mathrm{mL}^{-1} \\
(\mathrm{CVB} 3)\end{array}$ & $\begin{array}{l}0.01 \quad \text { pfu per } \\
\text { reaction mixture } \\
(\mathrm{RT}-\mathrm{LAMP}) \\
(\mathrm{EV71})^{131}\end{array}$ & 139 \\
\hline $\begin{array}{l}\text { Avian glycan } \\
\text { receptor } \\
\text { (Neu5Aca2,3 } \\
\text { Gal- } \beta 1,4 G l c) \\
\text { and a human } \\
\text { glycan } \\
\text { receptor } \\
\text { (Neu5Aca2,6 } \\
\text {-Gal- } \\
\beta 1,4 \text { Glc) }\end{array}$ & $\begin{array}{l}\mathrm{GO} \\
\mathrm{MoS}_{2}\end{array}$ & $\begin{array}{l}\text { Influenza } \\
\text { viruses }\end{array}$ & $\begin{array}{l}\text { Hemagglutini } \\
n\end{array}$ & Fluorescent & 1 & $\begin{array}{l}0.04 \mathrm{HAU} \cdot 50 \\
\mu \mathrm{L}^{-1} \\
(\mathrm{H} 1 \mathrm{~N} 1 \mathrm{pdm} 09 \\
), \quad 0.02 \\
\text { HAU.50 } \mu \mathrm{L}^{-1} \\
\text { (H10N8), } \\
0.06-0.07 \\
\text { HAU.50 } \mu \mathrm{L}^{-1} \\
\text { (H7N9) }\end{array}$ & n.d. & $\begin{array}{l}3.2 \mathrm{HAU} \cdot 50 \mu \mathrm{L}^{-1} \\
(\mathrm{H} 1 \mathrm{~N} 1)(\mathrm{HPLC})^{132}\end{array}$ & 140 \\
\hline $\begin{array}{l}\text { Peptides } \\
\text { derived from } \\
\text { the fragment } \\
\text { antigen- } \\
\text { binding- } \\
\text { region of an } \\
\text { anti- } \\
\text { glycoprotein } \\
\text { antibody }\end{array}$ & GO & $\begin{array}{l}\text { Ebola } \\
\text { virus }\end{array}$ & $\begin{array}{l}\text { Glycoprotein } \\
\mathrm{s}\end{array}$ & Fluorescent & 1 & $15 \mathrm{ng} \cdot \mathrm{mL}^{-1}$ & n.d. & I & 141 \\
\hline $\begin{array}{l}\text { Dengue } \\
\text { virus- }\end{array}$ & rGO & $\begin{array}{l}\text { Dengue } \\
\text { virus }\end{array}$ & n.d. & SPR & 1 & $0.1 \mathrm{pM}$ & n.d. & I & 143 \\
\hline
\end{tabular}




\begin{tabular}{|c|c|c|c|c|c|c|c|c|c|}
\hline $\begin{array}{l}\text { specific- } \\
\text { antibody }\end{array}$ & & & & & & & & & \\
\hline $\begin{array}{l}\text { Glycoprotein } \\
\text { fetuin A }\end{array}$ & rGO & $\begin{array}{l}\text { Influenza } \\
\text { virus A } \\
\text { H9N2 }\end{array}$ & $\begin{array}{l}\text { Neuraminida } \\
\text { se }\end{array}$ & $\begin{array}{l}\text { Electroche } \\
\text { mical }\end{array}$ & / & $10^{-8} \mathrm{U} \cdot \mathrm{mL}^{-1}$ & $\begin{array}{l}10^{-8}-10^{-1} \\
\mathrm{U} \cdot \mathrm{mL}^{-1}\end{array}$ & $\begin{array}{l}33 \quad \mathrm{ng} \cdot \mathrm{mL}^{-1} \\
(\mathrm{ELISA})^{133}\end{array}$ & 144 \\
\hline l & $\mathrm{GO}$ & $\begin{array}{l}\text { Dengue } \\
\text { virus }\end{array}$ & n.d. & $\begin{array}{l}\text { Electroche } \\
\text { mical }\end{array}$ & / & $\begin{array}{l}0.12 \text { (DENV- } \\
1) \text {, } 0.10 \\
\text { (DENV-2), } \\
0.50 \text { (DENV- } \\
\text { 3), and } 0.46 \\
\text { pfu.mL- } \\
\text { 1(DENV-4) }\end{array}$ & $\begin{array}{l}1-2 \quad x \quad 10^{3} \\
\text { pfu-mL-1 } \\
\text { (DENV-1, } \\
\text { DENV-2) and } \\
1-2 \quad x \quad 10^{3} \\
\text { pfu-mL-1 } \\
\text { (DENV-3, } \\
\text { DENV-4) }\end{array}$ & / & 146 \\
\hline $\begin{array}{l}\text { 2Dm2m } \\
\text { antibody }\end{array}$ & $\mathrm{GO}$ & HIV-1 & $\begin{array}{l}\text { HIV-1 } \\
\text { envelope } \\
\text { glycoprotein } \\
\text { ectodomain } \\
\text { (gp140MS) }\end{array}$ & $\begin{array}{l}\text { Electroche } \\
\text { mical }\end{array}$ & $\begin{array}{l}\text { HIV- } \\
\text { infected } \\
\text { human } \\
\text { serum }\end{array}$ & $8.3 \mathrm{fM}$ & $\begin{array}{l}670 \text { fM to } 0.1 \\
\mu \mathrm{M}\end{array}$ & $\begin{array}{l}30 \quad \text { aM } \\
\text { (electrochemical } \\
\text { graphene-based } \\
\text { biosensor) }^{134}\end{array}$ & 148 \\
\hline $\begin{array}{l}\text { Nucleoprotei } \\
\text { n-specific } \\
\text { influenza A } \\
\text { antibody }\end{array}$ & $\mathrm{GO}$ & $\begin{array}{l}\mathrm{H} 1 \mathrm{~N} 1 \\
\text { influenza } \\
\text { A virus }\end{array}$ & $\begin{array}{l}\text { H1N1 } \\
\text { influenza A } \\
\text { protein }\end{array}$ & $\begin{array}{l}\text { Electroche } \\
\text { mical }\end{array}$ & / & $10 \mathrm{ng} \cdot \mathrm{mL}^{-1}$ & $\begin{array}{l}10 \mathrm{ng} \cdot \mathrm{mL}^{-1} \text { to } \\
10 \mu \mathrm{g} \cdot \mathrm{mL}^{-1}\end{array}$ & / & 149 \\
\hline $\begin{array}{l}\text { Antibody } \\
\text { against the } \\
\text { SARS-CoV-2 }\end{array}$ & $\begin{array}{l}\text { Graphe } \\
\text { ne }\end{array}$ & $\begin{array}{l}\text { SARS- } \\
\text { CoV-2 }\end{array}$ & $\begin{array}{l}\text { Nucleocapsid } \\
\text { protein }\end{array}$ & $\begin{array}{l}\text { Electroche } \\
\text { mical }\end{array}$ & $\begin{array}{l}\text { COVID-19- } \\
\text { positive } \\
\text { patient } \\
\text { serum and } \\
\text { saliva } \\
\text { samples }\end{array}$ & $\begin{array}{l}0.1 \mu \mathrm{g} \cdot \mathrm{mL}^{-1} \\
\text { (serum) and } \\
0.5 \mathrm{ng} \cdot \mathrm{mL}^{-1} \\
\text { (saliva) }\end{array}$ & $\begin{array}{l}0.1-0.8 \\
\mu \mathrm{g} \cdot \mathrm{mL}^{-1} \\
\text { (serum) and } \\
0.5-2.0 \\
\mathrm{ng} \cdot \mathrm{mL}^{-1} \\
\text { (saliva) }\end{array}$ & / & 150 \\
\hline $\begin{array}{l}\text { Antibody } \\
\text { against the } \\
\text { Ebola virus } \\
\text { glycoprotein }\end{array}$ & rGO & $\begin{array}{l}\text { Ebola } \\
\text { virus }\end{array}$ & Glycoprotein & FET & $\begin{array}{l}\text { Spiked } \\
\text { human } \\
\text { serum }\end{array}$ & $2.4 \mathrm{pg} \cdot \mathrm{mL}^{-1}$ & $\begin{array}{l}2.4 \times 10^{-12} \text { to } \\
1.2 \times 10^{-7} \\
g \cdot \mathrm{mL}^{-1}\end{array}$ & $\begin{array}{l}5.2 \quad \mathrm{pg} \cdot \mathrm{mL}^{-1} \\
\text { (electroluminesce } \\
\text { nt nanospheres } \\
\text { coupled to } \\
\text { immunomagnetic } \\
\text { separation) }^{135}\end{array}$ & 151 \\
\hline $\begin{array}{l}\text { Hepatitis } \quad \text { B } \\
\text { surface } \\
\text { antigen- } \\
\text { binding } \\
\text { aptamer }\end{array}$ & $\begin{array}{l}\text { Graphe } \\
\text { ne }\end{array}$ & $\begin{array}{l}\text { Hepatitis } \\
\text { B virus }\end{array}$ & $\begin{array}{l}\text { Hepatitis B } \\
\text { surface } \\
\text { antigen }\end{array}$ & FET & $\begin{array}{l}\text { Diluted } \\
\text { human } \\
\text { serum and } \\
\text { artificial } \\
\text { saliva } \\
\text { containing }\end{array}$ & $10 \mathrm{aM}$ & $\begin{array}{l}10 \text { aM to } 0.1 \\
\mu \mathrm{M}\end{array}$ & $\begin{array}{l}33 \quad \text { aM } \\
\text { (electrochemilumi } \\
\text { nescence) }{ }^{136}\end{array}$ & 152 \\
\hline
\end{tabular}




\begin{tabular}{|c|c|c|c|c|c|c|c|c|c|}
\hline & & & & & $\begin{array}{l}\text { hepatitis B } \\
\text { surface } \\
\text { antigen }\end{array}$ & & & & \\
\hline $\begin{array}{l}\text { Specific } \\
\text { antibody } \\
\text { against } \\
\text { SARS-CoV-2 } \\
\text { spike protein }\end{array}$ & $\begin{array}{l}\text { Graphe } \\
\text { ne }\end{array}$ & $\begin{array}{l}\text { SARS- } \\
\text { CoV-2 }\end{array}$ & Spike protein & FET & $\begin{array}{l}\text { Nasophary } \\
\text { ngeal } \\
\text { swabs from } \\
\text { SARS- } \\
\text { CoV-2 } \\
\text { patients }\end{array}$ & 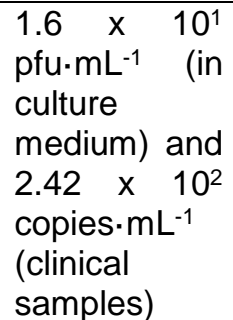 & n.d. & $\begin{array}{l}1.00 \quad \mathrm{x} \\
\text { copies } \mathrm{mL}^{-1} \\
\left(\text { LAMP) }^{137}\right.\end{array}$ & 153 \\
\hline $\begin{array}{l}\text { Anti-Zika } \\
\text { nonstructural } \\
\text { protein } 1 \\
\text { antibody }\end{array}$ & $\begin{array}{l}\text { Graphe } \\
\text { ne }\end{array}$ & Zika virus & $\begin{array}{lr}\text { Zika virus } \\
\text { nonstructural } \\
\text { protein } \\
\text { antigen }\end{array}$ & FET & $\begin{array}{l}\text { Spiked } \\
\text { simulated } \\
\text { human } \\
\text { serum }\end{array}$ & $0.45 \mathrm{nM}$ & n.d. & l & 154 \\
\hline
\end{tabular}

a: techniques mentioned in the cited articles for comparison with the 2DM-based biosensors

n.d.: non-determined

pfu: plaque-forming unit

HAU: hemagglutination unit 


\section{Optical biosensors}

A pioneering work in the field of fluorescent biosensors incorporating 2DMs for virus detection was reported in 2010 and relied on GO photoluminescence quenching induced by FRET between gold nanoparticles and GO (Figure 8A). ${ }^{138}$ The performance of this system was shown on rotavirus that was first captured by specific antigen-antibody interactions with rotavirus-specific antibodies conjugated on GO arrays. The addition of a rotavirus antibody that was linked to gold nanoparticles through DNA linkers resulted in the binding to the virus, thus placing the gold nanoparticles in close proximity to $\mathrm{GO}$, inducing fluorescence quenching. 
A)

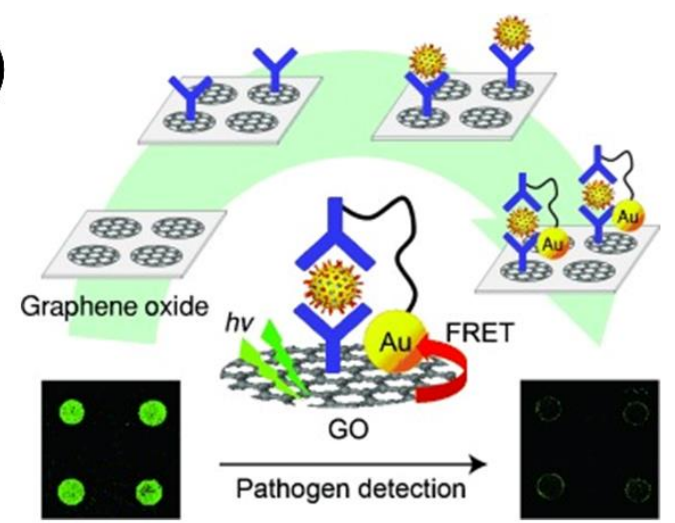

B)

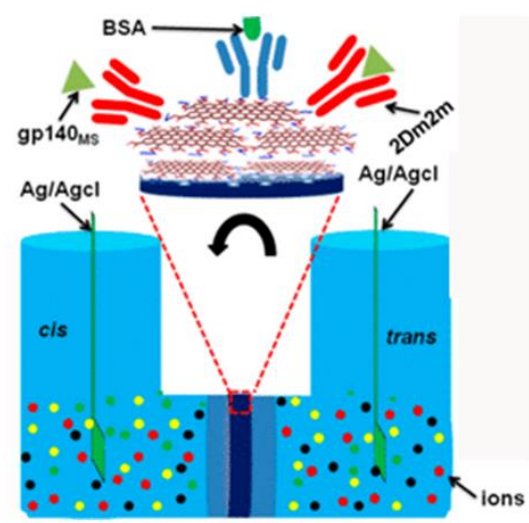

C)

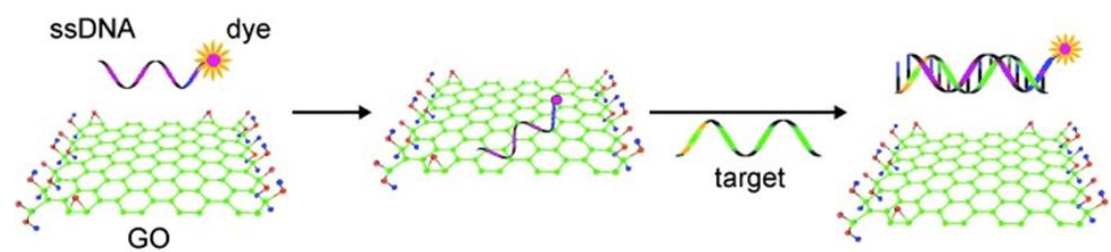

D)
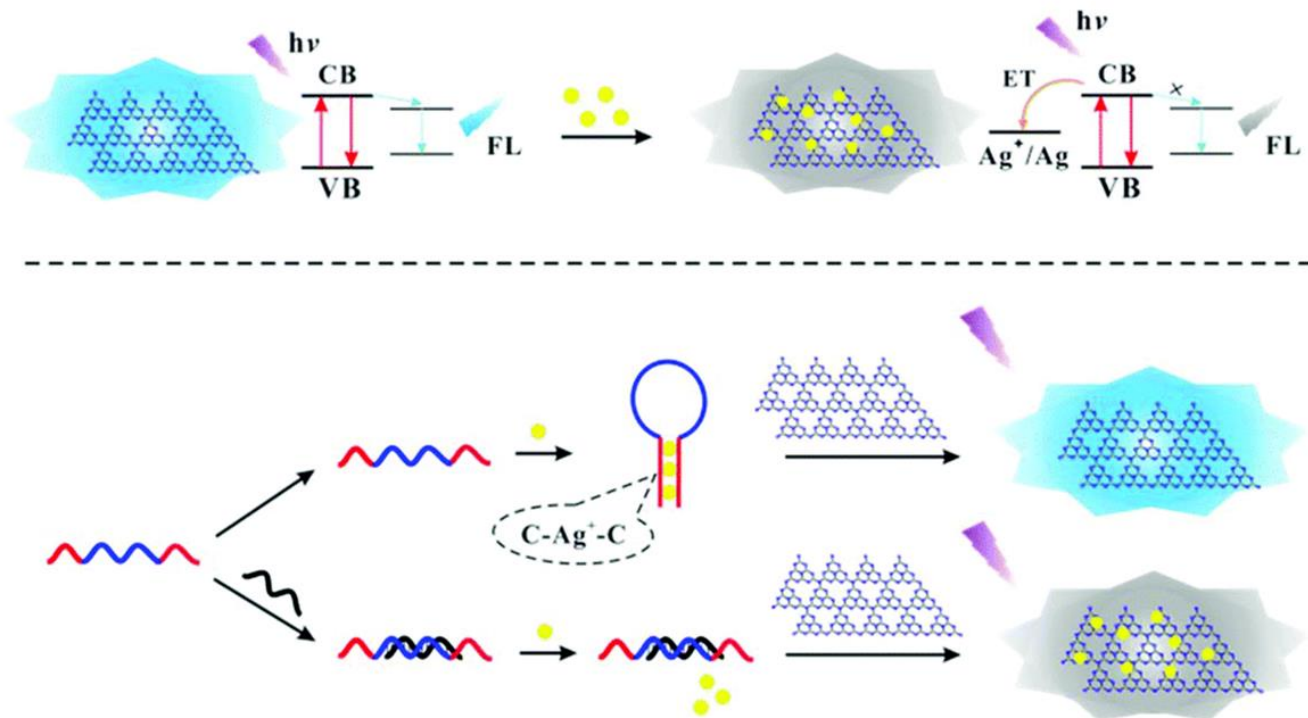

$\sim$

Probe DNA

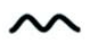

Target

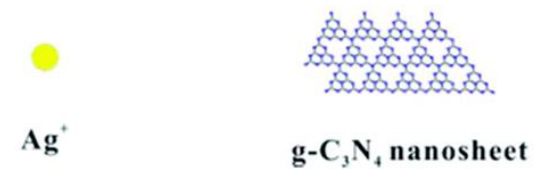

Figure 8. A) A GO-based immuno-biosensor for the detection of rotavirus. Reprinted with permission from Ref. 138. Copyright 2010 WILEY-VCH Verlag GmbH \& Co. B) GO laminatepolycarbonate track-etched nanosieve platform to detect the envelope glycoprotein on HIV (BSA: bovine serum albumin). Reprinted with permission from Ref. 148. Copyright 2017 American 
Chemical Society. C) The use of GO as fluorescence quenching platform for the detection of viral DNA. Reprinted with permission from Ref. 164. Copyright 2009 WILEY-VCH Verlag GmbH \& Co. D) $\mathrm{gC}_{3} \mathrm{~N}_{4}$-based biosensors based on metal ion binding-induced fluorescence quenching for DNA detection of viruses. Reproduced from Ref. 176 with permission from The Royal Society of Chemistry.

The use of several antibodies labeled with fluorophores of different color fluorescence emissions enables the simultaneous detection of multiple viruses simultaneously. This strategy was exploited for the detection of enterovirus 71 and Coxsakievirus B3 (CVB3), two human enteroviruses. ${ }^{139}$ Their symptoms are quite similar causing high risks for mortality in neonates. Therefore, the development of biosensors to distinguish these two viruses for accurate early diagnosis is critical. For this purpose, a GO-based biosensor was prepared by immobilizing two EV71 and CVB3 antibodies labeled with quantum dots of different color fluorescence emissions on the surface of GO. The addition of EV71 and CVB3 viruses destabilized the complex between GO and the quantum dot-labeled antibodies due to specific antibody-antigen interactions, enabling fluorescence recovery for simultaneous quantitative detection of both enteroviruses in clinical samples (human throat swabs).

Another fluorescent biosensor allowed to simultaneously identify the human- and avianreceptor specificity in influenza viruses. ${ }^{140}$ Generally, influenza viruses circulate mainly in birds, but mutations can induce infection to humans. The hemagglutinin protein is a crucial mediator for influenza virus infection to host cells. The avian and human hemagglutinin of influenza viruses preferentially binds to the $\alpha 2,3$ - and $\alpha 2,6$-sialic acid receptors on host cells, respectively. The switch in the receptor-binding specificity can result in interspecies transmission of the viruses. As a consequence, tools capable of simultaneous identifying different receptor specificities of a single virus strain are required for the rapid identification of human- and bird-infection ability of the virus. In this context, two fluorophores with different emission colors were coupled to an avian or a human glycan receptor followed by adsorption on $\mathrm{MoS}_{2}$ or GO used as fluorescence quenching platforms. The detection of the H7N9 influenza A virus, which contains dual (human- and avian-) receptor specificity, led to the emission of both colors. Hence, this biosensor showed the capacity of concomitant identification of the receptor specificity of the virus, which could be exploited to 
probe the switch of receptor specificity for seasonal influenza viruses. Although the sensitivity was lower compared to other methods, ${ }^{132}$ the detection time was much shorter.

A fluorogenic peptide-GO sensor array was designed to allow the differentiation of Ebola virus from two other viruses namely Marburg virus, which has a similar capsid protein composition, and receptor-extensive vesicular stomatitis virus, a common control virus. ${ }^{141}$ The approach was different from most fluorescent chemosensors that generally use ligands to specifically bind to target receptors as this biosensor relied on an array of different receptor molecules with modest affinity and selectivity for viruses. The combination with principal component analysis, a method appropriate for statistical analysis of complex data, ${ }^{142}$ enabled to extract characteristic patterns for each virus. The sensor array consisted of GO and three adsorbed fluorescent peptides derived from the fragment antigen-binding (Fab)-region of an anti-glycoprotein antibody. The three viruses were detected and the different fluorescence recovery rates allowed to differentiate the viruses. This rapid distinction of viruses from various origins did not require the use of specific ligands, providing opportunities for the differentiation of viruses expressing different capsid proteins. In another study, a rGO-based SPR optical sensor chip functionalized with specific antibodies was constructed for the detection of dengue virus. ${ }^{143}$ The binding of the virus on the sensor film induced an increase of the resonance angle resulting in sensor film thickness changes and thus in a higher refractive index.

\section{Electrochemical biosensors}

Electrochemical biosensors based on 2DMs operate on the possibility that either an oxidation or reduction event occurs on the surface of these planar materials. Functionalization of the surface of 2DMs is the necessary step for establishing such sensors while a variety of methods have been implemented to increase the output signal such as incorporating secondary materials onto 2DMs. For example, a rGO-gold nanocomposite electrochemical biosensor was exploited for the electrochemical detection of influenza virus A (H9N2) via the assessment of neuraminidase enzyme activity. ${ }^{144}$ Influenza A viruses are categorized into subtypes based on the combination of two surface glycoproteins: hemagglutinin and neuraminidase (Figure 1a). There are 18 hemagglutinin (H1-H18) and 11 neuraminidase (N1-N11) subtypes. The latter is involved in the release of influenza viruses and viral aggregates from the surface of host cells and in the targeting of the viruses to respiratory epithelial cells. The protein cleaves sialic acid moieties to induce the 
release of the virus. The biosensor was built with the glycoprotein fetuin A, which contains sialic acid residues and was conjugated on the surface of a rGO-Au-based electrode. The enzymatic activity of neuraminidase was monitored through electrode resistance changes upon interactions with the viruses. Here, neuraminidase at the surface of influenza virus A was able to cleave the sialic acid molecules, inducing the binding of peanut agglutinin lectin, immobilized on the surface of the electrode, to the galactose moieties that appeared after the cleavage. These changes were monitored by electrochemical impedance spectroscopy.

Dengue viruses are classified into four serotypes depending on the proteins present on the surface. The serotypes have similar geometry but display unique antigenicity. While patients infected for the first time generally develop immunity against the virus, subsequent infections by other serotypes may still lead to serious symptoms. The sensitive detection of dengue viruses using electrochemical biosensors functionalized with dengue-specific antibodies is possible, but the serotype classification is generally limited. ${ }^{145}$ To overcome this issue, a strategy inspired by molecular imprinting was developed. ${ }^{146}$ For this purpose, a strategy based on the self-assembly of copolymers immobilized on the surface of GO around a specific dengue virus serotype followed by crosslinking of the polymer chains and removal of the virus template was proposed. Here, the templating by a specific virus could provide sensitivity and selectivity to this virus. This electrochemical impedance biosensor was able to discriminate a dengue virus from the other three subtypes and also from influenza A virus H5N1. Additionally, the sensor could be exploited for the screening of dengue virus antibodies as a dengue virus 4G2 antibody was able to inhibit the binding of the virus to the GO-polymer composite. When bound to the virus, the antibody modified the viral surface properties such as the charge, size, and shape, thus preventing interactions with the GO-polymer composite. Overall, this method could be generalized to other viruses for their detection and classification, as well as for antibody screening, which provide interesting opportunities for vaccine research.

The mechanical properties, hydrophilicity, and flexibility of GO make them promising as membranes for nanofiltration. ${ }^{147}$ These remarkable features were exploited for the design of an electrochemical biosensor using few-layered GO laminate nanosieves, immobilized on a polycarbonate track etch nanoporous membrane for the detection of HIV-1 (Figure 8B). ${ }^{148}$ The device was coated with $2 \mathrm{Dm} 2 \mathrm{~m}$ antibody for targeting a highly conserved cluster of differentiation 4 (CD4) binding-induced epitope on HIV-1. The envelope glycoprotein ectodomain (gp140MS) of 
HIV-1 and the virus present in HIV-positive human serum samples were successfully detected by the sensor. Upon the application of an electric field, ions are trafficked through the GO laminates, inducing ionic current changes, while the specific interactions between $2 \mathrm{Dm} 2 \mathrm{~m}$ and gp140MS or the virus could result in a decrease of the ionic current as the sensing mechanism.

With perspectives for point-of-exposure detection of H1N1 influenza A virus, a textile screenprinted flexible impedance GO-based biosensor was conceived. ${ }^{149}$ This system was composed of silver electrodes and a GO transduction film, implemented on a flexible polyamide substrate or textile. The sensor surface was functionalized with a nucleoprotein-specific influenza A antibody to sense H1N1 influenza A protein. Improvements are necessary before reaching real applications based on textile screen-printed sensors, in particular the response of the sensor to some environmental parameters including humidity, temperature, and contaminants.

Recently, a portable and wireless electrochemical graphene-based sensor functionalized with specific capture antibodies was designed for the detection of SARS-CoV-2 antigen nucleocapsid protein in COVID-19-positive patient serum and saliva samples. ${ }^{150}$

\section{Field-effect transistors}

The fact that many viruses are negatively charged can be exploited for their detection using FETs. In a model example, a rGO-FET biosensor with p-type doping profile was developed for the detection of Ebola virus, which was modified with an antibody against the Ebola virus glycoprotein. ${ }^{151}$ It was shown that conductance change occurred when the virus bound to the antibody and the net carrier density increased, resulting in a shift of the Dirac voltage due to ndoping.

In another study, a FET aptasensor was built to detect hepatitis B virus infection using a multidimensional conductive nanofilm consisting of carboxylic polypyrrole nanowires vertically oriented on graphene, as well as an aptamer binding to the hepatitis B surface antigen. ${ }^{152}$ The nanofilm was prepared by electropolymerization of pyrrole on graphene. In this case, it was suggested that graphene was an ideal substrate for electropolymerization due to chemical inertness, high electrical conductivity, flexibility, and transferability to various substrates. The developed aptasensor was able to distinguish hepatitis B surface antigen in diluted human serum and artificial saliva samples. 
Recently, a FET graphene biosensor was developed for the detection of SARS-CoV-2 in clinical samples (nasopharyngeal swabs from COVID-19 patients). ${ }^{153}$ Coronaviruses encode four structural proteins: spike, envelope, matrix, and nucleocapsid. The spike protein was used as the antigen, as its amino acid sequence varies among coronaviruses allowing SARS-CoV-2 specificity. The spike protein of SARS-CoV-2 binds to angiotensin-converting enzyme II used as a host cellular entry receptor. A specific antibody against SARS-CoV-2 spike protein was immobilized on the graphene-based device, which was able to differentiate SARS-CoV-2 from another coronavirus (MERS-CoV). More accurate detection could be reached by increasing the signal-tonoise ratio, likely using other 2DMs.

With regards to the direct detection of antigens in a serum, graphene-based immunosensors incorporating specific antibodies can also be designed. For instance, a graphene-based transistor, with covalently linked anti-Zika nonstructural protein 1 (NS1) antibodies, was used for selectively detecting the Zika viral NS1 antigen in simulated human serum. ${ }^{154}$ Although the Japanese encephalitis NS1 protein has $56.5 \%$ amino acid sequence identical to Zika NS1, the biosensor did not detect the Japanese encephalitis NS1 protein, as the NS1 C-terminus has electrostatic characteristics different from co-circulating viruses. Because of high cross-reactivity with other cocirculating flaviviruses, such as the Japanese encephalitis, the validation of presumptive positive results for Zika detection is generally not satisfactory for diagnostic standard assays such as RTPCR, IgM antibody capture ELISA, and RNA nucleic acid testing. These limitations can be potentially overcome by the strategy implemented in the aforementioned graphene-based immunosensor.

\section{Future directions for the detection of virus particles and antigens}

The development of rapid and accurate diagnostic methods for the direct detection of intact viruses and viral antigens in clinical samples, without sample preparation as it is the case for PCR, is essential to mitigate future pandemics. Whereas most approaches detailed in this section involved the covalent conjugation or immobilization of specific antibodies (or peptides derived from the Fab-region) on 2DM surface, glycoproteins, glycans, and aptamers were also used. Many antibodies, having the capacity to bind to different viruses, are commercially available. While rGO and graphene were exploited for FETs, mainly GO was used for optical and electrochemical detection of viruses. Such biosensors allow the simultaneous detection of multiple different viruses 
with similar symptoms thanks to the conjugation of many specific antibodies. The differentiation of viruses from one another with a similar capsid protein composition is possible. In such cases, the use of specific aptamers or avian/human glycan receptors enables distinguishing a specific subtype of influenza viruses or their human- and avian-receptor specificity, respectively. Original strategies based on molecular imprinting or GO laminates nanosieving are potentially promising for future developments.

\section{Detection of viral nucleic acids}

Nucleic acid biosensors are widely developed for the detection of viruses. These devices mainly rely on electrochemical, ${ }^{134,155,156}$ and fluorescence detection, while colorimetric, ${ }^{157}$ electrical,

photoelectrochemical, ${ }^{158,159}$ SERS ${ }^{160,161}$ and electrochemiluminescence-based devices for sensing nucleic acids were also designed.

Many fluorescence detection systems exploit different adsorption profiles of oligonucleotide fragments on the surface of various types of 2DMs upon conformational change after binding with the target viral nucleic acids. The planar structure of 2DMs allows the stable adsorption of many types of DNA probes. 2DMs are known to offer great adsorption properties for single-stranded DNA (ssDNA) over double-stranded (dsDNA). The bases of ssDNA are partially uncoiled and can be exposed to the 2DM surface. For instance, $\mathrm{GO}$ can strongly adsorb ssDNA mainly via $\pi$-stacking with the purine/pyrimidine rings of the nucleobases and hydrogen bonding between the hydroxyl and carboxyl groups of GO and the amine and hydroxyl functions of ssDNA. ${ }^{162}$ In the case of $\mathrm{MoS}_{2}$, mainly van der Waals forces are involved. ${ }^{163}$ The hybridization of ssDNA with the complementary target strand leads to the formation of a double helix dsDNA with a more rigid conformation, which induces a conformation transition from "lying" ssDNA to "standing" dsDNA. The exposure of the nucleobases is reduced in the dsDNA structure since the nucleobases are shielded within the dense negatively charged dsDNA phosphate backbones. As a result, dsDNA is desorbed from the $2 \mathrm{DM}$ surface due to much weaker $\pi$-stacking interactions, leading to the restoration of the dye fluorescence.

\section{Optical biosensors}

Since the first work using GO to detect viral nucleic acids in 2009 by the desorption of fluorophoremodified HIV-1 nucleic acid probes resulting in fluorescence recovery ${ }^{164}, \mathrm{GO}$ has extensively been 
used as fluorescence quencher incorporating ssDNA probes labeled with organic dyes, quantum dots, silver nanoclusters, or upconversion nanoparticles (Figure 8C). ${ }^{165,166}$ Metal nanoclusters present substantial advantages over organic fluorophores due to their high photostability and luminescence quantum yield, as well as tunable emissions. ${ }^{167}$ As alternative to labeling with fluorophores, ssDNA probes can be conjugated to DNAzymes ${ }^{168}$ which are catalytic nucleic acids serving as amplifying labels for sensing of nucleic acids and proteins. ${ }^{169}$ DNAzymes (also named DNA enzymes or deoxyribozymes) are RNA-cleaving antisense oligodeoxyribozymes. They display a high catalytic activity and specificity to metal ions together with low cost and stable physiochemical properties. For instance, a HIV ssDNA probe was labeled with a horseradish peroxidase-mimicking DNAzyme that generated chemiluminescence in the presence of luminol and hydrogen peroxide. ${ }^{168}$ When the ssDNA was adsorbed onto GO, the chemiluminescence emission was quenched because of enzymatic activity inhibition by GO when in close proximity. In the presence of the target DNA, the chemiluminescence was restored.

In another study, using the fact that doping allows enhancing the electrical properties of $2 \mathrm{DMs}$, $\mathrm{N}, \mathrm{S}$-codoped $\mathrm{rGO}$ was exploited as a quenching platform for the simultaneous detection of hepatitis B virus and HIV DNA targets. ${ }^{170}$ The $\mathrm{sp}^{2}$-hybridized carbon atoms of rGO could be activated thanks to the doping, which improved the capacity of rGO as an electron/energy acceptor.

In addition to GO, other types of $2 \mathrm{DMs}$ can be used as fluorescence quenchers. For example, the discrimination properties of MXenes, such as $\mathrm{Ti}_{3} \mathrm{C}_{2}$, towards ssDNA and dsDNA can be exploited for the detection of PCR-amplified HPV-18 DNA from cervical scrape samples obtained from human papillomavirus (HPV) infected patients. ${ }^{171}$ In another study, the difference in fluorescence quenching capacity of $\mathrm{PtS}_{2}$ nanosheets with fluorescently labeled ssDNA $v s$. dsDNA was exploited to construct a $\mathrm{PtS}_{2}$-based biosensor for HPV genotyping. ${ }^{172}$ To date, more than 100 different types of HPV have been identified. Many of transition metal dichalcogenides (e.g., $\mathrm{PtS}_{2}$ ) are semi-metals, and hence are electrically conductive. The $\mathrm{PtS}_{2}$ biosensor using HPV16 DNA probe was selective to the complementary HPV16 target sequence among three other HPV genotype sequences in clinical samples containing DNA extracted from cervical scrapes. In another study, few-layer graphdiyne nanosheets were exploited as novel sensing platforms for the simultaneous detection of influenza virus subtypes H1N1 and H5N1, as well as bacterial M13 genes as target DNA molecules. ${ }^{173}$ Graphdyine is a one-atom-thick planar sheet of sp- and $\mathrm{sp}^{2}$ hybridized carbon atoms arranged in a crystal lattice. The multiplexed DNA detection was shown 
to be more sensitive and faster using graphdiyne compared to $\mathrm{GO}$ and $\mathrm{MoS}_{2}$. The higher efficiency may be explained by strong interactions between graphdiyne and the dye labeled-DNA molecules ${ }^{174}$ and also by favorable electronic properties. ${ }^{175}$ Graphitic- $\mathrm{C}_{3} \mathrm{~N}_{4}$ nanosheets are also interesting platforms for biosensing applications due to their long persistent fluorescence. The g$\mathrm{C}_{3} \mathrm{~N}_{4}$ nanosheets are composed of tris-triazine units connected by trigonal nitrogen and stacked in a graphitic manner. They can interact strongly with some metal ions, resulting in the quenching of their fluorescence because of electron transfer. The affinity of metal ions for biomolecules such as DNA, leading to the formation of metal ion-base pairs in DNA duplexes, was exploited for hepatitis B virus gene determination. ${ }^{176}$ The DNA probe constituted of several cytosines at both ends to allow the binding of $\mathrm{Ag}^{+}$and the formation of a hairpin structure. In the presence of the hepatitis $\mathrm{B}$ virus DNA, the specific recognition between the probe and target DNA molecules induced the release of $\mathrm{Ag}^{+}$(Figure 8D). Fluorescence quenching was observed because of the coordination of silver ions to $\mathrm{g}-\mathrm{C}_{3} \mathrm{~N}_{4}$. Another strategy of 'turning-on' fluorescence relies on different adsorption capacity of 2DMs not only for ssDNA $v s$. dsDNA, but also for different length ssDNA molecules. For example, a biosensor made of feroxyhyte nanosheets $(\delta-\mathrm{FeOOH})$ was used for detecting hepatitis C virus DNA based on exonuclease III-assisted signal amplification. ${ }^{177}$ As an inorganic graphene analog, $\delta$-FeOOH nanosheets display unique ferromagnetic and semiconducting properties. In particular, their magnetic properties at room temperature are stronger than hexagonal boron nitride, $\mathrm{SnO}_{2}$, and $\beta-\mathrm{Ni}(\mathrm{OH})_{2}$ nanosheets. In this work, the adsorption of a dye-labeled complementary ssDNA onto a labeled hepatitis $\mathrm{C}$ virus sequence on the $\delta$-FeOOH surface induced fluorescence quenching. In the presence of the target DNA, a DNA duplex was formed and short oligonucleotide fragments were generated from hydrolysis by exonuclease III enzyme. The low affinity of the short ssDNA fragments for the $\delta$-FeOOH surface allowed recovering the fluorescence. The magnetic properties of feroxyhyte were exploited to separate the fragments from the DNA/ $\delta-\mathrm{FeOOH}$ complex by application of an external magnetic field, thereby allowing to obtain low background fluorescence signals. Similarly, $\mathrm{MoS}_{2}$ showed a high affinity for long ssDNA vs. short oligonucleotide fragments formed after hydrolysis of duplex DNA by exonuclease III. ${ }^{178}$ This strategy was exploited for the detection of HIV DNA.

To increase the sensitivity of DNA/2DM-based biosensors, the rolling circle amplification was exploited as signal amplification strategy. ${ }^{179}$ This isothermal DNA replication enzymatic process could produce DNA molecules with thousands of tandem sequence repeats that were easily 
detected by a biosensor consisted in rGO and a hepatitis $\mathrm{C}$ virus type 1 ssDNA probe. When GO was used instead of rGO, it led to lower quenching efficiency, as $\mathrm{rGO}$ can be a more efficient distance-dependent fluorescence quencher compared to GO or even graphene. ${ }^{180}$

Another type of 2DMs based on metal organic framework (MOF) nanosheets was used for HIV-1 DNA detection, namely $N, N$ '-bis(2-hydroxyethyl)dithiooxamidatocopper(II) [Cu( $\left.\left.\mathrm{H}_{2} \mathrm{dtoa}\right)\right]$ where $\mathrm{Cu}^{2+}$ ions are coordination centers and dithiooxamide are bridging ligands. ${ }^{181} \mathrm{MOFs}$ can be synthesized from metal ions/clusters and organic linkers and they offer well-defined configurations, tunable organic functionalities, porosity, high surface area, and open metal sites in the skeleton. ${ }^{182}$ It is noteworthy to consider that the metal ions used as coordination centers and open sites can display intrinsic fluorescence quenching properties. As a result, MOFs were exploited as fluorescent sensors and applied for nucleic acid detection. ${ }^{183}$ In general, the ligands in MOFs constitute of $\pi$-conjugated moieties that can interact efficiently with DNA molecules and favor their adsorption on the MOF surface. Additionally, electrostatic interactions between positively charged metal centers and negatively charged DNA sequences are also involved. However, the development of MOFs as nucleic acid detection systems is still at its infancy, mainly because of low water solubility and poor stability. Conventional DNA detection generally relies on the hybridization of complementary ssDNA molecules, a method that requires the generation of ssDNA before the analysis. In this context, the triplex DNA technology is an attractive alternative. ${ }^{184}$ In this case, a conformationally flexible triplex-forming oligonucleotide interacts with the bases in the major groove of dsDNA (i.e. when the backbones are far apart) resulting in the formation of a rigid triplex structure through Hoogsteen hydrogen bonds or reverse Hoogsteen hydrogen bonds. ${ }^{185}$ In this regard, MOFs were used for the detection of viral dsDNA molecules. For instance, a fluorescently labeled triplex-forming oligonucleotide probe was adsorbed onto $\left[\mathrm{Cu}\left(\mathrm{H}_{2} \mathrm{dtoa}\right)\right]$ leading to fluorescence quenching. ${ }^{186}$ In the presence of the target HIV dsDNA, the formed rigid triplex structure was released from the MOF surface, inducing fluorescence recovery. A similar strategy was applied using substrate-supported MOF nanosheets based on 5,10,15,20tetrakis[40-(terpyridinyl)phenyl]porphyrin-cobalt(II) (Co-TTPP) coordination polymer for multiplexed detection of two influenza virus subtypes of H5N1 and H1N1 genes (Figure 9A). ${ }^{187}$ To date, the development of MOFs for nucleic acid detection is still limited since most MOFs are insoluble and unstable in water. To overcome this issue, 2D MOFs based on highly water soluble zwitterionic quaternized-carboxylate ligands containing positively charged pyridinium moieties 
were synthesized and used as sensing platforms of HIV dsDNA sequences. ${ }^{188}$ A DNA sensing mechanism study reported that the preferred adsorption of ssDNA over dsDNA on MOFs is not primarily due to multiple non-covalent interactions including $\pi$-stacking, electrostatic interactions, hydrogen bonding, van der Waals forces, and hydrophobic interactions. ${ }^{187}$ It is most probably due to the selective inclusion of ssDNA in the MOF pores rather than dsDNA resulting in efficient discrimination of both DNA molecules (Figure 9A). 


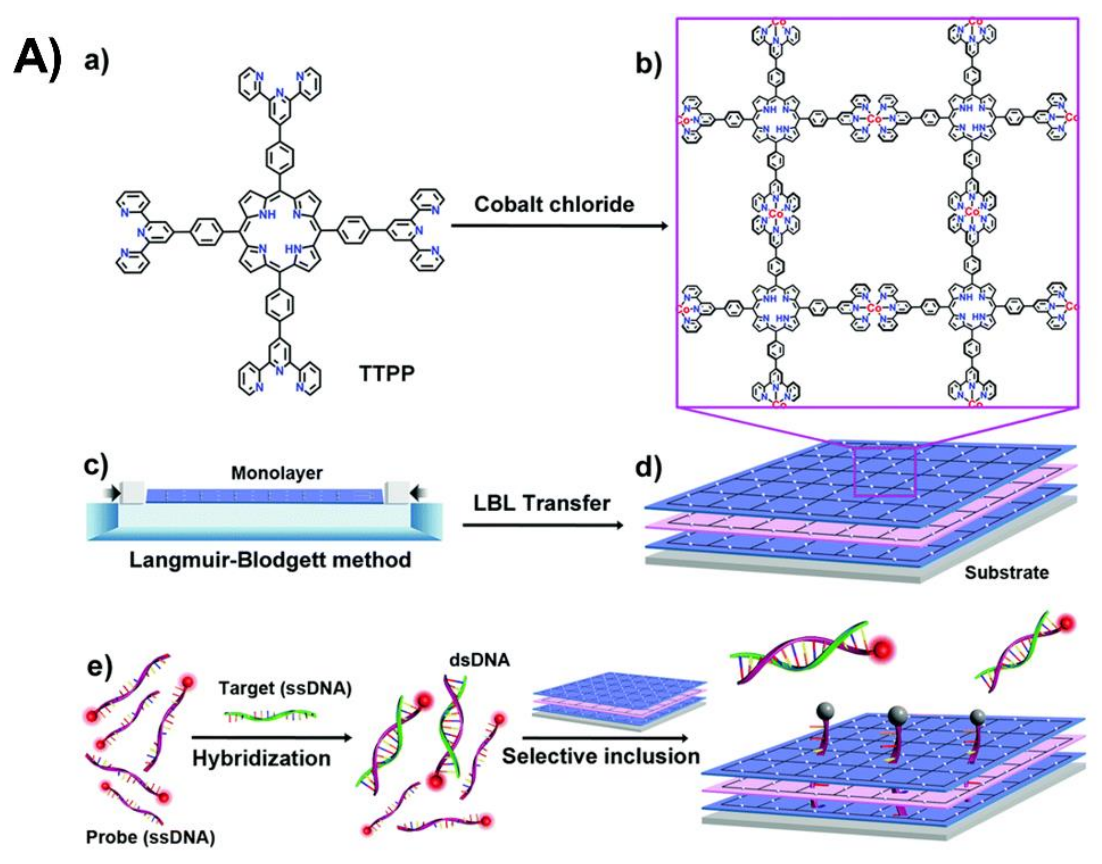

B) a)
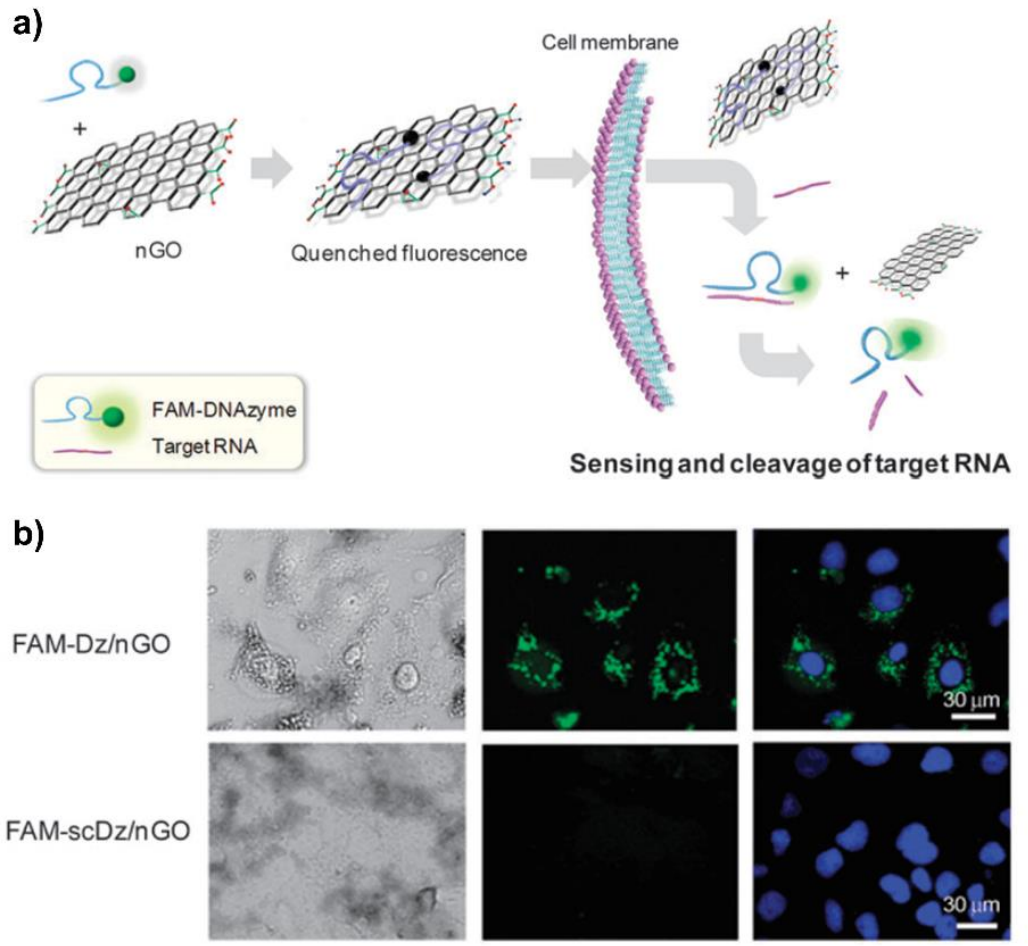

Figure 9. A) Molecular structure of (a) TTPP and (b) Co-TTPP. (c) Co-TTPP monolayer prepared by the Langmuir-Blodgett method. (d) Substrate-supported Co-TTPP with a controlled number of layers made by layer-by-layer Co-TTPP monolayer transfer. (e) Detection of dsDNA by fluorescence using substrate-assisted Co-TTPP sheets. Reproduced from Ref. 187 with permission 
from The Royal Society of Chemistry. B) a) Detection and silencing of a hepatitis C virus gene using a DNAzyme/GO conjugate (nGO: nano-sized GO; FAM: fluorescein amidite). b) Fluorescence images of human liver cells carrying a subgenomic hepatitis $\mathrm{C}$ virus replicon incubated with FAM-labeled DNAzyme/GO (FAM-Dz/nGO) and FAM-labeled scrambled sequence DNAzyme/GO (FAM-scDz/nGO). Fluorescence of FAM turned on when DNAzyme was complementary to the target gene. Blue: nucleus stained with Hoechst 33342, green: FAM. Reproduced from Ref. 193 with permission from The Royal Society of Chemistry.

Very recently, another type of organic framework nanosheets was used for the detection of viral DNA based on the preferential adsorption of dye-labeled ssDNA over dsDNA. In this work, covalent organic framework (COF) nanosheets, decorated with gold nanoparticles, were used as fluorescence quenching platform for the multiplexed detection of hepatitis A virus DNA and hepatitis B virus DNA. ${ }^{189}$ COFs are crystalline porous materials synthesized from organic molecular blocks linked by covalent bonds periodically. Similar to MOFs, they have well-defined structures, tunable topology and functionalities, good stability, as well as high porosity. Fewlayered ultrathin 2D COF nanosheets have a high density of unsaturated atoms on their surface and a large surface area-to-volume ratio. ${ }^{190}$ Thanks to their unprecedented properties, ultrathin COF nanosheets with a highly ordered hexagonal network are promising for sensing. ${ }^{191,192}$ However, only few studies have been reported to date.

2DMs can both serve for biosensing, and also for therapeutic purposes. In this context, a DNAzyme/GO conjugate was exploited for simultaneous sensing and silencing of the hepatitis $\mathrm{C}$ virus gene in infected living cells (Figure 9B). ${ }^{193}$ The DNAzyme constituted of a complementary sequence for mRNA of the hepatitis $\mathrm{C}$ virus nonstructural gene 3 (NS3) and a dye at the 5'-end. NS3-derived proteins are crucial for replication of hepatitis $\mathrm{C}$ virus in cells. The nucleobases of the DNAzyme favored the interactions with GO, resulting in fluorescence quenching. In the presence of the complementary target hepatitis C virus NS3 mRNA, the formation of a double helix with the DNAzyme led to its desorption from the GO surface and fluorescence recovery. The mRNA was subsequently cleaved by the DNAzyme in a sequence-specific manner with the consequence of knockdown of the hepatitis C virus NS3 gene expression resulting in inhibition of the virus replication in the host cells. This work combined the properties of GO as a carrier to deliver therapeutic molecules intracellularly and as fluorescence quencher. In addition, DNAzyme 
presents the advantages of high chemical stability and low cost compared to other types of oligonucleotides used for gene silencing such as small interfering RNA (siRNA), antisense oligonucleotides and ribozymes. Moreover, siRNA is dependent on the cellular machinery as it requires the multiprotein RNA-induced silencing complex, which is not the case for DNAzyme.

Localized surface plasmons can also be used for enhancing electrochemiluminescence (luminescence produced following electrochemical reactions). Electrochemiluminescence of luminophores such as quantum dots is generally limited by low emission intensities. As a result, the enhancement using plasmonic nanoparticles offers possibilities for higher quality sensing. ${ }^{194}$ The surface plasmon-enhanced electrochemiluminescence mechanism can be explained by a resonant interaction of light with electron oscillations in the plasmonic nanoparticles. As $\mathrm{MoS}_{2}$ displays strong surface plasmon coupling light absorption in the visible and NIR region when it is fully intercalated, ${ }^{65}$ it was used for enhancing the electrochemiluminescence signal of S-doped boron nitrogen quantum dots. ${ }^{195}$ By exploiting an isothermal enzyme-free hybridization chain reaction for DNA amplification to form long dsDNA, the $\mathrm{MoS}_{2}$-based biosensor was able to quantify a hepatitis $\mathrm{C}$ virus gene labeled with these quantum dots.

\section{Electrical and colorimetric biosensors}

The different affinities of ss- and dsDNA for 2DMs was also exploited to develop a colorimetric detection system based on rGO functionalized with hemin, having a peroxidase-like activity. ${ }^{196}$ The approach relied on the precipitation of hepatitis B virus dsDNA/hemin-rGO in the presence of an electrolyte, in contrast to ssDNA adsorbed onto hemin-rGO. In the latter case, the hemin-rGO catalyzed the reaction between the peroxidase substrate 3,3',5,5'-tetramethylbenzidine and hydrogen peroxide leading to a colored compound. In the presence of different amounts of target hepatitis B virus DNA, the absorbance decreased linearly with the concentration of complementary target DNA. The system also enabled the detection of a mutation in the hepatitis B virus gene.

In another study, a paper-plastic microchip with finger electrodes prepared by a screen-printing protocol, using a graphene-silver ink, was conceived for the detection of Zika virus after a lysis step. ${ }^{197}$ Magnetic beads modified with an anti-Zika virus envelope antibody were used for capturing the virus followed by lysis using $1 \%$ Triton $\mathrm{X}-100$. Here, the viral lysate containing charged molecules, such as viral nucleic acids and proteins, induced a decrease of the impedance value. 
A solution-gated graphene FET was developed to monitor real-time loop-mediated isothermal amplification of a viral DNA (phage $\lambda$ genomic DNA). ${ }^{198}$ This amplification strategy is one of the most advanced genetic techniques with rapid sequential progression and a relatively high selectivity. Here, the proton release during the amplification induced a change of the $\mathrm{pH}$ of the solution on the graphene surface, which altered the Dirac point voltage of the FET. In solutiongated field-effect transistor, the gate and the graphene active layer were shown to be separated by an electrolyte and not by a dielectric insulator.

As a final example, a nucleic acid amplification by RT-PCR was combined with gold nanoparticle-based lateral flow test strips, integrating GO to allow on-strip purification and direct visual detection of PCR products amplified from HIV-1 plasmids with both higher sensitivity and specificity. ${ }^{199}$ This approach was more rapid than conventional PCR as no nucleic acid extraction was required. Additionally, GO improved the signal-to-noise ratio by selectively adsorbing and eliminating residual primers and primer-dimers that usually lead to some interference. Therefore, this detection method potentially provides prospects for nucleic acid analysis in point-of-care diagnosis.

\section{Prospects for the detection of viral nucleic acids}

Genosensors that do not require an amplification step are highly needed to simplify and reduce the costs and time of conventional assays. In this context, most 2DM platforms designed for viral nucleic acid sensing are based on optical detection. In addition to the wide use of $\mathrm{GO}, \mathrm{MoS}_{2}$, graphdiyne, $\mathrm{g}-\mathrm{C}_{3} \mathrm{~N}_{4}, \delta-\mathrm{FeOOH}, \mathrm{Ti}_{3} \mathrm{C}_{2}, \mathrm{MOF}$, and $\mathrm{COF}$ nanosheets can also be exploited as fluorescence quenchers. The biosensors rely mainly on different adsorption capacities of fluorescently labeled DNA or RNA on the 2DM surface after binding with the target viral nucleic acids that induced conformational changes. As an alternative to the labeling with fluorophores, DNA probes can also be conjugated to DNAzymes. Altogether, combining lateral flow test strips incorporating 2DMs and nucleic acid amplification by PCR can allow the development of relatively fast response devices at low cost. In our opinion, FETs can be investigated further for DNA sensing because of the charged phosphate backbone that could induce doping and hence be used as the transducing mechanism in such devices. Finally, beyond virus detection, the possibility of concomitant detection and silencing of viral genes offers a great example that such a use of 2DMs is an effective approach for developing future theranostic platforms for viral infections. 


\section{Detection of proteins produced by host organisms following a viral infection}

Infected organisms respond to a viral infection by secreting antibodies to neutralize viruses. In some cases, certain enzymes can be upregulated or downregulated. A viral infection may also induce inflammation and the production of infection-related proteins such as cytokines and Creactive protein. The well-known case is the cytokine storm which occurs during the viral infection by SARS-CoV-2 and may result in the failure of body organs including lungs and kidney. ${ }^{200}$

\section{Detection of antibodies}

The remarkable electrical properties and quenching capacity of 2DMs were extensively exploited to develop systems capable of detecting antibodies produced by infected patients. In one example, peptide sequences present in the human immunodeficiency virus type 1 and type 2 (HIV-2) envelope glycoproteins were immobilized onto GO via a fluorescent pyrene moiety through $\pi$ stacking and hydrophobic interactions to detect HIV-1 and HIV-2, respectively, in serum and saliva. $^{201}$ Out of the two types of HIV, HIV-1 is the most common cause of acquired immunodeficiency syndrome (AIDS). In this study, the fluorescence was quenched because of energy-transfer or electron-transfer processes. A highly antigenic peptide present in the HIV-1 glycoprotein gp120, which is essential for receptor binding and membrane fusion, and a specific immunodominant epitope from the transmembrane portion of the HIV-2 glycoprotein gp36 enabled the detection of anti-HIV-1 gp120 and anti-HIV-2 gp36 antibodies, respectively. Here, the formation of the specific peptide-antibody complex was evidenced by fluorescence recovery.

An original approach relies on an immunosensor made of $\mathrm{GO}$ and quantum dots encapsulated in simian vacuolating virus 40 (SV40) virus-like particles, which was exploited for the detection of anti-SV40 antibodies in serum. ${ }^{202} \mathrm{SV} 40$ is a non-enveloped tumorigenic virus and the occurrence of nucleic acid sequences identical to SV40 sequences was observed in some tumors. As a result, the detection of serum anti-SV40 antibodies allows the diagnosis of cancer related to SV40. The capsid protein VP1 can self-assemble into SV40 virus-like particles in vitro and this capacity was exploited to encapsulate quantum dots followed by their adsorption onto GO. Contrarily to surface labeling of viruses with fluorophores, this strategy did not impact the infectivity and immunogenicity of SV40. In the absence of anti-SV40 antibodies, the fluorescence of the quantum dots was quenched by FRET due to close proximity with the GO surface. In contrast, the 
fluorescence was recovered upon specific binding of the SV40 virus-like particles to the antibodies, leading to a larger complex that increased the distance between GO and the quantum dots.

\section{Detection of enzymes}

Ribonuclease (RNase) $\mathrm{H}$ activity is upregulated in patients infected by hepatitis $\mathrm{C}$ virus. RNase $\mathrm{H}$ is able to mediate the replication of the virus. Indeed, it maintains genome replication and stability by specifically hydrolyzing RNA strands in RNA/DNA duplexes. In this context, a system combining rGO, a fluorescent ssDNA probe adsorbed onto the rGO surface, and a DNAzymecomprising a DNA-RNA chimeric strand was built to detect RNase $\mathrm{H}$ activity (Figure 10A) ${ }^{203}$ The DNA-RNA chimeric strand forms a hairpin structure causing a loss of the DNAzyme catalytic activity because of steric hindrance. In the presence of RNase $\mathrm{H}$, the DNAzyme could be released from the DNA-RNA chimeric strand. This enabled the cleavage of the ssDNA probe into short fragments having much less affinity for the rGO surface and consequently the fluorescence was recovered. This fluorescence cycle amplification assay was also applied for the screening of natural compounds as antiviral drugs by assessing their capacity to reversibly regulate RNase $\mathrm{H}$ activity. 
A)



B) Dye-labeled dsDNAs

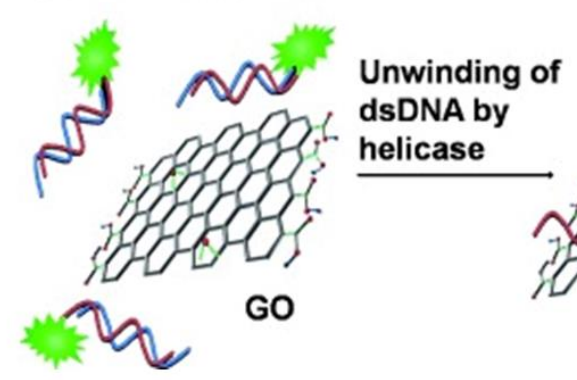

Quenched fluorescence

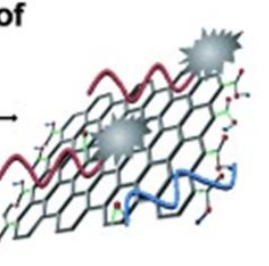
[helicase]

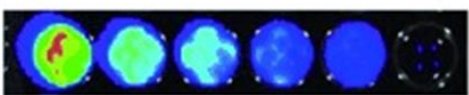

Figure 10. A) rGO-DNAzyme-based sensing platform to detect RNase H. The enzyme triggered the release of DNAzyme from the DNA-RNA chimeric strand. DNAzyme subsequently became active and cleaved the FAM-labeled probes to FAM-labeled short fragments with the help of the cofactor $\mathrm{Mg}^{2+}$, thus resulting in the amplification of the fluorescence signal. Reprinted by permission from Springer Nature Customer Service Centre GmbH: Springer Microchimica Acta Ref. 203, Copyright (2019). B) A GO-based fluorescent platform for the assay of duplex-DNA unwinding activity by the SARS-CoV helicase. Reprinted with permission from Ref. 207. Copyright 2010 WILEY-VCH Verlag GmbH \& Co.

The activity of another type of RNase, RNase A, was measured by a rGO-based FRET biosensor consisting of a labeled RNA strand probe for the detection of hepatitis B virus. ${ }^{204}$ This enzyme 
produces smaller RNA fragments by specific hydrolysis of RNA cytosine or uracil moieties of single stranded/double stranded RNA and RNA-DNA hybrids. It can inhibit the replication of HIV1 and has been used as an anti-HIV-1 drug. The level of RNase A is lower in the case of hepatitis B virus infection, which can explain the decreased immune ability of infected patients. In the presence of RNase A, the RNA probe was cleaved into smaller fragments leading to the desorption from the rGO surface and fluorescence recovery. The assay was also exploited for RNase A targeted drug screening. Similarly, a sensing platform composed of GO and a DNA-RNA substrate was used for detecting HIV-1 RNase H activity and for screening of inhibitors. ${ }^{205}$

Alternatively, proteases, which are enzymes for cleaving specific amide bonds in peptides, can be used for indirect detection of viruses. For example, a fluorescent peptide-GO biosensor was prepared for the detection of tobacco etch virus (TEV) protease and Escherichia coli bacteria infected with a bacteriophage engineered to carry TEV protease genes. ${ }^{206}$ Phages are viruses able to specifically infect host bacteria, replicate in the cells, and lyse the bacteria, resulting in the release of the TEV protease. A positively charged fluorescent TEV-substrate peptide was adsorbed onto GO through electrostatic interactions leading to fluorescence quenching. In the presence of the TEV protease, the peptide was recognized by the enzyme and it was specifically cleaved. The intensity of the recovered fluorescence signal was correlated with the TEV protease concentration, thus enabling to measure the concentration of bacteria.

GO-based biosensors can also be conceived for the detection of helicases, which are enzymes involved in virus replication and proliferation. Helicases have the capacity to unwind doublestranded nucleic acids into single-stranded counterparts. A GO-based platform was employed to monitor the unwinding activity of SARS-CoV helicase nsP13 through the preferential adsorption of ssDNA vs. dsDNA onto the GO surface resulting in the fluorescence quenching of the dye conjugated to ssDNA (Figure 10B). ${ }^{207}$ This approach was faster, simpler and cost-effective compared to conventional techniques including radiolabeling, ELISA, FRET, and chemiluminescence. The biosensors were exploited for the screening of antiviral drugs such as viral helicase inhibitors. The feasibility of multiplexed high-throughput screening was also demonstrated for measuring the activities of SARS-CoV helicase and hepatitis C virus NS3 helicase in a mixed solution using two distinct DNA molecules labeled with different dyes. ${ }^{208}$ 


\section{Detection of cytokines and $C$-reactive protein}

The accurate detection of viral infection-related proteins with high sensitivity can be fundamental for better clinical prognosis. For instance, the monitoring of cytokine levels secreted by immune cells in response to pathogens affords diagnostic information. In particular, interleukin-15 (IL-15) is a cytokine that plays a key role in the immune response during HIV-1 infection and it can be considered as a biomarker of the stage of infection. Indeed, while a higher concentration of IL-15 is present in the blood of infected patients in the early stage compared to healthy persons, low levels are found in AIDS-stage patients probably because of the impairment of immune responses against HIV-1. In this regard, the electrochemical detection of IL-15 was performed by a GOmodified screen-printed carbon electrode functionalized covalently with anti-IL-15 antibodies. ${ }^{209}$ Although some improvements are required to reach higher sensitivity and lower detection limits, this immunosensor is promising for the determination of HIV-1 acute infection, allowing HIV-1 pathogenesis monitoring as a point-of-care tool.

The detection of another type of cytokines, interferon- $\gamma($ IFN- $\gamma)$, is also relevant in the context of viral infections. IFN- $\gamma$ has antiviral, antitumor, immunoregulatory and antiproliferation activities. The amount of IFN- $\gamma$ can be useful to evaluate the response of immune cells to pathogens. For example, a high production of IFN- $\gamma$ results in low viremia and slow HIV progression. As a result, it can be used as a biomarker to detect the earlier stage of various diseases such as HIV, cancer, and tuberculosis. To this aim, a FRET-based aptasensor was developed using transition metal dichalcogenides nanosheets $\left(\operatorname{ReS}_{2}\right.$ and $\left.\mathrm{TiS}_{2}\right)$ and a dye-labeled IFN- $\gamma$ ssDNA aptamer through fluorescence quenching and subsequent recovery. ${ }^{210}$ Importantly, the sensing platform was successfully implemented in human kidney live cells, showing excellent detection and good biocompatibility. Another biosensor, which was based on rGO and a specific fluorescent aptamer, was constructed for the quantification of IFN- $\gamma$ in serum from HIV-infected patients. ${ }^{211}$ The aptamer was hybridized with a complementary sequence to avoid adsorption on rGO and fluorescence quenching. The double stranded fluorescent aptamer was derivatized with two Black Hole Quencher 1 (BHQ-1) moieties for efficient immobilization on the rGO surface. BHQ-1 is a non-fluorescent chromophore that contains three aromatic rings allowing strong $\pi-\pi$ interactions with rGO. It is widely used in FRET DNA detection probes. ${ }^{212}$ Upon interactions with the target IFN- $\gamma$ the double stranded aptamer was dissociated to the single stranded-aptamer because of the higher affinity of the latter for IFN- $\gamma$. Consequently, the proximity between the fluorophore of the 
denatured strand and the surface of rGO led to fluorescence quenching. As the levels of various cytokines are high in the blood of HIV-positive patients, the biosensor was also tested to detect IL2 and TNF- $\alpha$ showing slight fluorescence intensity changes and thus demonstrating high selectivity for IFN- $\gamma$ thanks to the specific aptamer.

A high concentration of C-reactive protein (CRP), an inflammatory biomarker, is found in patients diagnosed with COVID-19 pneumonia. The aforementioned electrochemical graphenebased sensor developed for sensing the SARS-CoV-2 antigen nucleocapsid protein, was used for the detection of CRP, as well as specific immunoglobulins (IgG and IgM) against the SARS-CoV2 spike S1 protein, via functionalization with an anti-CRP antibody and capture antigens, respectively. ${ }^{150}$

\section{Prospects on viral infection detection}

Overall, 2DM biosensors allow rapid and efficient detection of viruses and viral nucleic acids, which enable simplification in construction and also reduction of both cost and time in comparison to conventional assays. The selectivity can be made high, allowing the differentiation of virus subtypes. Thanks to the high specific surface area of 2DMs and diverse possibilities of functionalization, multiplex detection is also possible for simultaneously detecting different viruses. To date, significant progress has been achieved providing future opportuning for point-ofcare devices and wearable biosensors. Among the different 2DMs investigated in the context of viral infection, GO is the most widely explored probably due to its easy and low-cost synthesis, rich surface chemistry and different strategies of functionalization. ${ }^{213}$ Recently, few other 2DMs were also studied such as transition metal dichalcogenides $\left(\mathrm{MoS}_{2}, \mathrm{PtS}_{2}, \mathrm{ReS}_{2}\right.$, and $\left.\mathrm{TiS}_{2}\right)$, graphdiyne, $\mathrm{gC}_{3} \mathrm{~N}_{4}$, MXenes (e.g., $\mathrm{Ti}_{3} \mathrm{C}_{2}$ ), $\delta$-FeOOH nanosheets, as well as $2 \mathrm{D}$ MOFs and COFs. We encourage future research on other 2DMs given the myriad of possibilities and different intrinsic properties. Beyond virus detection, 2DM-based biosensors can be also exploited for the screening of virus-specific antibodies and drug inhibitors of RNAses and viral helicases.

\section{CONCLUSION AND FUTURE OUTLOOK}

2DMs are a class of nanomaterials that offer tremendous opportunities for virus sensing. Their dimensional relevance to viruses and capability to exchange free charges make them one of the 
most synergetic and sensitive platforms for such purpose. The possibility to modify their surface properties by functionalization of the edges and basal surface allows 2DM-based biosensors to respond to specific target viruses with high selectivity. They have demonstrated great potential for interactions with viruses either directly through hydrophobic and/or electrostatic interactions, or via functionalization with the utilization of entities such as heparin sulfate mimics and aptamers, permitting efficient binding to viral proteins. Specifically, aptamers offer great perspectives for multiplex detection compared to antibodies that often show cross-reactivity. The 2DM family consists of members that can exhibit specific electrical, optical, and electrochemical properties, which should be efficiently exploited for enhancing the sensitivity and reaching minimum detection limits of biosensing platforms. 2DMs span a broad range of electronic properties, ranging from metallic/semimetallic (e.g., graphene) to semiconducting (e.g., $\mathrm{MoS}_{2}$ ) and insulating (e.g., hexagonal boron nitride) that are essential for establishing different elements of biosensors. They also display unique optical properties such as fluorescence quenching or emitting, and plasmonic behavior. They have been exploited for the detection of viruses, either as whole particles, viral proteins or nucleic acids, with high accuracy and sensitivity associated to fast response and low cost. Additionally, 2DMs can be integrated into emerging strategies to overcome limitations of PCR methods such as loop-mediated isothermal amplification and rolling circle amplification techniques, as well as lateral flow assays.

\section{Perspectives for virus detection}

Point-of-care diagnostics for virus detection, taking place near and/or by patients, rather than in a hospital or medical testing laboratory, are urgently needed in the healthcare system. However, this requires the development of highly sensitive, portable, reusable, or at least low-cost disposable devices. We have already discussed that $2 \mathrm{DMs}$ are amongst the best platforms for the realization of point-of-care tools.

Field-effect based-biosensors may be the first choice as they present major advantages such as operation by simple resistance measurements and mass production using microfabrication technology. ${ }^{214}$ Nevertheless, their sensitivity and selectivity must be enhanced before being developed into reliable point-of-care diagnostic tools. A good example is a graphene-based sensor that was recently developed by Graphene Leaders Canada Inc. and GLC Medical Inc. for the rapid detection of SARS-CoV-2 using electrical frequencies in saliva samples. ${ }^{215}$ This biosensor 
generates a signal upon exposure to SARS-CoV-2 antigens in a very short time, within less than one minute.

Electrochemical devices are also advantageous, but they are still at the early stages of commercialization for biomarker sensing (at the exception of enzymatic glucose sensors available since 1975). ${ }^{216}$ The SARS-CoV-2 pandemic may accelerate the translation of 2DM-based detection systems into point-of-care devices based on electrochemical detection.

Finally, owing to their simplicity in terms of production and cost effectiveness, lateral flow immunoassays may be appropriate. In contrast, optical sensors may be unsuitable because of drawbacks related to the need for high-precision light alignment, expensive hardware for measurements and calculations, or scattering. ${ }^{217}$

In our opinion, other detection methods could be investigated further such as chemiluminescence resonance energy transfer. ${ }^{218}$ In this case, no external light source is required and no photobleaching is involved. This technique relies on the oxidation of a luminescent substrate that excites a fluorescent acceptor. As a result, non-specific signals that can be caused by external light excitation are minimized.

Besides, multiplex detection involving different fluorophores can be limited by spectral overlap. In this regard, SERS can be an attractive method as the molecular specific vibrational spectra of a mixture of DNA molecules can easily be differentiated.

Despite their great potential, piezoelectric biosensors composed of 2DMs have not been investigated for virus detection. Piezoelectric materials allow conversion of mechanical energy into electrical and vice versa. Some 2D monolayer transition metal dichalcogenides such as $\mathrm{MoS}_{2}$, $\mathrm{MoTe}_{2}, \mathrm{WTe}_{2}$, and $\mathrm{MoO}_{2}$, are piezoelectric. ${ }^{219-221}$ Specially, monolayers of post transition metal mono-chalchogenides, such as $\mathrm{SnS}$, show very high piezoelectric coupling coefficients. ${ }^{222}$

A precise control of the liquid flow is important in biosensing to direct the analytes onto the surface of 2DMs. In this context, microfluidic technology could significantly contribute to the development of point-of-care tools thanks to portability, low production cost, and the use of small volume samples. ${ }^{223}$ In particular, the use of microfluidics can help the incorporation of 2DMs into practical miniaturized devices.

Clustered regularly interspaced short palindromic repeats (CRISPR)-associated nuclease (Cas)-based strategies were recently developed to improve conventional optical detection of viral nucleic acids. ${ }^{224}$ CRISPR-Cas is an adaptive immune system originally discovered in bacteria to 
defend against the invasion of nucleic acids such as viral genomes. Indeed, several CRISPR/Cas systems were established for the detection of viruses, ${ }^{225}$ for instance Zika and dengue viruses, ${ }^{226}$ and for the discrimination of distinct Zika genotypes ${ }^{227}$ and human papillomavirus genotypes in clinical patient samples. ${ }^{228}$ The development of strategies for efficient immobilization of CRISPR/Cas systems to various interfaces is currently one of the major issues to overcome for practical diagnostics. In the context of Duchenne muscular dystrophy, a biosensor combining a graphene-based FET and the gene-targeting capacity of CRISPR-Cas9 was recently designed for the facile, fast, and sensitive detection of a target sequence contained within intact purified genomic DNA samples without the need for nucleic acid amplification. ${ }^{229}$ CRISPR-based methods have great potential for point-of-care diagnosis as they are low-cost and rapid, can be established using paper strips and they do not need complex instrumentation. Based on these considerations, we encourage future research towards the combination of 2DM-based biosensors and CRISPR/Cas technology to extend the boundaries of virus detection. Similar technologies are currently under the development for SARS-CoV-2 detection. ${ }^{230}$

Although the family of $2 \mathrm{DMs}$ is very broad, only a few members of this family, mainly graphene and to some extent $\mathrm{MoS}_{2}$ and MOF nanosheets, have been investigated for viral infection detection. We encourage the study of emerging 2D Xenes (e.g., arsenene, antimonene, bismuthene, borophene, gallenene, germanene, phosphorene, selinene, silicene, stanene, and tellurene) as they could overcome some of the shortcomings in the practical applications of 2DMs. The broad range of electronic properties of 2DMs is essential for establishing different biosensor elements with specific advantages. MXenes and graphene display higher carrier mobilities than Xenes. However, the zero band gap of graphene and the limited band gaps of MXenes hamper their real applications in optical and FET sensors. Contrarily, Xenes have tunable layer-dependent band gaps, which could be a complementary alternative to hexagonal boron nitride (insulating), graphene (metallic/semimetallic with zero band gap), MXenes (metallic/semiconducting with limited band gaps) and transition metal dichalcogenides (semiconducting with large band gaps). ${ }^{231,232}$ The strong interactions between Xenes and electromagnetic waves (from UV to NIR region) can be manipulated and be taken advantage of; thereby, imparting photoredox capacity and large extinction coefficients allowing their use in biosensing. The unprecedented properties of MOF and COF nanosheets, in particular their well-defined structure and porosity, as well as the possibility 
to modulate their functionalities make these $2 \mathrm{D}$ organic frameworks promising for sensing applications. Future studies in this direction will certainly provide major breakthroughs in the field.

It is noteworthy that one of the major drawbacks of 2DMs other than graphene, is the lack of well-developed and reliable synthesis methods for large-scale production to ensure structural homogeneity of 2DMs in terms of size and thickness. Moreover, some 2DMs, in particular graphene, can have a tendency to restack through the formation of multilayers due to strong noncovalent interlayer interactions. The reduced active surface area may impact the performance and reproducibility of 2DM-based biosensors. To overcome this issue, the introduction of spacers or the construction of three-dimensional (3D) networks can limit restacking. In addition, 3D graphene materials display remarkable properties, such as enhanced conductivity and electrocatalytic properties in all directions, high surface area and more controlled pore sizes. ${ }^{3,233,234}$ They can also be coupled more efficiently with other nanomaterials to reach new hybrid properties. ${ }^{235}$ In the context of virus detection, 3D structures provide a large surface-to-volume ratio for the binding of viruses, or analytes extracted from viruses, and an accessible inner space for their fast diffusion. Nevertheless, despite these advantages, only a limited number of studies have exploited 3D architectures composed of 2DMs. For example, a plasmonic-magnetic 3D GO macroporous network was developed for the detection of rotavirus and removal from infected drinking water. ${ }^{236}$ In another study, a 3D nanoflower-like structure containing $\mathrm{MnO}_{2}$ nanosheets was used in an enzyme-free colorimetric assay of EV71. ${ }^{237}$ Additionally, 3D MOFs have shown great sensing performance owing to their geometrical structures and porosity. ${ }^{238}$ To extend the applications of 2DMs for virus detection, we encourage further studies on the development of 3D architectures suitable for efficient and selective biosensing.

Finally, we suggest that the functionalization of $2 \mathrm{DMs}$, for instance with heparin sulfate mimics, should be further exploited for simple and direct detection of viruses, although selectivity should be imparted by functionalization with specific targeting molecules, if needed. In the case of SARS-CoV-2, it was recently found that the spike S1 protein surface receptor binding domain interacts with heparin, undergoing conformational change. ${ }^{239}$ This observation leads to perspectives for the design of SARS-CoV-2 biosensors and also for the development of heparin and glycosaminoglycan-based antiviral drugs. ${ }^{240}$ In this context, sulfated/sulfonated graphenefamily nanomaterials and other 2DMs could have great potential. 
To conclude, 2DMs, in particular graphene, $\mathrm{MoS}_{2}$ and MOF nanosheets, demonstrated great potential for interactions with viruses and integration into biosensors for the detection of intact viruses, viral fingerprints, and antibodies. The development of new technologies for nucleic acid detection such as CRISPR/Cas, associated to the plethora of 2DMs, which is constantly growing, and the possibility to tune their electrical and optical properties provide many opportunities to advance current technologies for rapid, accurate, and early diagnosis of viral diseases and hopefully to generate ideas for ongoing research on SARS-CoV-2. Specifically, the functionalization of 2DMs with diverse functional molecules could be essential to tailor their properties and design advanced diagnostic tools. The combination of different 2DMs may also bring exciting breakthrough approaches solving real-world problems in the field of biosensing, which is particularly desirable in the context of COVID-19.

\section{AUTHOR INFORMATION}

Corresponding authors

Cécilia Ménard-Moyon - CNRS, Immunology, Immunopathology and Therapeutic Chemistry, UPR3572, University of Strasbourg, ISIS, 67000 Strasbourg, France; orcid.org/0000-0003-03482466; Email: c.menard@ibmc-cnrs.unistra.fr

Kourosh Kalantar-Zadeh - School of Chemical Engineering, University of New South Wales, Kensington, New South Wales 2052, Australia; orcid.org/0000-0001-6109-132X; Email: k.kalantar-zadeh@unsw.edu.au

\section{Author}

Alberto Bianco - CNRS, Immunology, Immunopathology and Therapeutic Chemistry, UPR3572, University of Strasbourg, ISIS, 67000 Strasbourg, France; orcid.org/0000-0002-1090-296X; Email: a.bianco@ibmc-cnrs.unsitra.fr

\section{Notes}

The authors declare no competing financial interest. 


\section{ACKNOWLEDGMENTS}

We gratefully acknowledge the support of the Centre National de la Recherche Scientifique (CNRS), the International Center for Frontier Research in Chemistry (icFRC), and financial support from the Agence Nationale de la Recherche (ANR) through the LabEx project Chemistry of Complex Systems (ANR-10-LABX-0026_CSC). Kalantar-Zadeh would like to thank the National Health and Medical Research Council (NHMRC), Australia, for financial support (APP1154969).

\section{VOCABULARY}

Aptamers: Short single-stranded oligonucleotides able to bind target molecules with high affinity and specificity. The conventional method for aptamer engineering is based on systematic evolution of ligands by exponential enrichment (SELEX).

Band gap: Energy difference between the top of the valence band and the bottom of the conduction band in insulating and semiconducting materials.

Capsid: Protein envelope containing and protecting the viral genome. The capsid shape provides different virus morphologies.

Nucleic acids: Molecules composed of long strands of nucleotides storing genetic information and enabling protein production. The two main classes are deoxyribonucleic acid (DNA) and ribonucleic acid (RNA).

Polymerase chain reaction: Technique allowing to make millions to billions of copies of a specific DNA sample from a very small amount of DNA. This amplification method is used for highly specific diagnosis of infectious diseases such as those caused by viruses.

Spike: Protein anchored on the viral envelope that binds to cellular receptors and mediates viruscell fusion resulting in cellular internalization of the virus.

Viral antigen: Protein encoded by the viral genome that causes an immune response in the host organism. A viral antigen protrudes from the capsid and plays a key role in the binding to the host cell, fusion, and injection of viral nucleic acids. 


\section{REFERENCES}

(1) Bolotsky, A.; Butler, D.; Dong, C.; Gerace, K.; Glavin, N. R.; Muratore, C.; Robinson, J. A.; Ebrahimi, A. Two-Dimensional Materials in Biosensing and Healthcare: From In Vitro Diagnostics to Optogenetics and Beyond. ACS Nano 2019, 13 (9), 9781-9810.

(2) Su, S.; Sun, Q.; Gu, X.; Xu, Y.; Shen, J.; Zhu, D.; Chao, J.; Fan, C.; Wang, L. Two-Dimensional Nanomaterials for Biosensing Applications. TrAC Trends Anal. Chem. 2019, 119, 115610.

(3) Vermisoglou, E.; Panáček, D.; Jayaramulu, K.; Pykal, M.; Frébort, I.; Kolář, M.; Hajdúch, M.; Zbořil, R.; Otyepka, M. Human Virus Detection with Graphene-Based Materials. Biosens. Bioelectron. 2020, 166, 112436.

(4) Jiang, Z.; Feng, B.; Xu, J.; Qing, T.; Zhang, P.; Qing, Z. Graphene Biosensors for Bacterial and Viral Pathogens. Biosens. Bioelectron. 2020, 166, 112471.

(5) Moutaouakil, A. E.; Poovathy, S.; Belmoubarik, M.; Peng, W. K. Review: Graphene-Based Biosensor for Viral Detection. arXiv:2006.11881 [physics] 2020.

(6) Sun, W.; Wu, F.-G. Two-Dimensional Materials for Antimicrobial Applications: Graphene Materials and Beyond. Chem. Asian J. 2018, 13 (22), 3378-3410.

(7) Xia, M.-Y.; Xie, Y.; Yu, C.-H.; Chen, G.-Y.; Li, Y.-H.; Zhang, T.; Peng, Q. Graphene-Based Nanomaterials: The Promising Active Agents for Antibiotics-Independent Antibacterial Applications. J. Control. Release 2019, 307, 16-31.

(8) Mohammed, H.; Kumar, A.; Bekyarova, E.; Al-Hadeethi, Y.; Zhang, X.; Chen, M.; Ansari, M. S.; Cochis, A.; Rimondini, L. Antimicrobial Mechanisms and Effectiveness of Graphene and Graphene-Functionalized Biomaterials. A Scope Review. Front. Bioeng. Biotechnol. 2020, 8, 465. (9) Baltimore, D. Expression of Animal Virus Genomes. Bacteriol. Rev. 1971, 35 (3), 235-241.

(10) Mrázek, J.; Karlin, S. Distinctive Features of Large Complex Virus Genomes and Proteomes. PNAS 2007, 104 (12), 5127-5132.

(11) Cheng, X.; Chen, G.; Rodriguez, W. R. Micro- and Nanotechnology for Viral Detection. Anal. Bioanal. Chem. 2009, 393 (2), 487-501.

(12) Carter, L. J.; Garner, L. V.; Smoot, J. W.; Li, Y.; Zhou, Q.; Saveson, C. J.; Sasso, J. M.; Gregg, A. C.; Soares, D. J.; Beskid, T. R.; Jervey, S. R.; Liu, C. Assay Techniques and Test Development for COVID-19 Diagnosis. ACS Cent. Sci. 2020, 6 (5), 591-605. 
(13) Leroy, E. M.; Baize, S.; Lu, C. Y.; McCormick, J. B.; Georges, A. J.; Georges-Courbot, M.C.; Lansoud-Soukate, J.; Fisher-Hoch, S. P. Diagnosis of Ebola Haemorrhagic Fever by RT-PCR in an Epidemic Setting. J. Med. Virol. 2000, 60 (4), 463-467.

(14) Sivasankarapillai, V. S.; Pillai, A. M.; Rahdar, A.; Sobha, A. P.; Das, S. S.; Mitropoulos, A. C.; Mokarrar, M. H.; Kyzas, G. Z. On Facing the SARS-CoV-2 (COVID-19) with Combination of Nanomaterials and Medicine: Possible Strategies and First Challenges. Nanomaterials 2020, 10 (5), 852 .

(15) Santiago-Rodriguez, T. M. Identification and Quantification of DNA Viral Populations in Human Urine Using Next-Generation Sequencing Approaches. Methods Mol. Biol. 2018, 1838, 191-200.

(16) Houldcroft, C. J.; Beale, M. A.; Breuer, J. Clinical and Biological Insights from Viral Genome Sequencing. Nat. Rev. Microbiol. 2017, 15 (3), 183-192.

(17) Pokhrel, P.; Hu, C.; Mao, H. Detecting the Coronavirus (COVID-19). ACS Sens. 2020, 5 (8), 2283-2296.

(18) Kilic, T.; Weissleder, R.; Lee, H. Molecular and Immunological Diagnostic Tests of COVID19: Current Status and Challenges. iScience 2020, 23 (8), 101406.

(19) Saylan, Y.; Erdem, Ö.; Ünal, S.; Denizli, A. An Alternative Medical Diagnosis Method: Biosensors for Virus Detection. Biosensors 2019, 9 (2), 65.

(20) Mokhtarzadeh, A.; Eivazzadeh-Keihan, R.; Pashazadeh, P.; Hejazi, M.; Gharaatifar, N.; Hasanzadeh, M.; Baradaran, B.; de la Guardia, M. Nanomaterial-Based Biosensors for Detection of Pathogenic Virus. TrAC Trends Anal. Chem. 2017, 97, 445-457.

(21) Wang, B.; Sun, Y.; Ding, H.; Zhao, X.; Zhang, L.; Bai, J.; Liu, K. Bioelectronics-Related 2D Materials Beyond Graphene: Fundamentals, Properties, and Applications. Adv. Funct. Mater. DOI: 10.1002/adfm.202003732.

(22) Novoselov, K. S.; Geim, A. K.; Morozov, S. V.; Jiang, D.; Zhang, Y.; Dubonos, S. V.; Grigorieva, I. V.; Firsov, A. A. Electric Field Effect in Atomically Thin Carbon Films. Science 2004, 306 (5696), 666-669.

(23) Zhang, X.; Jing, Q.; Ao, S.; Schneider, G. F.; Kireev, D.; Zhang, Z.; Fu, W. Ultrasensitive Field-Effect Biosensors Enabled by the Unique Electronic Properties of Graphene. Small 2020, 16 (15), 1902820. 
(24) Allahbakhsh, A.; Arjmand, M. Graphene-Based Phase Change Composites for Energy Harvesting and Storage: State of the Art and Future Prospects. Carbon 2019, 148, 441-480.

(25) Morales-Narváez, E.; Baptista-Pires, L.; Zamora-Gálvez, A.; Merkoçi, A. Graphene-Based Biosensors: Going Simple. Adv. Mater. 2017, 29 (7), 1604905.

(26) Wang, Z.; Pu, Y.; Wang, D.; Wang, J.-X.; Chen, J.-F. Recent Advances on Metal-Free Graphene-Based Catalysts for the Production of Industrial Chemicals. Front. Chem. Sci. Eng. 2018, $12(4), 855-866$.

(27) Liu, G.; Jin, W.; Xu, N. Graphene-Based Membranes. Chem. Soc. Rev. 2015, 44 (15), 50165030 .

(28) Reina, G.; González-Domínguez, J. M.; Criado, A.; Vázquez, E.; Bianco, A.; Prato, M. Promises, Facts and Challenges for Graphene in Biomedical Applications. Chem. Soc. Rev. 2017, 46 (15), 4400-4416.

(29) Li, Y.; Yang, C.; Guo, X. Single-Molecule Electrical Detection: A Promising Route toward the Fundamental Limits of Chemistry and Life Science. Acc. Chem. Res. 2020, 53 (1), 159-169. (30) Balandin, A. A.; Ghosh, S.; Bao, W.; Calizo, I.; Teweldebrhan, D.; Miao, F.; Lau, C. N. Superior Thermal Conductivity of Single-Layer Graphene. Nano Lett. 2008, 8 (3), 902-907.

(31) Nair, R. R.; Blake, P.; Grigorenko, A. N.; Novoselov, K. S.; Booth, T. J.; Stauber, T.; Peres, N. M. R.; Geim, A. K. Fine Structure Constant Defines Visual Transparency of Graphene. Science 2008, 320 (5881), 1308-1308.

(32) Bonaccorso, F.; Sun, Z.; Hasan, T.; Ferrari, A. C. Graphene Photonics and Optoelectronics. Nat. Photon. 2010, 4 (9), 611-622.

(33) Geim, A. K.; Novoselov, K. S. The Rise of Graphene. Nat. Mater. 2007, 6 (3), 183-191.

(34) Lee, C.; Wei, X.; Kysar, J. W.; Hone, J. Measurement of the Elastic Properties and Intrinsic Strength of Monolayer Graphene. Science 2008, 321 (5887), 385-388.

(35) Bunch, J. S.; Zande, A. M. van der; Verbridge, S. S.; Frank, I. W.; Tanenbaum, D. M.; Parpia, J. M.; Craighead, H. G.; McEuen, P. L. Electromechanical Resonators from Graphene Sheets. Science 2007, 315 (5811), 490-493.

(36) Glavin, N. R.; Rao, R.; Varshney, V.; Bianco, E.; Apte, A.; Roy, A.; Ringe, E.; Ajayan, P. M. Emerging Applications of Elemental 2D Materials. Adv. Mater. 2020, 32 (7), 1904302.

(37) Cai, X.; Luo, Y.; Liu, B.; Cheng, H.-M. Preparation of 2D Material Dispersions and Their Applications. Chem. Soc. Rev. 2018, 47 (16), 6224-6266. 
(38) Zhan, H.; Guo, D.; Xie, G. Two-Dimensional Layered Materials: From Mechanical and Coupling Properties towards Applications in Electronics. Nanoscale 2019, 11 (28), 13181-13212. (39) Wang, H.; Li, C.; Fang, P.; Zhang, Z.; Zhang, J. Z. Synthesis, Properties, and Optoelectronic Applications of Two-Dimensional $\mathrm{MoS}_{2}$ and $\mathrm{MoS}_{2}$-Based Heterostructures. Chem. Soc. Rev. 2018, 47 (16), 6101-6127.

(40) Nan, J.; Guo, X.; Xiao, J.; Li, X.; Chen, W.; Wu, W.; Liu, H.; Wang, Y.; Wu, M.; Wang, G. Nanoengineering of 2D MXene-Based Materials for Energy Storage Applications. Small. DOI: 10.1002/smll.201902085.

(41) Wen, W.; Song, Y.; Yan, X.; Zhu, C.; Du, D.; Wang, S.; Asiri, A. M.; Lin, Y. Recent Advances in Emerging 2D Nanomaterials for Biosensing and Bioimaging Applications. Mater. Today 2018, $21(2), 164-177$.

(42) Wang, Y.; Mao, J.; Meng, X.; Yu, L.; Deng, D.; Bao, X. Catalysis with Two-Dimensional Materials Confining Single Atoms: Concept, Design, and Applications. Chem. Rev. 2019, 119 (3), 1806-1854.

(43) Ghosal, K.; Sarkar, K. Biomedical Applications of Graphene Nanomaterials and Beyond. ACS Biomater. Sci. Eng. 2018, 4 (8), 2653-2703.

(44) Tao, W.; Kong, N.; Ji, X.; Zhang, Y.; Sharma, A.; Ouyang, J.; Qi, B.; Wang, J.; Xie, N.; Kang, C.; Zhang, H.; Farokhzad, O. C.; Kim, J. S. Emerging Two-Dimensional Monoelemental Materials (Xenes) for Biomedical Applications. Chem. Soc. Rev. 2019, 48 (11), 2891-2912.

(45) Agarwal, V.; Chatterjee, K. Recent Advances in the Field of Transition Metal Dichalcogenides for Biomedical Applications. Nanoscale 2018, 10 (35), 16365-16397.

(46) Yadav, V.; Roy, S.; Singh, P.; Khan, Z.; Jaiswal, A. 2D MoS2-Based Nanomaterials for Therapeutic, Bioimaging, and Biosensing Applications. Small 2019, 15 (1), 1803706.

(47) Zheng, J.; Li, J.; Zhang, L.; Chen, X.; Yu, Y.; Huang, H. Post-Graphene 2D Materials-Based Antimicrobial Agents: Focus on Fabrication Strategies and Biosafety Assessments. J. Mater. Sci. 2020, 55 (17), 7226-7246.

(48) Liu, S.; Pan, X.; Liu, H. Two-Dimensional Nanomaterials for Photothermal Therapy. Angew. Chem. Int. Ed. 2020, 59 (15), 5890-5900.

(49) Cheng, L.; Wang, X.; Gong, F.; Liu, T.; Liu, Z. 2D Nanomaterials for Cancer Theranostic Applications. Adv. Mater. 2020, 32 (13), 1902333. 
(50) Soltani, R.; Guo, S.; Bianco, A.; Ménard-Moyon, C. Carbon Nanomaterials Applied for the Treatment of Inflammatory Diseases: Preclinical Evidence. Adv. Therap. 2020, 3 (9), 2000051.

(51) Chen, L.; Liang, J. An Overview of Functional Nanoparticles as Novel Emerging Antiviral Therapeutic Agents. Mater. Sci. Eng. C 2020, 112, 110924.

(52) Reina, G.; Peng, S.; Jacquemin, L.; Andrade, A. F.; Bianco, A. Hard Nanomaterials in Time of Viral Pandemics. ACS Nano 2020, 14 (8), 9364-9388.

(53) Huang, H.; Su, S.; Wu, N.; Wan, H.; Wan, S.; Bi, H.; Sun, L. Graphene-Based Sensors for Human Health Monitoring. Front. Chem. 2019, 7, 399.

(54) Lu, Y.; Lyu, H.; Richardson, A. G.; Lucas, T. H.; Kuzum, D. Flexible Neural Electrode Array Based-on Porous Graphene for Cortical Microstimulation and Sensing. Sci. Rep. 2016, 19 (6), 33526.

(55) Zhong, H.; Zhu, Z.; Lin, J.; Cheung, C. F.; Lu, V. L.; Yan, F.; Chan, C.-Y.; Li, G. Reusable and Recyclable Graphene Masks with Outstanding Superhydrophobic and Photothermal Performances. ACS Nano 2020, 14 (5), 6213-6221.

(56) Chen, Y.; Tan, C.; Zhang, H.; Wang, L. Two-Dimensional Graphene Analogues for Biomedical Applications. Chem. Soc. Rev. 2015, 44 (9), 2681-2701.

(57) Sarkar, D.; Liu, W.; Xie, X.; Anselmo, A. C.; Mitragotri, S.; Banerjee, K. MoS 2 Field-Effect Transistor for Next-Generation Label-Free Biosensors. ACS Nano 2014, 8 (4), 3992-4003.

(58) Chen, L.; Song, J. Tailored Graphitic Carbon Nitride Nanostructures: Synthesis, Modification, and Sensing Applications. Adv. Funct. Mater. 2017, 27 (39), 1702695.

(59) Song, Y.; Luo, Y.; Zhu, C.; Li, H.; Du, D.; Lin, Y. Recent Advances in Electrochemical Biosensors Based on Graphene Two-Dimensional Nanomaterials. Biosens. Bioelectron. 2016, 76, 195-212.

(60) Bollella, P.; Fusco, G.; Tortolini, C.; Sanzò, G.; Favero, G.; Gorton, L.; Antiochia, R. Beyond Graphene: Electrochemical Sensors and Biosensors for Biomarkers Detection. Biosens. Bioelectron. 2017, 89, 152-166.

(61) Mohamad Nasir, M. Z.; Pumera, M. Emerging Mono-Elemental 2D Nanomaterials for Electrochemical Sensing Applications: From Borophene to Bismuthene. TrAC Trends Anal. Chem. 2019, 121, 115696.

(62) Swathi, R. S.; Sebastian, K. L. Long Range Resonance Energy Transfer from a Dye Molecule to Graphene Has (Distance)-4 Dependence. J. Chem. Phys. 2009, 130 (8), 086101. 
(63) Kalantar-zadeh, K.; Ou, J. Z. Biosensors Based on Two-Dimensional MoS 2 . ACS Sens. 2016, $1(1), 5-16$.

(64) Li, M.; Chen, T.; Gooding, J. J.; Liu, J. Review of Carbon and Graphene Quantum Dots for Sensing. ACS Sens 2019, 4 (7), 1732-1748.

(65) Ou, J. Z.; Chrimes, A. F.; Wang, Y.; Tang, S.; Strano, M. S.; Kalantar-zadeh, K. Ion-Driven Photoluminescence Modulation of Quasi-Two-Dimensional $\mathrm{MoS}_{2}$ Nanoflakes for Applications in Biological Systems. Nano Lett. 2014, 14 (2), 857-863.

(66) Maier, S. A. All Eyes on Flatland. Nat. Phys. 2012, 8 (8), 581-582.

(67) Wang, Y.; Ou, J. Z.; Chrimes, A. F.; Carey, B. J.; Daeneke, T.; Alsaif, M. M. Y. A.; Mortazavi, M.; Zhuiykov, S.; Medhekar, N.; Bhaskaran, M.; Friend, J. R.; Strano, M. S.; Kalantar-Zadeh, K. Plasmon Resonances of Highly Doped Two-Dimensional MoS 2 . Nano Lett. 2015, 15 (2), 883-890. (68) Zeng, S.; Baillargeat, D.; Ho, H.-P.; Yong, K.-T. Nanomaterials Enhanced Surface Plasmon Resonance for Biological and Chemical Sensing Applications. Chem. Soc. Rev. 2014, 43 (10), $3426-3452$.

(69) Alsaif, M. M. Y. A.; Latham, K.; Field, M. R.; Yao, D. D.; Medehkar, N. V.; Beane, G. A.; Kaner, R. B.; Russo, S. P.; Ou, J. Z.; Kalantar-zadeh, K. Tunable Plasmon Resonances in TwoDimensional Molybdenum Oxide Nanoflakes. Adv. Mater. 2014, 26 (23), 3931-3937.

(70) Zhang, B. Y.; Zavabeti, A.; Chrimes, A. F.; Haque, F.; O’Dell, L. A.; Khan, H.; Syed, N.; Datta, R.; Wang, Y.; Chesman, A. S. R.; Daeneke, T.; Kalantar-zadeh, K.; Ou, J. Z. Degenerately Hydrogen Doped Molybdenum Oxide Nanodisks for Ultrasensitive Plasmonic Biosensing. Adv. Funct. Mater. 2018, 28 (11), 1706006.

(71) Lee, J.; Takemura, K.; Park, E. Y. Plasmonic Nanomaterial-Based Optical Biosensing Platforms for Virus Detection. Sensors 2017, 17 (10), 2332.

(72) Ling, X.; Xie, L.; Fang, Y.; Xu, H.; Zhang, H.; Kong, J.; Dresselhaus, M. S.; Zhang, J.; Liu, Z. Can Graphene Be Used as a Substrate for Raman Enhancement? Nano Lett. 2010, 10 (2), 553561.

(73) Sriram, P.; Manikandan, A.; Chuang, F.-C.; Chueh, Y.-L. Hybridizing Plasmonic Materials with 2D-Transition Metal Dichalcogenides toward Functional Applications. Small 2020, 16 (15), 1904271. 
(74) Banerjee, A.; Chakraborty, S.; Altan-Bonnet, N.; Grebel, H. Monitoring Bound HA1(H1N1) and HA1(H5N1) on Freely Suspended Graphene over Plasmonic Platforms with Infrared Spectroscopy. Chem. Phys. Lett. 2013, 582, 134-140.

(75) Khatib, O.; Wood, J. D.; McLeod, A. S.; Goldflam, M. D.; Wagner, M.; Damhorst, G. L.; Koepke, J. C.; Doidge, G. P.; Rangarajan, A.; Bashir, R.; Pop, E.; Lyding, J. W.; Thiemens, M. H.; Keilmann, F.; Basov, D. N. Graphene-Based Platform for Infrared Near-Field Nanospectroscopy of Water and Biological Materials in an Aqueous Environment. ACS Nano 2015, 9 (8), 7968-7975. (76) Park, J.; Park, H.; Ercius, P.; Pegoraro, A. F.; Xu, C.; Kim, J. W.; Han, S. H.; Weitz, D. A. Direct Observation of Wet Biological Samples by Graphene Liquid Cell Transmission Electron Microscopy. Nano Lett. 2015, 15 (7), 4737-4744.

(77) Nair, R. R.; Blake, P.; Blake, J. R.; Zan, R.; Anissimova, S.; Bangert, U.; Golovanov, A. P.; Morozov, S. V.; Geim, A. K.; Novoselov, K. S.; Latychevskaia, T. Graphene as a Transparent Conductive Support for Studying Biological Molecules by Transmission Electron Microscopy. Appl. Phys. Lett. 2010, 97 (15), 153102.

(78) Kato, R.; Hatano, Y.; Kasahata, N.; Sato, C.; Suenaga, K.; Hasegawa, M. High-Precision Thickness Control of Ice Layer on CVD Grown Bilayer Graphene for Cryo-TEM. Carbon 2020, 160, 107-112.

(79) Pantelic, R. S.; Suk, J. W.; Hao, Y.; Ruoff, R. S.; Stahlberg, H. Oxidative Doping Renders Graphene Hydrophilic, Facilitating its Use as a Support in Biological TEM. Nano Lett. 2011, 11 (10), 4319-4323.

(80) Longchamp, J.-N.; Latychevskaia, T.; Escher, C.; Fink, H.-W. Low-Energy Electron Holographic Imaging of Individual Tobacco Mosaic Virions. Appl. Phys. Lett. 2015, 107 (13), 133101.

(81) Seuring, C.; Ayyer, K.; Filippaki, E.; Barthelmess, M.; Longchamp, J.-N.; Ringler, P.; Pardini, T.; Wojtas, D. H.; Coleman, M. A.; Dörner, K.; Fuglerud, S.; Hammarin, G.; Habenstein, B.; Langkilde, A. E.; Loquet, A.; Meents, A.; Riek, R.; Stahlberg, H.; Boutet, S.; Hunter, M. S.; Koglin, J.; Liang, M.; Ginn, H. M.; Millane, R. P.; Frank, M.; Barty, A.; Chapman, H. N. Femtosecond XRay Coherent Diffraction of Aligned Amyloid Fibrils on Low Background Graphene. Nat. Commun. 2018, 9, 1836. 
(82) Li, D.; Zhang, W.; Yu, X.; Wang, Z.; Su, Z.; Wei, G. When Biomolecules Meet Graphene: From Molecular Level Interactions to Material Design and Applications. Nanoscale 2016, 8 (47), 19491-19509.

(83) Iliafar, S.; Wagner, K.; Manohar, S.; Jagota, A.; Vezenov, D. Quantifying Interactions between DNA Oligomers and Graphite Surface Using Single Molecule Force Spectroscopy. $J$. Phys. Chem. C 2012, 116 (26), 13896-13903.

(84) Wei, G.; Li, Q.; Steckbeck, S.; Ciacchi, L. C. Direct Force Measurements on Peeling Heteropolymer ssDNA from a Graphite Surface Using Single-Molecule Force Spectroscopy. Phys. Chem. Chem. Phys. 2014, 16 (9), 3995-4001.

(85) Ye, S.; Shao, K.; Li, Z.; Guo, N.; Zuo, Y.; Li, Q.; Lu, Z.; Chen, L.; He, Q.; Han, H. Antiviral Activity of Graphene Oxide: How Sharp Edged Structure and Charge Matter. ACS Appl. Mater. Interfaces 2015, 7 (38), 21571-21579.

(86) Singh, M.; Zannella, C.; Folliero, V.; Di Girolamo, R.; Bajardi, F.; Chianese, A.; Altucci, L.; Damasco, A.; Del Sorbo, M. R.; Imperatore, C.; Rossi, M.; Valadan, M.; Varra, M.; Vergara, A.; Franci, G.; Galdiero, M.; Altucci, C. Combating Actions of Green 2D-Materials on Gram Positive and Negative Bacteria and Enveloped Viruses. Front. Bioeng. Biotechnol. 2020, 8, 569967.

(87) Maio, F. D.; Palmieri, V.; Babini, G.; Augello, A.; Palucci, I.; Perini, G.; Salustri, A.; Spirito, M. D.; Sanguinetti, M.; Delogu, G.; Rizzi, L. G.; Cesareo, G.; Soon-Shiong, P.; Sali, M.; Papi, M. Graphene Nanoplatelet and Graphene Oxide Functionalization of Face Mask Materials Inhibits Infectivity of Trapped SARS-CoV-2. medRxiv 2020, 2020.09.16.20194316. DOI: 10.1101/2020.09.16.20194316.

(88) Lee, W.-N.; Yoo, H. J.; Nguyen, K. H.; Baek, C.; Min, J. Semi-Automatic Instrumentation for Nucleic Acid Extraction and Purification to Quantify Pathogens on Surfaces. Analyst 2019, 144 (22), 6586-6594.

(89) Chen, Y.-N.; Hsueh, Y.-H.; Hsieh, C.-T.; Tzou, D.-Y.; Chang, P.-L. Antiviral Activity of Graphene-Silver Nanocomposites against Non-Enveloped and Enveloped Viruses. Int. J. Environ. Res. Public Health 2016, 13 (4), 430.

(90) Frost, R.; Jönsson, G. E.; Chakarov, D.; Svedhem, S.; Kasemo, B. Graphene Oxide and Lipid Membranes: Interactions and Nanocomposite Structures. Nano Lett. 2012, 12 (7), 3356-3362. 
(91) Du, T.; Lu, J.; Liu, L.; Dong, N.; Fang, L.; Xiao, S.; Han, H. Antiviral Activity of Graphene Oxide-Silver Nanocomposites by Preventing Viral Entry and Activation of the Antiviral Innate Immune Response. ACS Appl. Bio Mater. 2018, 1 (5), 1286-1293.

(92) Zhang, M.; Mao, X.; Wang, C.; Zeng, W.; Zhang, C.; Li, Z.; Fang, Y.; Yang, Y.; Liang, W.; Wang, C. The Effect of Graphene Oxide on Conformation Change, Aggregation and Cytotoxicity of HIV-1 Regulatory Protein (Vpr). Biomaterials 2013, 34 (4), 1383-1390.

(93) Zeng, S.; Zhou, G.; Guo, J.; Zhou, F.; Chen, J. Molecular Simulations of Conformation Change and Aggregation of HIV-1 Vpr13-33 on Graphene Oxide. Sci. Rep. 2016, 6 (1), 24906.

(94) Song, Z.; Wang, X.; Zhu, G.; Nian, Q.; Zhou, H.; Yang, D.; Qin, C.; Tang, R. Virus Capture and Destruction by Label-Free Graphene Oxide for Detection and Disinfection Applications. Small 2015, 11 (9-10), 1171-1176.

(95) Akhavan, O.; Choobtashani, M.; Ghaderi, E. Protein Degradation and RNA Efflux of Viruses Photocatalyzed by Graphene-Tungsten Oxide Composite Under Visible Light Irradiation. J. Phys. Chem. C 2012, 116 (17), 9653-9659.

(96) Li, Y.; Zhang, C.; Shuai, D.; Naraginti, S.; Wang, D.; Zhang, W. Visible-Light-Driven Photocatalytic Inactivation of $\mathrm{MS}_{2}$ by Metal-Free $\mathrm{g}-\mathrm{C}_{3} \mathrm{~N}_{4}$ : Virucidal Performance and Mechanism. Water Res. 2016, 106, 249-258.

(97) Zhang, C.; Li, Y.; Shuai, D.; Zhang, W.; Niu, L.; Wang, L.; Zhang, H. Visible-Light-Driven, Water-Surface-Floating Antimicrobials Developed from Graphitic Carbon Nitride and Expanded Perlite for Water Disinfection. Chemosphere 2018, 208, 84-92.

(98) Soylemez, E.; Boer, M. P. de; Sae-Ueng, U.; Evilevitch, A.; Stewart, T. A.; Nyman, M. Photocatalytic Degradation of Bacteriophages Evidenced by Atomic Force Microscopy. PLoS ONE 2013, 8 (1), e53601.

(99) Luan, B.; Huynh, T.; Zhao, L.; Zhou, R. Potential Toxicity of Graphene to Cell Functions via Disrupting Protein-Protein Interactions. ACS Nano 2015, 9 (1), 663-669.

(100) GC, J. B.; Pokhrel, R.; Bhattarai, N.; Johnson, K. A.; Gerstman, B. S.; Stahelin, R. V.; Chapagain, P. P. Graphene-VP40 Interactions and Potential Disruption of the Ebola Virus Matrix Filaments. Biochem. Biophys. Res. Commun. 2017, 493 (1), 176-181.

(101) Rathinam, N. K.; Saravanan, C.; Parimal, P.; Perumal, V.; Perumal, M. Molecular Interactions of Graphene with HIV-Vpr, Nef and Gag Proteins: A New Approach for Treating HIV Infections. Korean J. Chem. Eng. 2014, 31 (5), 744-747. 
(102) Calderón, M.; Quadir, M. A.; Sharma, S. K.; Haag, R. Dendritic Polyglycerols for Biomedical Applications. Adv. Mater. 2010, 22 (2), 190-218.

(103) Mammen, M.; Choi, S.-K.; Whitesides, G. M. Polyvalent Interactions in Biological Systems: Implications for Design and Use of Multivalent Ligands and Inhibitors. Angew. Chem. Int. Ed. 1998, 37 (20), 2754-2794.

(104) Sametband, M.; Kalt, I.; Gedanken, A.; Sarid, R. Herpes Simplex Virus Type-1 Attachment Inhibition by Functionalized Graphene Oxide. ACS Appl. Mater. Interfaces 2014, 6 (2), 12281235.

(105) Deokar, A. R.; Nagvenkar, A. P.; Kalt, I.; Shani, L.; Yeshurun, Y.; Gedanken, A.; Sarid, R. Graphene-Based "Hot Plate" for the Capture and Destruction of the Herpes Simplex Virus Type 1. Bioconjug. Chem. 2017, 28 (4), 1115-1122.

(106) Yang, X. X.; Li, C. M.; Li, Y. F.; Wang, J.; Huang, C. Z. Synergistic Antiviral Effect of Curcumin Functionalized Graphene Oxide against Respiratory Syncytial Virus Infection. Nanoscale 2017, 9 (41), 16086-16092.

(107) Ziem, B.; Thien, H.; Achazi, K.; Yue, C.; Stern, D.; Silberreis, K.; Gholami, M. F.; Beckert, F.; Gröger, D.; Mülhaupt, R.; Rabe, J. P.; Nitsche, A.; Haag, R. Highly Efficient Multivalent 2D Nanosystems for Inhibition of Orthopoxvirus Particles. Adv. Healthcare Mater. 2016, 5 (22), $2922-2930$.

(108) Gholami, M. F.; Lauster, D.; Ludwig, K.; Storm, J.; Ziem, B.; Severin, N.; Böttcher, C.; Rabe, J. P.; Herrmann, A.; Adeli, M.; Haag, R. Functionalized Graphene as Extracellular Matrix Mimics: Toward Well-Defined 2D Nanomaterials for Multivalent Virus Interactions. Adv. Funct. Mater. 2017, 27 (15), 1606477.

(109) Ziem, B.; Azab, W.; Gholami, M. F.; Rabe, J. P.; Osterrieder, N.; Haag, R. Size-Dependent Inhibition of Herpesvirus Cellular Entry by Polyvalent Nanoarchitectures. Nanoscale 2017, 9 (11), 3774-3783.

(110) McMahon, H. T.; Gallop, J. L. Membrane Curvature and Mechanisms of Dynamic Cell Membrane Remodelling. Nature 2005, 438 (7068), 590-596.

(111) Reynwar, B. J.; Illya, G.; Harmandaris, V. A.; Müller, M. M.; Kremer, K.; Deserno, M. Aggregation and Vesiculation of Membrane Proteins by Curvature-Mediated Interactions. Nature 2007, 447 (7143), 461-464. 
(112) Ziem, B.; Rahn, J.; Donskyi, I.; Silberreis, K.; Cuellar, L.; Dernedde, J.; Keil, G.; Mettenleiter, T. C.; Haag, R. Polyvalent 2D Entry Inhibitors for Pseudorabies and African Swine Fever Virus. Macromol. Biosci. 2017, 17 (6), 1600499.

(113) Donskyi, I. S.; Azab, W.; Cuellar-Camacho, J. L.; Guday, G.; Lippitz, A.; Unger, W. E. S.; Osterrieder, K.; Adeli, M.; Haag, R. Functionalized Nanographene Sheets with High Antiviral Activity through Synergistic Electrostatic and Hydrophobic Interactions. Nanoscale 2019, 11 (34), 15804-15809.

(114) Hu, X.; Mu, L.; Wen, J.; Zhou, Q. Covalently Synthesized Graphene Oxide-Aptamer Nanosheets for Efficient Visible-Light Photocatalysis of Nucleic Acids and Proteins of Viruses. Carbon 2012, 50 (8), 2772-2781.

(115) Krishnamoorthy, K.; Mohan, R.; Kim, S.-J. Graphene Oxide as a Photocatalytic Material. Appl. Phys. Lett. 2011, 98 (24), 244101.

(116) Tuzikov, A. B.; Chinarev, A. A.; Gambaryan, A. S.; Oleinikov, V. A.; Klinov, D. V.; Matsko, N. B.; Kadykov, V. A.; Ermishov, M. A.; Demin, I. V.; Demin, V. V.; Rye, P. D.; Bovin, N. V. Polyglycine II Nanosheets: Supramolecular Antivirals? ChemBioChem 2003, 4 (2-3), 147-154.

(117) Thiviyanathan, V.; Gorenstein, D. G. Aptamers and the next Generation of Diagnostic Reagents. Proteomics Clin. Appl. 2012, 6 (11-12), 563-573.

(118) Rasool, K.; Helal, M.; Ali, A.; Ren, C. E.; Gogotsi, Y.; Mahmoud, K. A. Antibacterial Activity of $\mathrm{Ti}_{3} \mathrm{C}_{2} \mathrm{~T}_{x}$ MXene. ACS Nano 2016, 10 (3), 3674-3684.

(119) Zhu, Z.; Bai, Q.; Li, S.; Li, S.; Liu, M.; Du, F.; Sui, N.; Yu, W. W. Antibacterial Activity of Graphdiyne and Graphdiyne Oxide. Small 2020, 16 (34), 2001440.

(120) Taheri, H.; Unal, M. A.; Sevim, M.; Gurcan, C.; Ekim, O.; Ceylan, A.; Syrgiannis, Z.; Christoforidis, K. C.; Bosi, S.; Ozgenç, O.; Gómez, M. J.; Erken, M. T.; Soydal, Ç.; Eroğlu, Z.; Bitirim, C. V.; Cagin, U.; Arı, F.; Ozen, A.; Kuçuk, O.; Delogu, L. G.; Prato, M.; Metin, Ö.; Yilmazer, A. Photocatalytically Active Graphitic Carbon Nitride as an Effective and Safe 2D Material for In Vitro and In Vivo Photodynamic Therapy. Small 2020, 16 (10), 1904619.

(121) Ji, D.-K.; Zhang, Y.; Zang, Y.; Li, J.; Chen, G.-R.; He, X.-P.; Tian, H. Targeted Intracellular Production of Reactive Oxygen Species by a 2D Molybdenum Disulfide Glycosheet. Adv. Mater. 2016, 28 (42), 9356-9363. 
(122) Mallineni, S. S. K.; Shannahan, J.; Raghavendra, A. J.; Rao, A. M.; Brown, J. M.; Podila, R. Biomolecular Interactions and Biological Responses of Emerging Two-Dimensional Materials and Aromatic Amino Acid Complexes. ACS Appl. Mater. Interfaces 2016, 8 (26), 16604-16611.

(123) Chand, R.; Neethirajan, S. Microfluidic Platform Integrated with Graphene-Gold NanoComposite Aptasensor for One-Step Detection of Norovirus. Biosens. Bioelectron. 2017, 98, 4753.

(124) Huang, J.; Xie, Z.; Xie, Z.; Luo, S.; Xie, L.; Huang, L.; Fan, Q.; Zhang, Y.; Wang, S.; Zeng, T. Silver Nanoparticles Coated Graphene Electrochemical Sensor for the Ultrasensitive Analysis of Avian Influenza Virus H7. Anal. Chim. Acta 2016, 913, 121-127.

(125) Liu, F.; Kim, Y. H.; Cheon, D. S.; Seo, T. S. Micropatterned Reduced Graphene Oxide Based Field-Effect Transistor for Real-Time Virus Detection. Sens. Actuators, B 2013, 186, 252-257. (126) Zhan, L.; Li, C. M.; Wu, W. B.; Huang, C. Z. A Colorimetric Immunoassay for Respiratory Syncytial Virus Detection Based on Gold Nanoparticles-Graphene Oxide Hybrids with MercuryEnhanced Peroxidase-like Activity. Chem. Commun. 2014, 50 (78), 11526-11528.

(127) Fan, Z.; Yust, B.; Nellore, B. P. V.; Sinha, S. S.; Kanchanapally, R.; Crouch, R. A.; Pramanik, A.; Chavva, S. R.; Sardar, D.; Ray, P. C. Accurate Identification and Selective Removal of Rotavirus Using a Plasmonic-Magnetic 3D Graphene Oxide Architecture. J. Phys. Chem. Lett. 2014, 5 (18), 3216-3221.

(128) Lee, J.; Takemura, K.; Park, E. Y. Plasmonic/Magnetic Graphene-Based MagnetofluoroImmunosensing Platform for Virus Detection. Sens. Actuators, B 2018, 276, 254-261.

(129) Peng, X.; Luo, G.; Wu, Z.; Wen, W.; Zhang, X.; Wang, S. Fluorescent-Magnetic-Catalytic Nanospheres for Dual-Modality Detection of H9N2 Avian Influenza Virus. ACS Appl. Mater. Interfaces 2019, 11 (44), 41148-41156.

(130) DiStefano, D. J.; Kraiouchkine, N.; Mallette, L.; Maliga, M.; Kulnis, G.; Keller, P. M.; Clark, H. F.; Shaw, A. R. Novel Rotavirus VP7 Typing Assay Using a One-Step Reverse Transcriptase PCR Protocol and Product Sequencing and Utility of the Assay for Epidemiological Studies and Strain Characterization, Including Serotype Subgroup Analysis. J. Clin. Microbiol. 2005, 43 (12), $5876-5880$.

(131) Chen, Q.; Hu, Z.; Zhang, Q.; Yu, M. Development and Evaluation of a Real-Time Method of Simultaneous Amplification and Testing of Enterovirus 71 Incorporating a RNA Internal Control System. J. Virol. Methods 2014, 196, 139-144. 
(132) Urbas, L.; Košir, B.; Peterka, M.; Pihlar, B.; Štrancar, A.; Barut, M. Reversed Phase Monolithic Analytical Columns for the Determination of HA1 Subunit of Influenza Virus Haemagglutinin. J. Chromatogr. A 2011, 1218 (17), 2432-2437.

(133) Wan, H.; Sultana, I.; Couzens, L. K.; Mindaye, S.; Eichelberger, M. C. Assessment of Influenza A Neuraminidase (Subtype N1) Potency by ELISA. J. Virol. Methods 2017, 244, 23-28. (134) Wang, Y.; Bai, X.; Wen, W.; Zhang, X.; Wang, S. Ultrasensitive Electrochemical Biosensor for HIV Gene Detection Based on Graphene Stabilized Gold Nanoclusters with Exonuclease Amplification. ACS Appl. Mater. Interfaces 2015, 7 (33), 18872-18879.

(135) Wu, Z.; Hu, J.; Zeng, T.; Zhang, Z.-L.; Chen, J.; Wong, G.; Qiu, X.; Liu, W.; Gao, G. F.; Bi, Y.; Pang, D.-W. Ultrasensitive Ebola Virus Detection Based on Electroluminescent Nanospheres and Immunomagnetic Separation. Anal. Chem. 2017, 89 (3), 2039-2048.

(136) Babamiri, B.; Hallaj, R.; Salimi, A. Ultrasensitive Electrochemiluminescence Immunosensor for Determination of Hepatitis B Virus Surface Antigen Using CdTe@CdS-PAMAM Dendrimer as Luminescent Labels and $\mathrm{Fe}_{3} \mathrm{O}_{4}$ Nanoparticles as Magnetic Beads. Sens. Actuators, B 2018, 254, $551-560$.

(137) Park, G.-S.; Ku, K.; Baek, S.-H.; Kim, S.-J.; Kim, S. I.; Kim, B.-T.; Maeng, J.-S. Development of Reverse Transcription Loop-Mediated Isothermal Amplification Assays Targeting Severe Acute Respiratory Syndrome Coronavirus 2 (SARS-CoV-2). J. Mol. Diagn. 2020, 22 (6), 729-735.

(138) Jung, J. H.; Cheon, D. S.; Liu, F.; Lee, K. B.; Seo, T. S. A Graphene Oxide Based ImmunoBiosensor for Pathogen Detection. Angew. Chem. Int. Ed. 2010, 49 (33), 5708-5711.

(139) Chen, L.; Zhang, X.; Zhou, G.; Xiang, X.; Ji, X.; Zheng, Z.; He, Z.; Wang, H. Simultaneous Determination of Human Enterovirus 71 and Coxsackievirus B3 by Dual-Color Quantum Dots and Homogeneous Immunoassay. Anal. Chem. 2012, 84 (7), 3200-3207.

(140) Song, J.-X.; Tang, X.-Y.; Zhou, D.-M.; Zhang, W.; James, T. D.; He, X.-P.; Tian, H. A Fluorogenic 2D Glycosheet for the Simultaneous Identification of Human- and Avian-Receptor Specificity in Influenza Viruses. Mater. Horiz. 2017, 4 (3), 431-436.

(141) Fu, M.-Q.; Wang, X.-C.; Dou, W.-T.; Chen, G.-R.; James, T. D.; Zhou, D.-M.; He, X.-P. Supramolecular Fluorogenic Peptide Sensor Array Based on Graphene Oxide for the Differential Sensing of Ebola Virus. Chem. Commun. 2020, 56 (43), 5735-5738. 
(142) Stewart, S.; Ivy, M. A.; Anslyn, E. V. The Use of Principal Component Analysis and Discriminant Analysis in Differential Sensing Routines. Chem. Soc. Rev. 2013, 43 (1), 70-84.

(143) Omar, N.A.S.; Fen, Y.W.; Saleviter, S.; Daniyal, W.M.E.M.M.; Anas, N.A.A.; Ramdzan, N.S.M.; Roshidi, M.D.A. Development of a Graphene-Based Surface Plasmon Resonance Optical Sensor Chip for Potential Biomedical Application. Materials 2019, 12, 1928.

(144) Anik, Ü.; Tepeli, Y.; Sayhi, M.; Nsiri, J.; Diouani, M. F. Towards the Electrochemical Diagnostic of Influenza Virus: Development of a Graphene-Au Hybrid Nanocomposite Modified Influenza Virus Biosensor Based on Neuraminidase Activity. Analyst 2018, 143 (1), 150-156.

(145) Peh, A. E. K.; Li, S. F. Y. Dengue Virus Detection Using Impedance Measured across Nanoporous Alumina Membrane. Biosens. Bioelectron. 2013, 42, 391-396.

(146) Navakul, K.; Warakulwit, C.; Yenchitsomanus, P.; Panya, A.; Lieberzeit, P. A.; Sangma, C. A Novel Method for Dengue Virus Detection and Antibody Screening Using a Graphene-Polymer Based Electrochemical Biosensor. Nanomedicine: NBM 2017, 13 (2), 549-557.

(147) Joshi, R. K.; Carbone, P.; Wang, F. C.; Kravets, V. G.; Su, Y.; Grigorieva, I. V.; Wu, H. A.; Geim, A. K.; Nair, R. R. Precise and Ultrafast Molecular Sieving Through Graphene Oxide Membranes. Science 2014, 343 (6172), 752-754.

(148) Nehra, A.; Chen, W.; Dimitrov, D. S.; Puri, A.; Singh, K. P. Graphene Oxide-Polycarbonate Track-Etched Nanosieve Platform for Sensitive Detection of Human Immunodeficiency Virus Envelope Glycoprotein. ACS Appl. Mater. Interfaces 2017, 9 (38), 32621-32634.

(149) Kinnamon, D. S.; Krishnan, S.; Brosler, S.; Sun, E.; Prasad, S. Screen Printed Graphene Oxide Textile Biosensor for Applications in Inexpensive and Wearable Point-of-Exposure Detection of Influenza for At-Risk Populations. J. Electrochem. Soc. 2018, 165 (8), B3084.

(150) Torrente-Rodríguez, R. M.; Lukas, H.; Tu, J.; Min, J.; Yang, Y.; Xu, C.; Rossiter, H. B.; Gao, W. SARS-CoV-2 RapidPlex: A Graphene-Based Multiplexed Telemedicine Platform for Rapid and Low-Cost COVID-19 Diagnosis and Monitoring. Matter 2020. DOI: 10.1016/j.matt.2020.09.027.

(151) Jin, X.; Zhang, H.; Li, Y.-T.; Xiao, M.-M.; Zhang, Z.-L.; Pang, D.-W.; Wong, G.; Zhang, Z.Y.; Zhang, G.-J. A Field Effect Transistor Modified with Reduced Graphene Oxide for Immunodetection of Ebola Virus. Microchim. Acta 2019, 186 (4), 223. 
(152) Cho, K. H.; Shin, D. H.; Oh, J.; An, J. H.; Lee, J. S.; Jang, J. Multidimensional Conductive Nanofilm-Based Flexible Aptasensor for Ultrasensitive and Selective HBsAg Detection. ACS Appl. Mater. Interfaces 2018, 10 (34), 28412-28419.

(153) Seo, G.; Lee, G.; Kim, M. J.; Baek, S.-H.; Choi, M.; Ku, K. B.; Lee, C.-S.; Jun, S.; Park, D.; Kim, H. G.; Kim, S.-J.; Lee, J.-O.; Kim, B. T.; Park, E. C.; Kim, S. I. Rapid Detection of COVID19 Causative Virus (SARS-CoV-2) in Human Nasopharyngeal Swab Specimens Using FieldEffect Transistor-Based Biosensor. ACS Nano 2020, 14 (4), 5135-5142.

(154) Afsahi, S.; Lerner, M. B.; Goldstein, J. M.; Lee, J.; Tang, X.; Bagarozzi, D. A.; Pan, D.; Locascio, L.; Walker, A.; Barron, F.; Goldsmith, B. R. Novel Graphene-Based Biosensor for Early Detection of Zika Virus Infection. Biosens. Bioelectron. 2018, 100, 85-88.

(155) Hu, Y.; Li, F.; Bai, X.; Li, D.; Hua, S.; Wang, K.; Niu, L. Label-Free Electrochemical Impedance Sensing of DNA Hybridization Based on Functionalized Graphene Sheets. Chem. Commun. 2011, 47 (6), 1743-1745.

(156) Zribi, B.; Castro-Arias, J.-M.; Decanini, D.; Gogneau, N.; Dragoe, D.; Cattoni, A.; Ouerghi, A.; Korri-Youssoufi, H.; Haghiri-Gosnet, A.-M. Large Area Graphene Nanomesh: An Artificial Platform for Edge-Electrochemical Biosensing at the Sub-Attomolar Level. Nanoscale 2016, 8 (34), 15479-15485.

(157) Liu, M.; Zhao, H.; Chen, S.; Yu, H.; Quan, X. Interface Engineering Catalytic Graphene for Smart Colorimetric Biosensing. ACS Nano 2012, 6 (4), 3142-3151.

(158) Shen, Q.; Han, L.; Fan, G.; Zhang, J.-R.; Jiang, L.; Zhu, J.-J. "Signal-On" Photoelectrochemical Biosensor for Sensitive Detection of Human T-Cell Lymphotropic Virus Type II DNA: Dual Signal Amplification Strategy Integrating Enzymatic Amplification with Terminal Deoxynucleotidyl Transferase-Mediated Extension. Anal. Chem. 2015, 87 (9), 49494956.

(159) Shi, X.-M.; Fan, G.-C.; Tang, X.; Shen, Q.; Zhu, J.-J. Ultrasensitive Photoelectrochemical Biosensor for the Detection of HTLV-I DNA: A Cascade Signal Amplification Strategy Integrating $\lambda$-Exonuclease Aided Target Recycling with Hybridization Chain Reaction and Enzyme Catalysis. Biosens. Bioelectron. 2018, 109, 190-196.

(160) He, S.; Liu, K.-K.; Su, S.; Yan, J.; Mao, X.; Wang, D.; He, Y.; Li, L.-J.; Song, S.; Fan, C. Graphene-Based High-Efficiency Surface-Enhanced Raman Scattering-Active Platform for Sensitive and Multiplex DNA Detection. Anal. Chem. 2012, 84 (10), 4622-4627. 
(161) Fan, Z.; Kanchanapally, R.; Ray, P. C. Hybrid Graphene Oxide Based Ultrasensitive SERS Probe for Label-Free Biosensing. J. Phys. Chem. Lett. 2013, 4 (21), 3813-3818.

(162) Varghese, N.; Mogera, U.; Govindaraj, A.; Das, A.; Maiti, P. K.; Sood, A. K.; Rao, C. N. R. Binding of DNA Nucleobases and Nucleosides with Graphene. ChemPhysChem 2009, 10 (1), 206210.

(163) Lu, C.; Liu, Y.; Ying, Y.; Liu, J. Comparison of $\mathrm{MoS}_{2}, \mathrm{WS}_{2}$, and Graphene Oxide for DNA Adsorption and Sensing. Langmuir 2017, 33 (2), 630-637.

(164) Lu, C.-H.; Yang, H.-H.; Zhu, C.-L.; Chen, X.; Chen, G.-N. A Graphene Platform for Sensing Biomolecules. Angew. Chem. Int. Ed. 2009, 48 (26), 4785-4787.

(165) Liu, X.; Wang, F.; Aizen, R.; Yehezkeli, O.; Willner, I. Graphene Oxide/Nucleic-AcidStabilized Silver Nanoclusters: Functional Hybrid Materials for Optical Aptamer Sensing and Multiplexed Analysis of Pathogenic DNAs. J. Am. Chem. Soc. 2013, 135 (32), 11832-11839.

(166) Wu, Y.-M.; Cen, Y.; Huang, L.-J.; Yu, R.-Q.; Chu, X. Upconversion Fluorescence Resonance Energy Transfer Biosensor for Sensitive Detection of Human Immunodeficiency Virus Antibodies in Human Serum. Chem. Commun. 2014, 50 (36), 4759-4762.

(167) Choi, S.; Dickson, R. M.; Yu, J. Developing Luminescent Silver Nanodots for Biological Applications. Chem. Soc. Rev. 2012, 41 (5), 1867-1891.

(168) Luo, M.; Chen, X.; Zhou, G.; Xiang, X.; Chen, L.; Ji, X.; He, Z. Chemiluminescence Biosensors for DNA Detection Using Graphene Oxide and a Horseradish Peroxidase-Mimicking DNAzyme. Chem. Commun. 2012, 48 (8), 1126-1128.

(169) Willner, I.; Shlyahovsky, B.; Zayats, M.; Willner, B. DNAzymes for Sensing, Nanobiotechnology and Logic Gate Applications. Chem. Soc. Rev. 2008, 37 (6), 1153-1165.

(170) Chen, L.; Song, L.; Zhang, Y.; Wang, P.; Xiao, Z.; Guo, Y.; Cao, F. Nitrogen and Sulfur Codoped Reduced Graphene Oxide as a General Platform for Rapid and Sensitive Fluorescent Detection of Biological Species. ACS Appl. Mater. Interfaces 2016, 8 (18), 11255-11261.

(171) Peng, X.; Zhang, Y.; Lu, D.; Guo, Y.; Guo, S. Ultrathin $\mathrm{Ti}_{3} \mathrm{C}_{2}$ Nanosheets Based "off-on" Fluorescent Nanoprobe for Rapid and Sensitive Detection of HPV Infection. Sens. Actuators, B 2019, 286, 222-229.

(172) Zhang, W.; Li, S.; Li, X.; Liu, M.; Cui, T.; Fu, H.; Yang, M.; Zhong, W.; Xu, B.; Yue, W. PEG-PtS 2 Nanosheet-Based Fluorescence Biosensor for Label-Free Human Papillomavirus Genotyping. Microchim. Acta 2020, 187 (7), 408. 
(173) Parvin, N.; Jin, Q.; Wei, Y.; Yu, R.; Zheng, B.; Huang, L.; Zhang, Y.; Wang, L.; Zhang, H.; Gao, M.; Zhao, H.; Hu, W.; Li, Y.; Wang, D. Few-Layer Graphdiyne Nanosheets Applied for Multiplexed Real-Time DNA Detection. Adv. Mater. 2017, 29 (18), 1606755.

(174) Chandra Shekar, S.; Swathi, R. S. Stability of Nucleobases and Base Pairs Adsorbed on Graphyne and Graphdiyne. J. Phys. Chem. C 2014, 118 (8), 4516-4528.

(175) Luo, G.; Zheng, Q.; Mei, W.-N.; Lu, J.; Nagase, S. Structural, Electronic, and Optical Properties of Bulk Graphdiyne. J. Phys. Chem. C 2013, 117 (25), 13072-13079.

(176) Xiao, Y.; Sheng, Y.; Zhou, J.; Chen, M.; Wen, W.; Zhang, X.; Wang, S. A Novel Label-Free Strategy for Pathogenic DNA Detection Based on Metal Ion Binding-Induced Fluorescence Quenching of Graphitic Carbon Nitride Nanosheets. Analyst 2017, 142 (14), 2617-2623.

(177) Wu, T.; Li, X.; Fu, Y.; Ding, X.; Li, Z.; Zhu, G.; Fan, J. A Highly Sensitive and Selective Fluorescence Biosensor for Hepatitis C Virus DNA Detection Based on $\delta$-FeOOH and Exonuclease III-Assisted Signal Amplification. Talanta 2020, 209, 120550.

(178) Wang, L.; Dong, L.; Liu, G.; Shen, X.; Wang, J.; Zhu, C.; Ding, M.; Wen, Y. Fluorometric Determination of HIV DNA Using Molybdenum Disulfide Nanosheets and Exonuclease IIIAssisted Amplification. Microchim. Acta 2019, 186 (5), 286.

(179) Liu, M.; Song, J.; Shuang, S.; Dong, C.; Brennan, J. D.; Li, Y. A Graphene-Based Biosensing Platform Based on the Release of DNA Probes and Rolling Circle Amplification. ACS Nano 2014, $8(6), 5564-5573$.

(180) Kim, J.; Cote, L. J.; Kim, F.; Huang, J. Visualizing Graphene Based Sheets by Fluorescence Quenching Microscopy. J. Am. Chem. Soc. 2010, 132 (1), 260-267.

(181) Zhu, X.; Zheng, H.; Wei, X.; Lin, Z.; Guo, L.; Qiu, B.; Chen, G. Metal-Organic Framework (MOF): A Novel Sensing Platform for Biomolecules. Chem. Commun. 2013, 49 (13), 1276-1278. (182) Furukawa, H.; Cordova, K. E.; O’Keeffe, M.; Yaghi, O. M. The Chemistry and Applications of Metal-Organic Frameworks. Science 2013, 341 (6149), 1230444.

(183) Qiu, Q.; Chen, H.; Wang, Y.; Ying, Y. Recent Advances in the Rational Synthesis and Sensing Applications of Metal-Organic Framework Biocomposites. Coord. Chem. Rev. 2019, 387, $60-78$.

(184) Mukherjee, A.; Vasquez, K. M. Triplex Technology in Studies of DNA Damage, DNA Repair, and Mutagenesis. Biochimie 2011, 93 (8), 1197-1208. 
(185) Kaur, H.; Babu, B. R.; Maiti, S. Perspectives on Chemistry and Therapeutic Applications of Locked Nucleic Acid (LNA). Chem. Rev. 2007, 107 (11), 4672-4697.

(186) Chen, L.; Zheng, H.; Zhu, X.; Lin, Z.; Guo, L.; Qiu, B.; Chen, G.; Chen, Z.-N. Metal-Organic Frameworks-Based Biosensor for Sequence-Specific Recognition of Double-Stranded DNA. Analyst 2013, 138 (12), 3490-3493.

(187) Liu, C.; Wang, T.; Ji, J.; Wang, C.; Wang, H.; Jin, P.; Zhou, W.; Jiang, J. The Effect of Pore Size and Layer Number of Metal-Porphyrin Coordination Nanosheets on Sensing DNA. J. Mater. Chem. C 2019, 7 (33), 10240-10246.

(188) Zhao, H.-Q.; Yang, S.-P.; Ding, N.-N.; Qin, L.; Qiu, G.-H.; Chen, J.-X.; Zhang, W.-H.; Chen, W.-H.; Hor, T. S. A. A Zwitterionic 1D/2D Polymer Co-Crystal and Its Polymorphic SubComponents: A Highly Selective Sensing Platform for HIV ds-DNA Sequences. Dalton Trans. 2016, 45 (12), 5092-5100.

(189) Tian, Y.; Lu, Q.; Guo, X.; Wang, S.; Gao, Y.; Wang, L. Au Nanoparticles Deposited on Ultrathin Two-Dimensional Covalent Organic Framework Nanosheets for in Vitro and Intracellular Sensing. Nanoscale 2020, 12 (14), 7776-7781.

(190) Li, Z.; He, T.; Gong, Y.; Jiang, D. Covalent Organic Frameworks: Pore Design and Interface Engineering. Acc. Chem. Res. 2020, 53 (8), 1672-1685.

(191) Kim, S.; Choi, H. C. Recent Advances in Covalent Organic Frameworks for Molecule-Based Two-Dimensional Materials. ACS Omega 2020, 5 (2), 948-958.

(192) Peng, Y.; Huang, Y.; Zhu, Y.; Chen, B.; Wang, L.; Lai, Z.; Zhang, Z.; Zhao, M.; Tan, C.; Yang, N.; Shao, F.; Han, Y.; Zhang, H. Ultrathin Two-Dimensional Covalent Organic Framework Nanosheets: Preparation and Application in Highly Sensitive and Selective DNA Detection. J. Am. Chem. Soc. 2017, 139 (25), 8698-8704.

(193) Kim, S.; Ryoo, S.-R.; Na, H.-K.; Kim, Y.-K.; Choi, B.-S.; Lee, Y.; Kim, D.-E.; Min, D.-H. Deoxyribozyme-Loaded Nano-Graphene Oxide for Simultaneous Sensing and Silencing of the Hepatitis C Virus Gene in Liver Cells. Chem. Commun. 2013, 49 (74), 8241-8243.

(194) Aslan, K.; Geddes, C. D. Metal-Enhanced Chemiluminescence: Advanced Chemiluminescence Concepts for the $21^{\text {st }}$ Century. Chem. Soc. Rev. 2009, 38 (9), 2556-2564.

(195) Liu, Y.; Nie, Y.; Wang, M.; Zhang, Q.; Ma, Q. Distance-Dependent Plasmon-Enhanced Electrochemiluminescence Biosensor Based on $\mathrm{MoS}_{2}$ Nanosheets. Biosens. Bioelectron. 2020, $148,111823$. 
(196) Guo, Y.; Deng, L.; Li, J.; Guo, S.; Wang, E.; Dong, S. Hemin-Graphene Hybrid Nanosheets with Intrinsic Peroxidase-like Activity for Label-Free Colorimetric Detection of Single-Nucleotide Polymorphism. ACS Nano 2011, 5 (2), 1282-1290.

(197) Draz, M. S.; Moazeni, M.; Venkataramani, M.; Lakshminarayanan, H.; Saygili, E.; Lakshminaraasimulu, N. K.; Kochehbyoki, K. M.; Kanakasabapathy, M. K.; Shabahang, S.; Vasan, A.; Bijarchi, M. A.; Memic, A.; Shafiee, H. Hybrid Paper-Plastic Microchip for Flexible and HighPerformance Point-of-Care Diagnostics. Adv. Funct. Mater. 2018, 28 (26), 1707161.

(198) Han, D.; Chand, R.; Kim, Y.-S. Microscale Loop-Mediated Isothermal Amplification of Viral DNA with Real-Time Monitoring on Solution-Gated Graphene FET Microchip. Biosens. Bioelectron. 2017, 93, 220-225.

(199) Li, S.; Gu, Y.; Lyu, Y.; Jiang, Y.; Liu, P. Integrated Graphene Oxide Purification-Lateral Flow Test Strips (IGOP-LFTS) for Direct Detection of PCR Products with Enhanced Sensitivity and Specificity. Anal. Chem. 2017, 89 (22), 12137-12144.

(200) Kalantar-Zadeh, K.; Ward, S. A.; Kalantar-Zadeh, K.; El-Omar, E. M. Considering the Effects of Microbiome and Diet on SARS-CoV-2 Infection: Nanotechnology Roles. ACS Nano 2020, 14 (5), 5179-5182.

(201) Lu, C.-H.; Li, J.; Zhang, X.-L.; Zheng, A.-X.; Yang, H.-H.; Chen, X.; Chen, G.-N. General Approach for Monitoring Peptide-Protein Interactions Based on Graphene-Peptide Complex. Anal. Chem. 2011, 83 (19), 7276-7282.

(202) Zhang, C.; Gao, D.; Zhou, G.; Chen, L.; Zhang, X.; Cui, Z.; He, Z. Label-Free Homogeneous Immunosensor Based on FRET for the Detection of Virus Antibody in Serum. Chem. Asian J. 2012, 7 (8), 1764-1767.

(203) Tong, C.; Zhou, T.; Zhao, C.; Yuan, L.; Xu, Y.; Liu, B.; Fan, J.; Li, D.; Zhu, A. Fluorometric Determination of RNase $\mathrm{H}$ via a DNAzyme Conjugated to Reduced Graphene Oxide, and Its Application to Screening for Inhibitors and Activators. Microchim. Acta 2019, 186 (6), 335.

(204) Tong, C.; Zhao, C.; Liu, B.; Li, B.; Ai, Z.; Fan, J.; Wang, W. Sensitive Detection of RNase A Activity and Collaborative Drug Screening Based on RGO and Fluorescence Probe. Anal. Chem. 2018, 90 (4), 2655-2661.

(205) Li, X.; Ding, X.; Wang, G.; Zhou, Y.; Hou, R.; Gao, S.; Lu, Y. A Fluorescence Assay for HIV-1 Ribonuclease H Activity and Inhibition Detection Using Graphene Oxide as Sensing Platform. Sci. Adv. Mater. 2014, 6 (9), 1936-1942. 
(206) Chen, J.; Nugen, S. R. Detection of Protease and Engineered Phage-Infected Bacteria Using Peptide-Graphene Oxide Nanosensors. Anal. Bioanal. Chem. 2019, 411 (12), 2487-2492.

(207) Jang, H.; Kim, Y.-K.; Kwon, H.-M.; Yeo, W.-S.; Kim, D.-E.; Min, D.-H. A Graphene-Based Platform for the Assay of Duplex-DNA Unwinding by Helicase. Angew. Chem. Int. Ed. Engl. 2010, 49 (33), 5703-5707.

(208) Jang, H.; Ryoo, S.-R.; Kim, Y.-K.; Yoon, S.; Kim, H.; Han, S. W.; Choi, B.-S.; Kim, D.-E.; Min, D.-H. Discovery of Hepatitis C Virus NS3 Helicase Inhibitors by a Multiplexed, HighThroughput Helicase Activity Assay Based on Graphene Oxide. Angew. Chem. Int. Ed. 2013, 52 (8), 2340-2344.

(209) Norfun, P.; Suree, N.; Kungwan, N.; Punyodom, W.; Jakmunee, J.; Ounnunkad, K. Electrochemical Detection of Human Interleukin-15 using a Graphene Oxide-Modified ScreenPrinted Carbon Electrode. Anal. Lett. 2017, 50 (7), 1112-1125.

(210) Dhenadhayalan, N.; Sriram, M. I.; Lin, K.-C. Aptamer-Based Fluorogenic Sensing of Interferon-Gamma Probed with $\mathrm{ReS}_{2}$ and $\mathrm{TiS}_{2}$ Nanosheets. Sens. Actuators, B 2018, 258, 929-936. (211) Kim, M.-G.; Shon, Y.; Lee, J.; Byun, Y.; Choi, B.-S.; Kim, Y. B.; Oh, Y.-K. Double Stranded Aptamer-Anchored Reduced Graphene Oxide as Target-Specific Nano Detector. Biomaterials 2014, 35 (9), 2999-3004.

(212) Le Reste, L.; Hohlbein, J.; Gryte, K.; Kapanidis, A. N. Characterization of Dark Quencher Chromophores as Nonfluorescent Acceptors for Single-Molecule FRET. Biophys. J. 2012, 102 (11), 2658-2668.

(213) Guo, S.; Nishina, Y.; Bianco, A.; Ménard-Moyon, C. A Flexible Method for Covalent Double Functionalization of Graphene Oxide. Angew. Chem. Int. Ed. 2020, 59 (4), 1542-1547.

(214) Zhang, A.; Lieber, C. M. Nano-Bioelectronics. Chem. Rev. 2016, 116 (1), 215-257.

$$
\text { https://www.labmedica.com/covid-19/articles/294783802/rapid-covid-19-test-uses- }
$$
graphene-enhanced-sensor-to-produce-signal-after-positively-identifying-viral-antigens.html (accessed 2020-11-06).

(216) Yoo, E.-H.; Lee, S.-Y. Glucose Biosensors: An Overview of Use in Clinical Practice. Sensors 2010, 10 (5), 4558-4576.

(217) Walper, S. A.; Lasarte Aragonés, G.; Sapsford, K. E.; Brown, C. W.; Rowland, C. E.; Breger, J. C.; Medintz, I. L. Detecting Biothreat Agents: From Current Diagnostics to Developing Sensor Technologies. ACS Sens. 2018, 3 (10), 1894-2024. 
(218) Bi, S.; Zhao, T.; Luo, B. A Graphene Oxide Platform for the Assay of Biomolecules Based on Chemiluminescence Resonance Energy Transfer. Chem. Commun. 2011, 48 (1), 106-108.

(219) Hinchet, R.; Khan, U.; Falconi, C.; Kim, S.-W. Piezoelectric Properties in Two-Dimensional Materials: Simulations and Experiments. Mater. Today 2018, 21 (6), 611-630.

(220) Duerloo, K.-A. N.; Ong, M. T.; Reed, E. J. Intrinsic Piezoelectricity in Two-Dimensional Materials. J. Phys. Chem. Lett. 2012, 3 (19), 2871-2876.

(221) Apte, A.; Mozaffari, K.; Samghabadi, F. S.; Hachtel, J. A.; Chang, L.; Susarla, S.; Idrobo, J. C.; Moore, D. C.; Glavin, N. R.; Litvinov, D.; Sharma, P.; Puthirath, A. B.; Ajayan, P. M. 2D Electrets of Ultrathin $\mathrm{MoO}_{2}$ with Apparent Piezoelectricity. Adv. Mater. 2020, 32 (24), 2000006. (222) Khan, H.; Mahmood, N.; Zavabeti, A.; Elbourne, A.; Rahman, M. A.; Zhang, B. Y.; Krishnamurthi, V.; Atkin, P.; Ghasemian, M. B.; Yang, J.; Zheng, G.; Ravindran, A. R.; Walia, S.; Wang, L.; Russo, S. P.; Daeneke, T.; Li, Y.; Kalantar-Zadeh, K. Liquid Metal-Based Synthesis of High Performance Monolayer SnS Piezoelectric Nanogenerators. Nat. Commun. 2020, 11, 3449. (223) Zhuang, J.; Yin, J.; Lv, S.; Wang, B.; Mu, Y. Advanced "Lab-on-a-Chip" to Detect Viruses - Current Challenges and Future Perspectives. Biosens. Bioelectron 2020, 163, 112291.

(224) Gootenberg, J. S.; Abudayyeh, O. O.; Lee, J. W.; Essletzbichler, P.; Dy, A. J.; Joung, J.; Verdine, V.; Donghia, N.; Daringer, N. M.; Freije, C. A.; Myhrvold, C.; Bhattacharyya, R. P.; Livny, J.; Regev, A.; Koonin, E. V.; Hung, D. T.; Sabeti, P. C.; Collins, J. J.; Zhang, F. Nucleic Acid Detection with CRISPR-Cas13a/C2c2. Science 2017, 356 (6336), 438-442.

(225) Li, Y.; Li, S.; Wang, J.; Liu, G. CRISPR/Cas Systems towards Next-Generation Biosensing. Trends Biotechnol. 2019, 37 (7), 730-743.

(226) Myhrvold, C.; Freije, C. A.; Gootenberg, J. S.; Abudayyeh, O. O.; Metsky, H. C.; Durbin, A. F.; Kellner, M. J.; Tan, A. L.; Paul, L. M.; Parham, L. A.; Garcia, K. F.; Barnes, K. G.; Chak, B.; Mondini, A.; Nogueira, M. L.; Isern, S.; Michael, S. F.; Lorenzana, I.; Yozwiak, N. L.; MacInnis, B. L.; Bosch, I.; Gehrke, L.; Zhang, F.; Sabeti, P. C. Field-Deployable Viral Diagnostics Using CRISPR-Cas13. Science 2018, 360 (6387), 444-448.

(227) Pardee, K.; Green, A. A.; Takahashi, M. K.; Braff, D.; Lambert, G.; Lee, J. W.; Ferrante, T.; Ma, D.; Donghia, N.; Fan, M.; Daringer, N. M.; Bosch, I.; Dudley, D. M.; O’Connor, D. H.; Gehrke, L.; Collins, J. J. Rapid, Low-Cost Detection of Zika Virus Using Programmable Biomolecular Components. Cell 2016, 165 (5), 1255-1266. 
(228) Chen, J. S.; Ma, E.; Harrington, L. B.; Costa, M. D.; Tian, X.; Palefsky, J. M.; Doudna, J. A. CRISPR-Cas12a Target Binding Unleashes Indiscriminate Single-Stranded DNase Activity. Science 2018, 360 (6387), 436-439.

(229) Hajian, R.; Balderston, S.; Tran, T.; deBoer, T.; Etienne, J.; Sandhu, M.; Wauford, N. A.; Chung, J.-Y.; Nokes, J.; Athaiya, M.; Paredes, J.; Peytavi, R.; Goldsmith, B.; Murthy, N.; Conboy, I. M.; Aran, K. Detection of Unamplified Target Genes via CRISPR-Cas9 Immobilized on a Graphene Field-Effect Transistor. Nat. Biomed. Eng. 2019, 3 (6), 427-437.

(230) Sheridan, C. COVID-19 Spurs Wave of Innovative Diagnostics. Nat. Biotechnol. 2020, 38 (7), 769-772.

(231) Huang, K.; Li, Z.; Lin, J.; Han, G.; Huang, P. Two-Dimensional Transition Metal Carbides and Nitrides (MXenes) for Biomedical Applications. Chem. Soc. Rev. 2018, 47 (14), 5109-5124. (232) Qiu, M.; Ren, W. X.; Jeong, T.; Won, M.; Park, G. Y.; Sang, D. K.; Liu, L.-P.; Zhang, H.; Kim, J. S. Omnipotent Phosphorene: A Next-Generation, Two-Dimensional Nanoplatform for Multidisciplinary Biomedical Applications. Chem. Soc. Rev. 2018, 47 (15), 5588-5601.

(233) Xia, X. H.; Chao, D. L.; Zhang, Y. Q.; Shen, Z. X.; Fan, H. J. Three-Dimensional Graphene and Their Integrated Electrodes. Nano Today 2014, 9 (6), 785-807.

(234) Lu, L. Recent Advances in Synthesis of Three-Dimensional Porous Graphene and Its Applications in Construction of Electrochemical (Bio)Sensors for Small Biomolecules Detection. Biosens. Bioelectron. 2018, 110, 180-192.

(235) Novoselov, K. S.; Mishchenko, A.; Carvalho, A.; Neto, A. H. C. 2D Materials and van der Waals Heterostructures. Science 2016, 353 (6298), aac9439.

(236) Fan, Z.; Yust, B.; Nellore, B. P. V.; Sinha, S. S.; Kanchanapally, R.; Crouch, R. A.; Pramanik, A.; Chavva, S. R.; Sardar, D.; Ray, P. C. Accurate Identification and Selective Removal of Rotavirus Using a Plasmonic-Magnetic 3D Graphene Oxide Architecture. J. Phys. Chem. Lett. 2014, 5 (18), 3216-3221.

(237) Chu, C.; Ge, S.; Zhang, J.; Lin, H.; Liu, G.; Chen, X. Enzyme-Free Colorimetric Determination of EV71 Virus Using a 3D- $\mathrm{MnO}_{2}$-PEG Nanoflower and 4-MBA-MA-AgNPs. Nanoscale 2016, 8 (36), 16168-16171.

(238) Wang, Y.; Hu, Y.; He, Q.; Yan, J.; Xiong, H.; Wen, N.; Cai, S.; Peng, D.; Liu, Y.; Liu, Z. Metal-Organic Frameworks for Virus Detection. Biosens. Bioelectron. 2020, 169, 112604. 
(239) Mycroft-West, C.; Su, D.; Elli, S.; Guimond, S.; Miller, G.; Turnbull, J.; Yates, E.; Guerrini, M.; Fernig, D.; Lima, M.; Skidmore, M. The 2019 Coronavirus (SARS-CoV-2) Surface Protein (Spike) S1 Receptor Binding Domain Undergoes Conformational Change upon Heparin Binding. bioRxiv 2020, 2020.02.29.971093. DOI: 10.1101/2020.02.29.971093.

(240) Palmieri, V.; Papi, M. Can Graphene Take Part in the Fight against COVID-19? Nano Today 2020, 33, 100883. 